\title{
NMR and Computational Studies on the Reactions of Enamines with Nitroalkenes That May Pass through Cyclobutanes
}

\author{
Alejandro Castro-Alvarez, ${ }^{\circledR}$ Héctor Carneros, Jaume Calafat, Anna M. Costa, ${ }^{*}$ Cristian Marco, \\ and Jaume Vilarrasa*(i) \\ Organic Chemistry Section, Facultat de Química, Universitat de Barcelona, Diagonal 645, 08028 Barcelona, Catalonia, Spain
}

\section{Supporting Information}

ABSTRACT: The addition of aldehyde enamines to nitroalkenes affords cyclobutanes in all solvents, with all of the pyrrolidine and proline derivatives tested by us and with all of the substrates we have examined. Depending on the temperature, concentration of water, solvent polarity, and other factors, the opening and hydrolysis of such a four-membered ring may take place rapidly or last for several days, producing the final Michael-like adducts (4-nitrobutanals). Thirteen new cyclobutanes have now been characterized by NMR spectroscopy. As could be expected, s-trans-enamine conformers give rise to alltrans-(4S)-4-nitrocyclobutylpyrrolidines, while s-cis-enamine conformers afford all-trans-(4R)-4-nitrocyclobutylpyrrolidines. These four-membered rings can isomerize to adduct enamines,
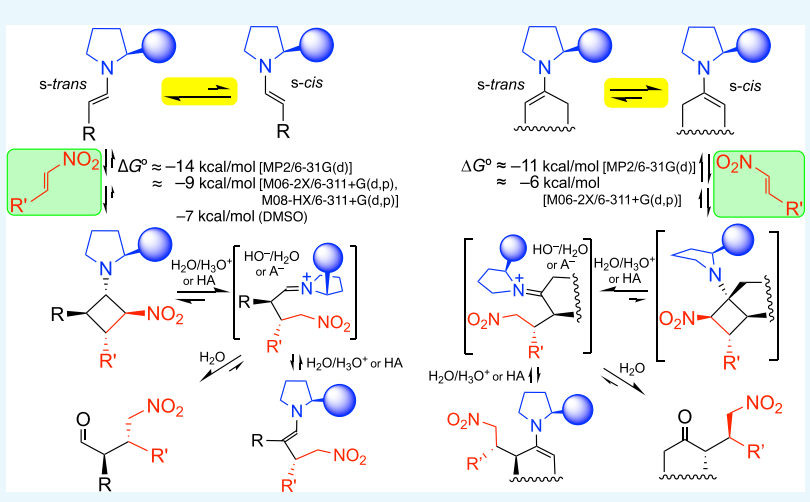
which should be hydrolyzed via their iminium ions. MP2 and M06-2X calculations predict that one iminium ion is more stable than the other iminium species, so that protonation of the adduct enamines can be quite stereoselective; in the presence of water, the so-called syn adducts (e.g., $\mathrm{OCH}-{ }^{*} \mathrm{CHR}-{ }^{*} \mathrm{CHPh}-\mathrm{CH}_{2} \mathrm{NO}_{2}$, with $\mathrm{R}$ and $\mathrm{Ph}$ syn) eventually become the major products. Why one syn adduct is obtained with aldehydes, whereas cyclic ketones (the predicted ring-fused cyclobutanes of which isomerize to their enamines more easily) produce the other syn adduct, is also explained by means of molecular orbital calculations. Nitro-Michael reactions of aldehyde enamines that "stop" at the nitrocyclobutane stage and final enamine stage do not work catalytically, as known, but those of cyclic ketone enamines that do not work stop at the final enamine stage (if their hydrolysis to the corresponding nitroethylketones is less favorable than expected). These and other facts are accounted for, and the proposals of the groups led by Seebach and Hayashi, Blackmond, and Pihko and Papai are reconciled.

\section{INTRODUCTION}

It is well known that many aminocatalytic reactions ${ }^{1}$ do not progress at all or require several days for completion-we will call this the first general issue-while others afford random stereoselectivities, depending strongly on features of the substrate and catalyst- the second general issue. Long series of trials are very often carried out to find appropriate catalysts and conditions. Hundreds of Michael-like reactions, catalyzed by proline, prolinol, or pyrrolidine derivatives, between enolizable carbonyl compounds and activated double bonds have thus been reported, mostly with $(E)-\mathrm{PhCH}=\mathrm{CHNO}_{2}, \beta$ nitrostyrene, as the acceptor. ${ }^{1}$ Indeed, the reaction of cyclohexanone with $\beta$-nitrostyrene has become the reference test for the performance of any new catalyst that is reported, i.e., it is the paradigm of the so-called nitro-Michael reaction.

Despite the fact that formation of cyclobutane derivatives from enamines and electron-withdrawing group (EWG)substituted alkenes has been reported since the 1960s (for representative instances see Figure 1), ${ }^{2}$ most papers seldom mention the role or involvement of cyclobutanes as intermediates. The more recent works of the groups of Seebach, Hayashi, Blackmond, Pihko, and Papai are the exception. ${ }^{3}$ Our eclectic view of their mechanistic proposals, for a large substituent at pyrrolidine C2, is shown in Figure 2. Whereas Seebach, Hayashi, and co-workers ${ }^{3 a}$ proposed that nitrocyclobutanes are off-cycle intermediates and may be considered "resting states" of the catalyst, Burés et al. ., $\mathrm{f}^{3}$ indicated that the stereochemical outcome can be determined by these "downstream intermediates" (nitrocyclobutanes), which may either enhance or reduce the selectivity established in the initial steps. Földes et al. $^{3 g}$ concluded that the stereoselectivity can be controlled at the first step even though the reaction rates may be dictated by the protonation steps of the intermediates.

The starting enamine is formed by the reaction of the aldehyde with a secondary amine (such as the JørgensenHayashi catalyst, henceforward JH), ${ }^{1}$ as in Figure 2. The first reaction intermediate, the hemiaminal ( $\mathrm{N}, \mathrm{O}$-acetal), which in polar solvents may be in equilibrium with its ionic counterpart, an iminium hydroxide, is rarely depicted. The enamine reacts

Received: July 6, 2019

Accepted: October 10, 2019

Published: October 25, 2019 
<smiles>[R]C1CC(C(=O)OC)[C@H]1N1CCCCC1</smiles>

$\mathrm{R}=\mathrm{H}, \mathrm{EWG}=\mathrm{CN}, \mathrm{COOR}, \mathrm{SO}_{2} \mathrm{R}$

$\mathrm{EWG}=\mathrm{EWG}=\mathrm{CN}$

$E W G=E W G^{\prime}=\mathrm{COOR}$

$\mathrm{R}=\mathrm{Ph}, \mathrm{EWG}=\mathrm{NO} 2$

Brannock et al. 1961/64

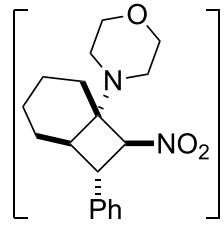<smiles>CC1C([N+](=O)[O-])C(c2ccccc2)[C@H]1N1CCOCC1</smiles>

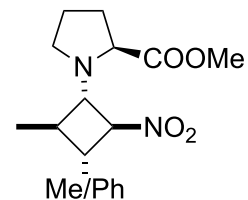

Colonna et al. 1973

Seebach et al. 1985

Felluga et al. 1989/92<smiles>[R]C1CC(C(=O)OC)C1C(C)=O</smiles>

Wallace et al. 2005

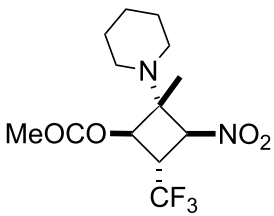

Korotaev et al. 2011

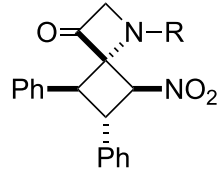

Dobi et al. 2017
Figure 1. Examples of cyclobutanes resulting from enamines and EWG-activated double bonds. Brackets indicate that the cyclobutane intermediate was proposed but not detected.

with an (E)-nitroalkene. Although single arrows are used in much of Figure 2 for the sake of simplicity, we should stress that most steps if not all are equilibria. Intermediates such as zwitterions zw, cyclobutanes cb (formal $2+2$-cycloadducts), dihydrooxazine- $N$-oxides $(2+4$-cycloadducts, $\mathbf{d h}),{ }^{4}$ and adduct enamines en (that is, the enamines of the final Michael products) have been proposed or detected. ${ }^{3}$ Seebach et al. have characterized up to 17 cyclobutanes of the cb type, all from the JH catalyst or related diphenylprolinols. ${ }^{3 \mathrm{~d}}$ They were even able, for $\mathrm{R}^{\prime}={ }^{t} \mathrm{Bu}$, to obtain crystals that were good and stable enough for X-ray analysis. Two of those nitrocyclobutanes, that from propanal and $\beta$-nitrostyrene and that from 2 -methylpropanal and $\beta$-nitrostyrene, were studied by NMR by Bures et al.; ${ }^{3 e}$ they also examined the conversion of the first into its $(E)$-enamine (see en in Figure 2). The equilibrium between adduct enamines $(Z)$-en and $(E)$-en, where these last isomers usually predominate, is not detailed in Figure 2. Seebach et al. have reported ${ }^{3 d}$ up to 12 enamines [(E)-en, JH type].

The relative thermodynamic and/or kinetic stability of these intermediates may explain the poor conversion percentages or disappointingly low rates often observed in several catalytic nitro-Michael reactions. Common sense suggests that, in the last steps of the process, if the secondary amine is not rapidly released by hydrolysis, the reaction stops. It may work if stoichiometric amounts of the starting secondary amine are used but not under catalytic conditions. We will not deal in depth with the dihydrooxazine- $N$-oxide intermediates ( $\mathbf{d h}$ in Figure 2) for two main reasons: they have been clearly analyzed $^{2 \mathrm{~g}, 3 \mathrm{~d}, 4}$ and they only predominate in the equilibrium mixtures when the nitroalkene is $\alpha$-substituted and/or in very polar solvents. Here, we will focus our attention on nitrocyclobutane intermediates (cb) and 4-nitroenamine

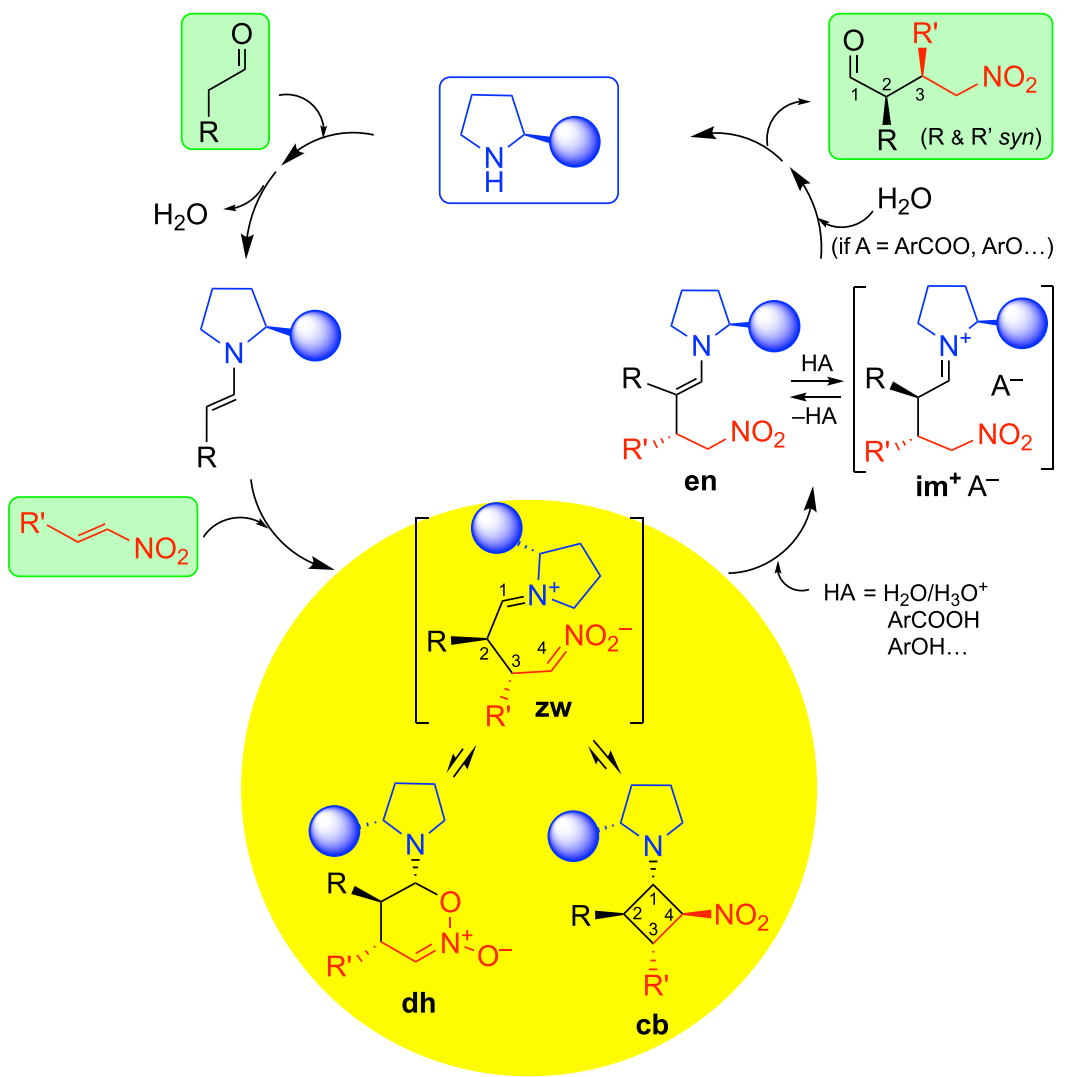

Figure 2. Main chemical entities involved in the reactions between aldehydes and nitroalkenes catalyzed by chiral secondary amines. The substituent on the pyrrolidine ring is usually $\mathrm{CPh}_{2} \mathrm{OTMS}$ [the Jørgensen-Hayashi $(\mathrm{JH})$ catalyst]. 
intermediates (en). We may well ask what factors make some cb particularly stable to ring opening or to hydrolysis. The answer will help solve the first general issue mentioned above.

If species $\mathbf{z w}$ and $\mathrm{im}^{+} \mathrm{A}^{-}$are not rapidly hydrolyzed, if equilibria with $(Z)$-en and $(E)$-en are quickly established, in which case the $\mathrm{C} 2$ stereocenter may partially epimerize, and if the protonation of these enamines is not very stereoselective (by the rear face), the so-called syn adducts of the 4nitrobutanals ( $\mathrm{R}$ and $\mathrm{R}^{\prime}$ syn) in Figure 2 may be contaminated with variable amounts of the corresponding anti adducts. In other words, the diastereomeric ratio ( $\mathrm{dr}$ ) may be reduced. To avoid this is key to solving the second issue mentioned above. In passing, we should recall that each nitro-Michael adduct, by rotation around single bonds, may exist as $3^{n}$ conformations. The huge number of conformers of close energy that can be present in many aminocatalytic reactions were remarked by us ${ }^{5}$ and by Seebach, Reiher, and co-workers. ${ }^{6}$

In this context, this work is an acknowledgement of the contributions of the authors mentioned so far, ${ }^{1-4}$ but we planned to go even further. We wish to account for the cases in which the stoichiometric reactions are feasible but do not work under catalytic conditions, as well as for the differences in the stereochemical outcome using aldehydes and ketones as Michael donors. Thus, we aim to answer question (a) and to find an explanation for points (b) $-(d)$ :

(a) Can cyclobutanes be formed in all reactions between enamines and polarized $\mathrm{C}-\mathrm{C}$ double bonds?

(b) When reacting with $\beta$-nitrostyrene in the presence of appropriate secondary amines, aldehydes afford syn adducts (usually 2R,3S) in excellent yields and stereoselectivities, whereas ketones afford the other syn adducts (usually $2 \mathrm{~S}, 3 \mathrm{R}$ ), ${ }^{1,7-10}$ with exceptions in special cases; ${ }^{11}$ this is known since the pioneering works on this Michael reaction. ${ }^{8}$ However, poor results are obtained with $(S)$-proline, often with disappointing enantiomeric ratios (er's), as shown in Figure 3, eqs 1 and 2. The

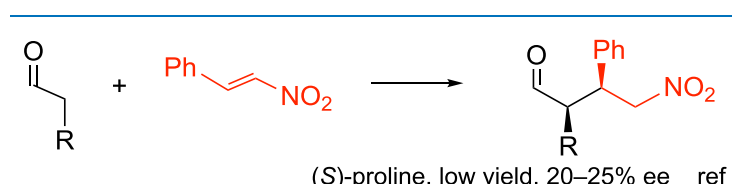

(S)-proline, low yield, $20-25 \%$ ee ref 8 (S)-prolinamines, $\leq 75 \%$ ee
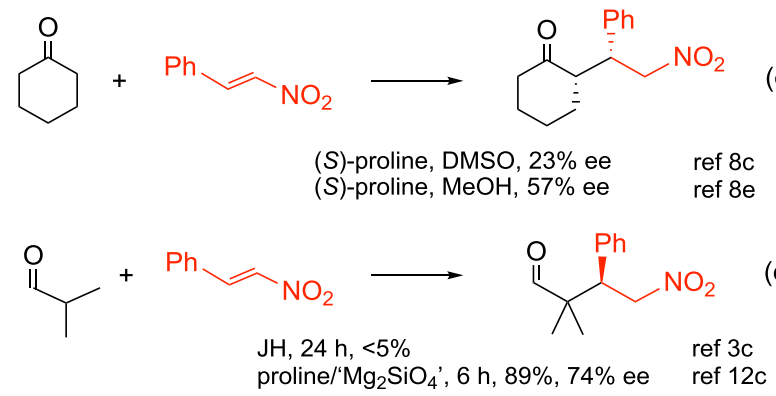

Figure 3. Representative examples of bizarre results concerning catalytic nitro-Michael reactions.

possible stereodirecting role of the $\mathrm{COOH}$ in these nitro-Michael reactions has therefore been questioned; ${ }^{9}$ nevertheless, the corresponding nitronate ions and nitronate-containing intermediates may strongly interact with acidic protons (of thioureas, for example) or with Lewis acids. (c) $\alpha$-Branched aldehydes such as isobutyraldehyde, plus $\beta$ nitrostyrene, give poor yields (in relation to non- $\alpha$ branched aldehydes $)^{1}$ with the $\mathrm{JH}$ catalyst. ${ }^{3 \mathrm{c}, 3 \mathrm{f}}$ Recourse to special catalysts is necessary for partial improvement (Figure 3, eq 3). ${ }^{12}$ Excellent enantiomeric excess (ee)\% values were only reported by using pyrrolidine-thiourea catalysts. $^{12 \mathrm{~h}-\mathrm{k}}$

(d) The non- $\alpha$-branched aliphatic nitroalkenes investigated to date afford lower stereoselectivities than aromatic nitroalkenes ( $\beta$-nitrostyrene and congeners) and $\alpha$ branched nitroalkenes. ${ }^{1}$

We too, several years ago, were faced with the two above-mentioned general issues when attempting to develop new prolinol derivatives ${ }^{13}$ related to that of Peng et al. (catalyst A). ${ }^{14}$ We hoped that some of the catalysts (B-I, Figure 4) might be applied to both aldehydes and ketones, as well as to aliphatic nitroalkenes (not only to $\beta$-nitrostyrene and its derivatives), and would therefore enjoy a wider use in total synthesis. Many of them gave excellent results with cyclohexanone and $\beta$-nitrostyrene (see the Supporting Information, SI). However, with an aldehyde such as 3-phenylpropanal and $\beta$-nitrostyrene, they afforded disappointing syn/anti diastereomeric ratios (ca. 65:35) and enantiomeric ratios $(38-70 \%$ ee $) .{ }^{13}$ Since the reactions were rapid, we assumed that the aldehyde enamines were readily formed and the Michael additions were also feasible and exergonic, but since the stereoselectivities were poor, we thought that the steric effects of the silylated substituents were not enough to distinguish one face of the enamine group from another. Apparently, there was no solution: with pyrrolidines containing sterically crowded substituents (such as the popular JH catalyst), the aldehydes afforded nitro-Michael adducts with excellent stereoselectivities but ketones did not react (enamines were formed in trace amounts ${ }^{5}$ ); with less crowded pyrrolidines A-I, ketones worked well, but aldehydes produced mixtures of stereoisomers.

With cyclohexanone and $\beta$-nitrostyrene, the best results were obtained with $\mathbf{D}$ and $\mathbf{E}$ (Figure 5, eq 1 ), which turned out to be slightly better than A (100\% conversions in few hours, with $>90 \%$ syn and $>90 \%$ ee values). $\mathbf{B}$ and $\mathbf{F}$ were worse than $\mathbf{D} / \mathbf{E} / \mathbf{A}$ (see the $\mathrm{SI}$ ).

More surprising was the fact that other nitro-Michael reactions did not progress under catalytic conditions (for examples, see Figure 5, eqs 2 and 3 ). These disappointing results cannot be related to very different equilibrium constants for the formation of the initial enamines among the A-I series, since we had determined by ${ }^{1} \mathrm{H}$ NMR spectroscopy that they were of the same order, but to a halt in the process during later steps.

Thus, we would like to address some further issues concerning nitro-Michael reactions to explain:

(e) Why aldehydes (in contrast to cyclohexanone) give nitro-Michael adducts with low stereoselectivities by using chiral pyrrolidines A-I.

(f) Why the nitro-Michael reactions of cyclopentanone and 2,2-dimethyl-1,3-dioxan-4-one did not progress under catalytic conditions. For completion within $24 \mathrm{~h}$, substoichiometric amounts $(>40 \mathrm{~mol} \%)$ of our best catalysts (D or $\mathbf{E})$ were required for the cyclopentanone case and stoichiometric amounts for the above- 

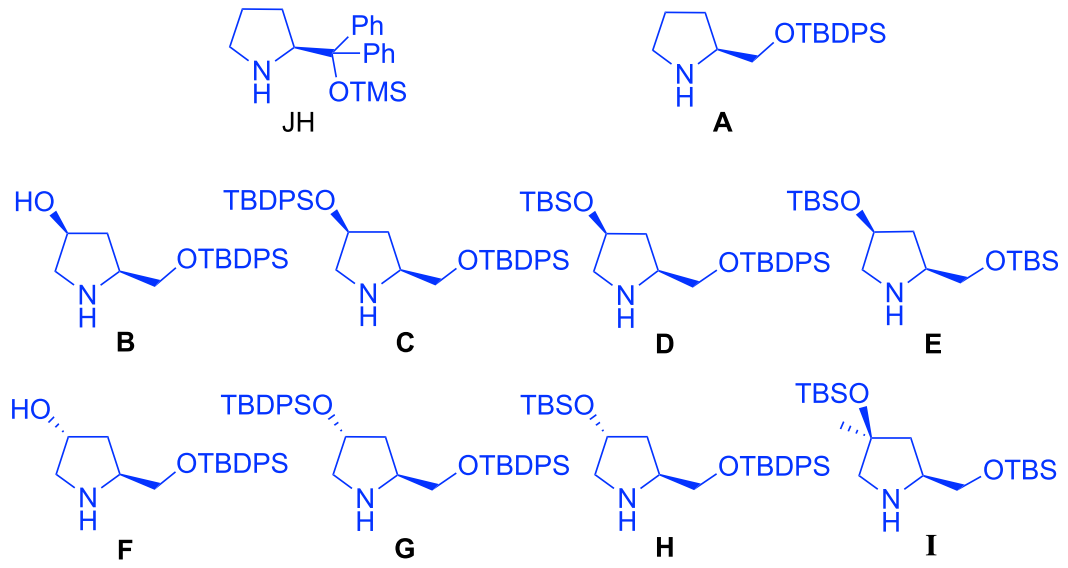

Figure 4. Silylated prolinediols (B-I) examined and compared to the JH catalyst and Peng's catalyst (A).

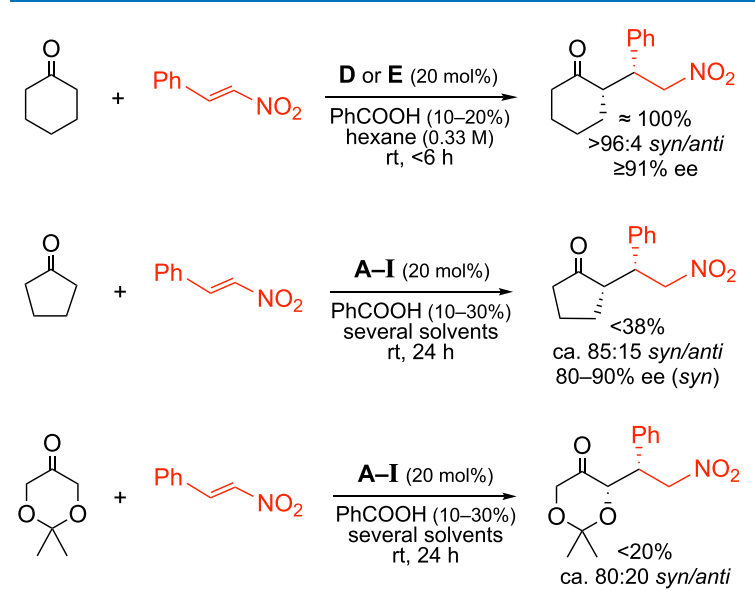

(eq 1)

Figure 5. Catalysts of choice (among those of Figure 4) for the paradigmatic nitro-Michael reaction (eq 1) and bizarre results for similar nitro-Michael reactions (eqs 2 and 3).

mentioned dioxanone. This is in sharp contrast with the reactivity of cyclohexanone, 4-thiacyclohexanone, 4oxacyclohexanone, and 4,4-dimethylcyclohexanone, which only needed $20 \mathrm{~mol} \%$ catalyst and few hours of reaction for a complete conversion, with excellent syn/ anti ratios and excellent ee\%. In fact, cyclohexanone is the best among the commercially available ketones tested by us, as far as the stereoselectivity of these aminocatalytic reactions is concerned.

To understand these experimental results (points $a-f$ ), we followed by ${ }^{1} \mathrm{H}$ NMR spectroscopy,15 the progress of the reactions using higher than catalytic amounts of the secondary amines. The nitrocyclobutanes formerly reported ${ }^{3 a-d}$ had been described with the $\mathrm{JH}$ catalyst or closely related pyrrolidine derivatives, in deuterated benzene ${ }^{3}\left(\mathrm{C}_{6} \mathrm{D}_{6}\right)$. Thus, we were interested in elucidating first whether nitrocyclobutanes can be generated with other catalysts and in other solvents or not.

\section{RESULTS AND DISCUSSION}

Preparation of the Starting Enamines. Under catalytic conditions, the concentration of the starting enamines is often very low, since their formation equilibria are not shifted to the right in most solvents ${ }^{5}$ and/or they rapidly react with the nitroalkene; it is then difficult to detect the changes by ${ }^{1} \mathrm{H}$ NMR spectroscopy, although small doublets of doublets or triplets characteristic of the all-trans-nitrocyclobutylpyrrolidine derivatives are often detected. ${ }^{3 a}$ Under stoichiometric conditions, the complex mixtures of several intermediates (those shown in Figure 2) and final products, together with remaining starting materials, prevent to reliably follow the reaction progress, although several hours later the final aldehydes predominate. To increase the chances of detecting all of the main intermediates, when they have shorter half-lives than those derived from the $\mathrm{JH}$ catalyst ${ }^{3 \mathrm{a}-\mathrm{d}}$ and/or when operating with solvents more polar than $\mathrm{C}_{6} \mathrm{D}_{6}$ or toluene- $d_{8}$, we increased as much as possible the concentration of the starting enamine in situ. We proceeded as follows: (a) the simple aldehydes were treated at room temperature (rt) with equivalent amounts of pyrrolidine, $(S)$-proline, or derivatives, in different solvents, in the presence of a crushed $3 \AA$ molecular sieve (MS); (b) except for the experiments with proline, powdered $\mathrm{CaH}_{2}$ was then added in portions and stirring was maintained until no more hydrogen bubbles were observed; (c) after filtering, the ${ }^{1} \mathrm{H}$ NMR spectra (adding a drop of $\mathrm{C}_{6} \mathrm{D}_{6}$ or two drops of $\mathrm{CDCl}_{3}$ when nondeuterated solvents were used) were registered, indicating that the initial enamines were now formed in appreciable amounts $(<1 \mathrm{~h}$, overall); (d) nearly equivalent amounts of $\beta$-nitrostyrene or of (E)-3-methyl-1-nitrobutene were slowly added, and the spectra were registered. This protocol did not ensure a completely anhydrous medium during the process (since the absolute formation of the starting enamines from the precursors in different solvents is impossible under these conditions), but the main intermediates were easily observed by NMR. With proline, as known, ${ }^{1}$ the major tautomers in the equilibria are the corresponding oxazolidinones, but the reactions progressed despite the low concentrations of the starting enamines present in the medium.

Generality of the Formation of Nitrocyclobutanes. The ${ }^{1} \mathrm{H},{ }^{13} \mathrm{C}$, and two-dimensional [heteronuclear singlequantum correlation (HSQC), correlated spectroscopy (COSY), nuclear Overhauser enhancement spectroscopy (NOESY)] NMR spectra, which are given as SI, clearly showed that on mixing the enamines and nitroalkenes just mentioned, all-trans isomers of nitrocyclobutylpyrrolidine derivatives $\mathbf{1 - 1 5}(\mathbf{1}-\mathbf{c b}-\mathbf{1 5}-\mathbf{c b}$, Figure 6) appeared first and became the major compounds. The first six compounds in Figure 6 are racemic, and the remaining nine compounds are enantiopure. The first 13 are reported here for the first time. Coupling constants $\left({ }^{3} \mathrm{~J}_{\mathrm{HH}}=7-9 \mathrm{~Hz}\right)$ indicate that all of the cyclobutane methine hydrogens are in a trans arrangement and appear as characteristic doublets of doublets or as triplets. 

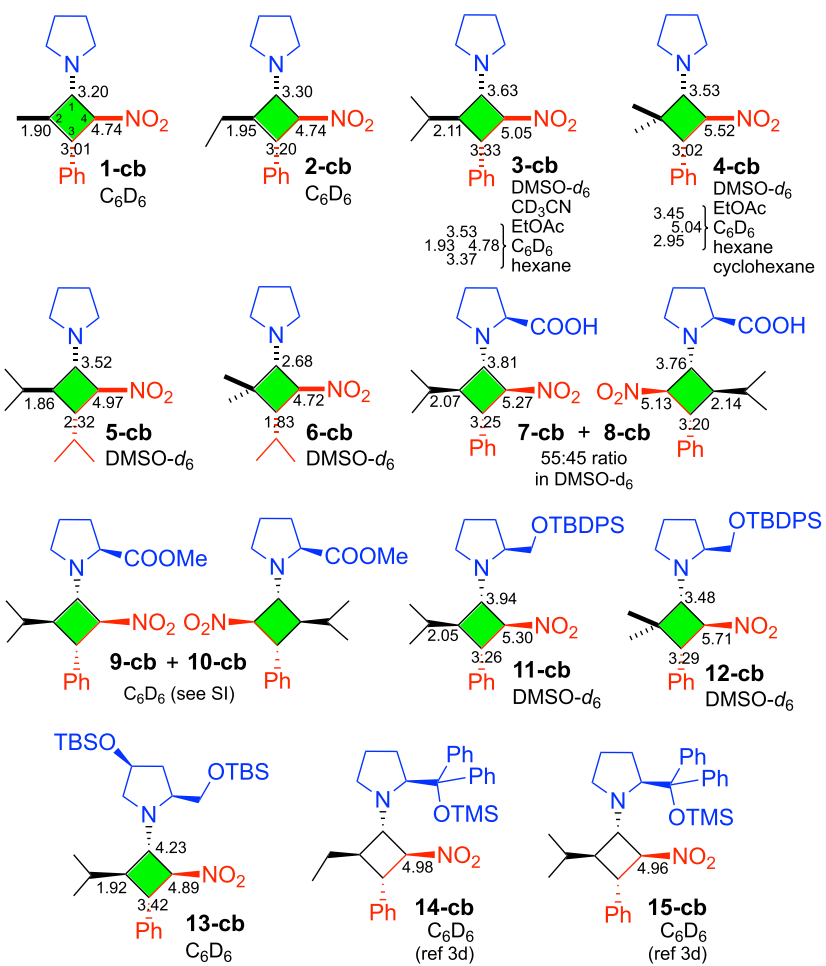

Figure 6. Nitrocyclobutanes characterized by NMR spectroscopy in the present work, starting from the corresponding enamines, previously prepared. The ${ }^{1} \mathrm{H}$ chemical shifts for the cyclobutane protons of structures 3-cb and 4-cb are those noted in the first of the solvents indicated.

Thus, the substituents are trans to one another (hence the trivial, nonsystematic name of all-trans-cyclobutanes). Chemical shifts $(\delta \mathrm{H}$ and $\delta \mathrm{C})$ agree with those reported by Seebach, Hayashi, et al. ${ }^{3 \mathrm{a}, \mathrm{d}}$ for the known compounds 14-cb and 15-cb. What matters here is that in all cases nitrocyclobutanes were the predominant species in the reaction mixtures. Thus, in any solvent, with any secondary amine, a formal $[2+2]$ cycloaddition always takes place, via a special stepwise mechanism, with retention of the relative trans configuration of both double bonds.

Some nitrocyclobutanes isomerized slowly to a mixture of enamines, where the $E$ adduct predominated. ${ }^{3 \mathrm{~b}}$ For example, Figure 7 shows how a sample of the racemic compound 1-cb in

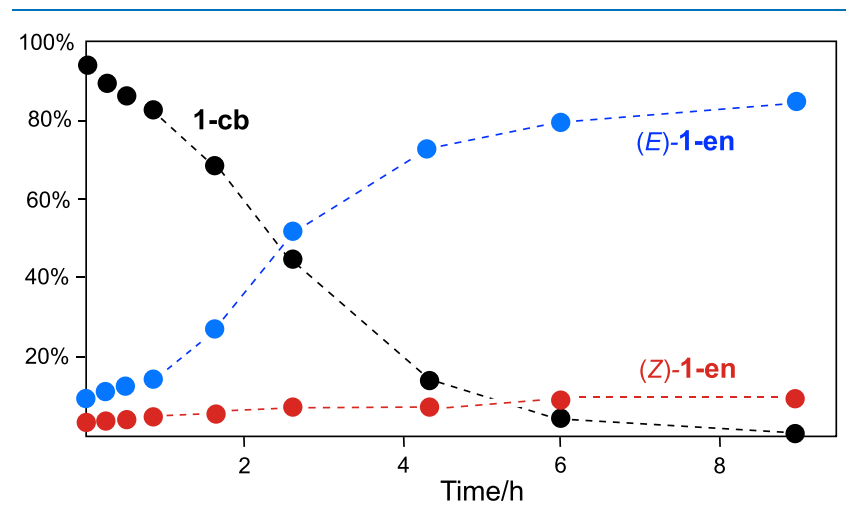

Figure 7. Spontaneous conversion, in $\mathrm{C}_{6} \mathrm{D}_{6}$ at $25{ }^{\circ} \mathrm{C}$, of nitrocyclobutane 1-cb into adduct enamines, 1-en, in the absence of water. Relative percentages as obtained from the integration of the proton signals in the ${ }^{1} \mathrm{H}$ NMR spectra.
$\mathrm{C}_{6} \mathrm{D}_{6}$, which we had prepared and stored at ca. $5{ }^{\circ} \mathrm{C}$, spontaneously isomerized when the NMR tube was introduced into the spectrometer, at ca. $25^{\circ} \mathrm{C}$, to $(Z)$-1-en (minor) and (E)-1-en (major): the signal at $\delta 4.74(\mathrm{dd}, J=8.3$ and $7.1 \mathrm{~Hz}$ ) disappeared, whereas broad singlets in a 1:9 final ratio appeared at $\delta 5.55$ and 5.82 ( $\mathrm{CH}$ olefinic proton by HSQC, $\delta \mathrm{C}$ at 137.6). The configurations were confirmed by NOESY.

Nitrocyclobutane $\mathbf{2 - c b}$ was also transformed to adduct or final enamines [mainly $(E)$-2-en] at the usual temperature of the NMR probe. We interpreted these ring-opening isomerizations in the simplest way (principle of least motion), as depicted in Figure 8. Calculations will be commented on below. We should indicate that in parallel reactions carried out in the more polar solvent dimethyl sulfoxide (DMSO)- $d_{6}$, we did not detect cyclobutanes $\mathbf{1 - c b}$ and $\mathbf{2 - c b}$, but the corresponding final enamines; slowly, due to the moisture, the expected adducts (final aldehydes) appeared.

Other nitrocyclobutanes were more stable than 1-cb and 2cb and could be characterized in DMSO- $d_{6}$ at rt, such as 3-cb to 8 -cb. With 3 and 4 , we used several solvents, with identical success. The solutions in nonpolar solvents could even be carefully evaporated under vacuum, and the oily residue dissolved in anhydrous DMSO- $d_{6}$ without the appearance of new NMR signals due to ring opening and/or hydrolysis. In the presence of an equimolar amount of $\mathrm{PhCOOH}$, nitrocyclobutanes 1-cb, 2-cb, and 3-cb were also immediately formed. The difference was that, at rt, 1-cb and 2-cb isomerized to their enamines more rapidly than in the absence of $\mathrm{PhCOOH}$; cyclobutane 3-cb survived for hours.

To summarize, with 1-cb and 2-cb, we were unable to detect nitrocyclobutanes in wet solvents. With substrates less susceptible to hydrolysis, under substoichiometric conditions, in the presence or not of $\mathrm{PhCOOH}$, we had observed by NMR that some or part of the intermediate species immediately disappeared to afford the final aldehyde, while the major part were nitrocyclobutanes that disappeared quite slowly.

Some authors ${ }^{3 \mathrm{c}}$ attributed the relatively high stability of 2,2dimethyl-4-nitrocyclobutyl derivatives from 2-methylpropanal, the $\mathrm{JH}$ catalyst, and $\beta$-nitrostyrene (see 4 -cb but with $\mathrm{CPh}_{2} \mathrm{OTMS}$ at the pyrrolidine ring) to the lack of proton $\mathrm{H} 2$ in such a gem-dimethyl derivative, since no enamine can be formed by prototropy from $\mathrm{C} 2$ to $\mathrm{C} 4$. This is absolutely true, but in our hands 2,2-dimethylcyclobutanes 4-cb and 6-cb did not survive purification by chromatography on silica gel, either with $\mathrm{CH}_{2} \mathrm{Cl}_{2}$-hexane or EtOAc-hexane as the eluents. We only recovered from the column the final aldehyde (nitroMichael adduct). These gem-dimethyl cyclobutanes could have been purified on other more anhydrous supports, but it was beyond the two objectives of the present work. What matters here is that gem-dimethylcyclobutylpyrrolidine derivatives are also hydrolyzable, probably via the zwitterions (Figure 8) or via iminium salts (see below).

When $(S)$-proline was used instead of pyrrolidine in the reaction between 3 -methylbutanal and $\beta$-nitrostyrene, a mixture of two diastereomeric nitrocyclobutanes was obtained $(7-\mathbf{c b}+8-\mathbf{c b}$, Figure 6) in a 55:45 ratio. Treatment of this mixture with $\mathrm{PhCOOH} / \mathrm{D}_{2} \mathrm{O}$ afforded the final aldehyde with a poor er (as expected, see Figure 3). With methyl $(S)$ prolinate, the same substrates also afforded a mixture of two nitrocyclobutanes $(9-\mathrm{cb}+10-\mathrm{cb})$.

When the substituents on the pyrrolidine ring were larger, one nitrocyclobutane stereoisomer (11-cb, 12-cb, and 13-cb) was predominant but the other was still detected; after 


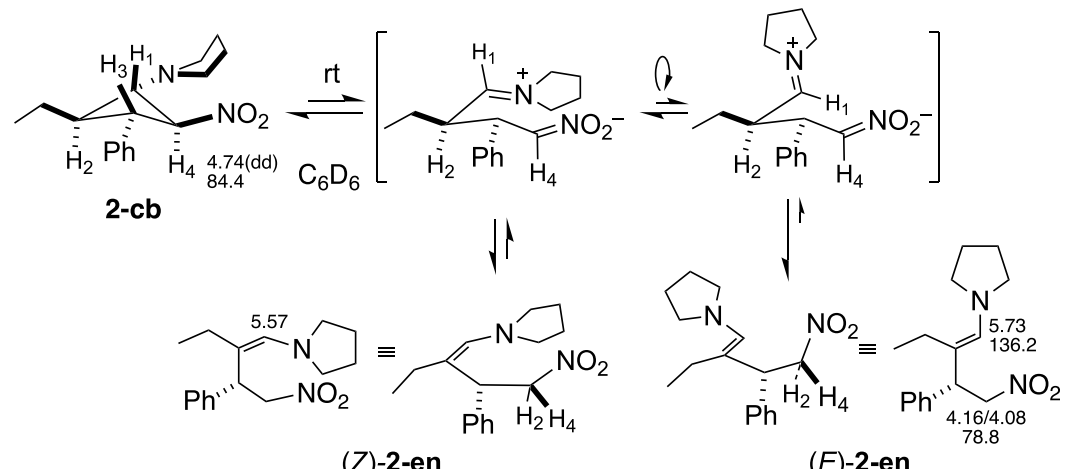

Figure 8. Within a few hours at rt, 2-cb underwent a ring-opening reaction to afford a 1:9 Z/E final mixture of its isomeric enamines; the plausible mechanism.

(A) Relative Energies of All the Possible N-(2,3-Dimethyl-4-nitrocyclobutyl)pyrrolidine Stereoisomers ${ }^{\text {a }}$

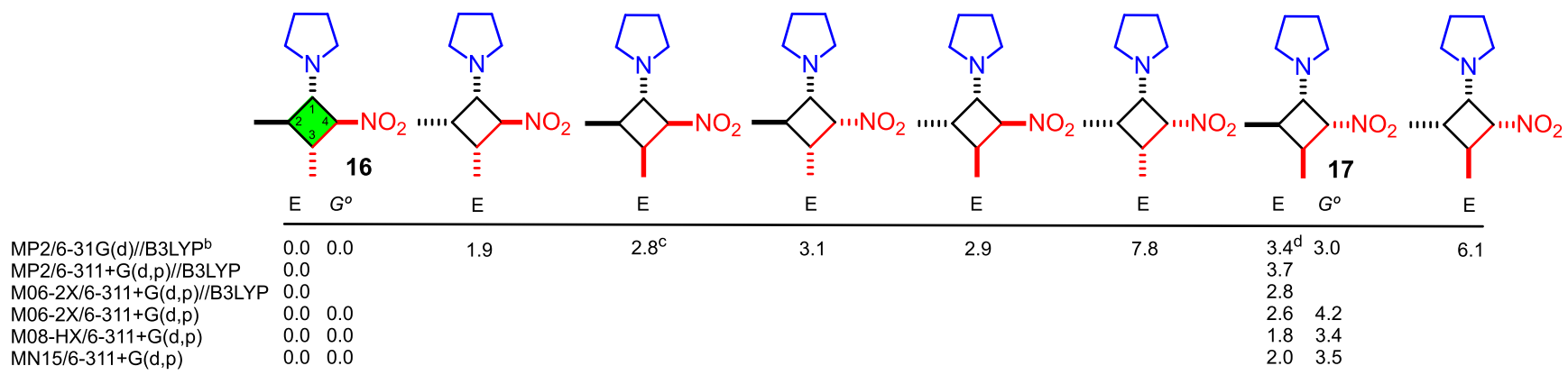

(B) Reaction Energies

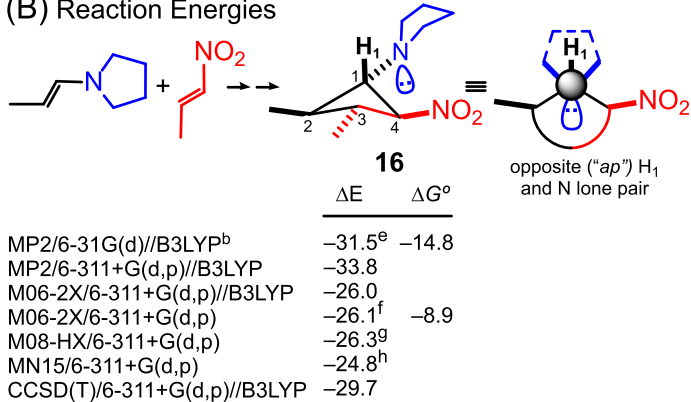

(C) Conformational Analysis of 16. 'Relative Energies

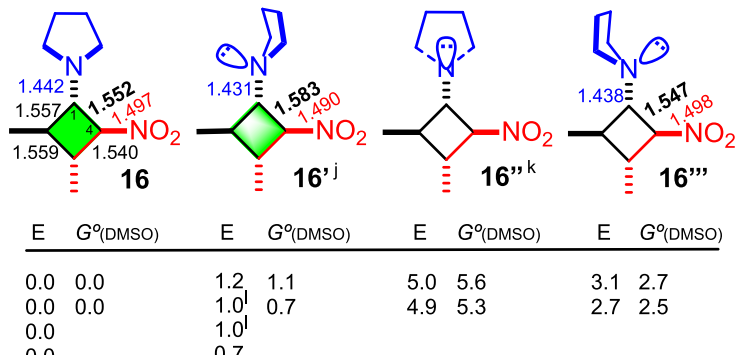

a Total energy differences in au or hartrees were converted to $\mathrm{kcal} / \mathrm{mol}(1 \mathrm{au}=627.5 \mathrm{kcal} / \mathrm{mol}) .{ }^{\mathrm{b}} \mathrm{B} 3 \mathrm{LYP} / 6-31 \mathrm{G}$ (d)-optimised geometries, unless otherwise indicated, but similar energy values were obtained using B3LYP/6-311+G(d,p) geometries, in representative cases. ${ }^{c} 3.1 \mathrm{kcal} / \mathrm{mol}^{\mathrm{m}}$ in benzene $\left(\mathrm{C}_{6} \mathrm{H}_{6}\right), 2.8$ in dimethyl sulphoxide $(D M S O)$; single-point calculations with the SMD model unless otherwise indicated. ${ }^{d} 0.3 \mathrm{kcal} / \mathrm{mol}$ less in $\mathrm{C}_{6} \mathrm{H}_{6}, 0.6 \mathrm{kcal} / \mathrm{mol}$ less in DMSO. ${ }^{\mathrm{e}}-31.0$ in $\mathrm{H}_{2} \mathrm{O}(\mathrm{PCM}){ }^{\mathrm{f}}-25.1$ in $\mathrm{C}_{6} \mathrm{H}_{6},-23.9$ in DMSO. ${ }^{\mathrm{g}}-25.3$ in $\mathrm{C}_{6} \mathrm{H}_{6},-24.1$ in DMSO. ${ }^{\mathrm{h}}-23.8$ in $\mathrm{C}_{6} \mathrm{H}_{6},-22.6$ in DMSO. ${ }^{i}$ All rotational barriers $\leq 5.6 \mathrm{kcal} / \mathrm{mol}$. Interatomic distances in $A$. At the MP2/6-31G(d)//B3LYP/6-31G(d) level, for 16, $\mathrm{E}=$ -649.64808 au and $G^{\circ}=-649.41550$ au. ${ }^{j}$ Conformer 17 ' (see 17 with the pyrrolidine ring perpendicular to the cyclobutane) lies $1.3(\Delta E, M P 2 / 6-31 G), 0.8(\Delta E, M 06-2 X)$, and 1.2 $\mathrm{kcal} / \mathrm{mol}(\Delta \mathrm{E}, \mathrm{M} 08-\mathrm{HX})$ above 17. ${ }^{\mathrm{k}} \mathrm{It}$ is not a relative minimum, but the TS between 16' and 16'”. The energy minimum has the pyrrolidine ring folded up: $\Delta \mathrm{E}=2.2(\mathrm{MP} 2 / 6-31 \mathrm{G}(\mathrm{d}))$ and $1.0(\mathrm{M} 06-2 \mathrm{X} / 6-311+\mathrm{G}(\mathrm{d}, \mathrm{p}))$; it becomes more significant dealing with substituted pyrrolidines (see below). ${ }^{\prime} 0.8 \mathrm{kcal} / \mathrm{mol}$ in $\mathrm{C}_{6} \mathrm{H}_{6}, 0.5$ in DMSO

Figure 9. Relative energies $(\mathrm{kcal} / \mathrm{mol})$ of stereoisomers and conformers of a nitrocyclobutane model (A). Reaction energies calculated for the formation of cyclobutane 16 at different levels of theory (B). Conformational analysis of $\mathrm{N}$-(4-nitrocyclobutyl)pyrrolidine 16 (C).

hydrolysis, these samples gave the corresponding final aldehydes with good, but not excellent, er values. Only in the last two examples (14-cb and $\mathbf{1 5}-\mathbf{c b}$, from the JH catalyst) we observed a single stereoisomer, as reported. ${ }^{3 \mathrm{~d}}$ The five nitrocyclobutanes just mentioned were more stable with respect to ring opening and hydrolysis than the previous members of our series. In general, we noted that the larger the substituents of the cyclobutane ring, the more resistant the reaction intermediates to ring opening and hydrolysis, for a given solvent.

In short, cyclobutanes are always observed monitoring by ${ }^{1} \mathrm{H}$ NMR the reaction of any aldehyde enamines and nitroalkenes, in several solvents. They are the predominant species. In general, they disappear (a) when the temperature rises; (b) in the presence of dissolved water (in polar solvents) or presumably if there is water solvating the polar intermediates (in apolar solvents); and (c) in the presence of appropriate organic acids (HA) and moisture.

General Relevance of the All-trans-cyclobutane Arrangement. According to Figure 2, ${ }^{1,3}$ it is probable that the $\mathrm{dr}$ (syn/anti ratio) of the final adduct is controlled by the relative thermodynamic stability of (and kinetic preference for) the all-trans-cyclobutanes in relation to the other cyclobutane isomers. Since C2-R and C3- $\mathrm{R}^{\prime}$ are trans, these groups ( $R$ and $\mathrm{R}^{\prime}$ ) will be syn in the final adduct after cleavage of the $\mathrm{C} 1-\mathrm{C} 4$ bond and rotation. However, if epimerization occurs during the last steps, the syn/anti ratios (the diastereomeric ratios, dr's) will be lower. 
(A)

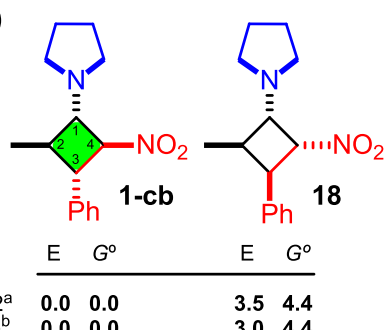

MO6 ${ }^{\mathrm{b}}$

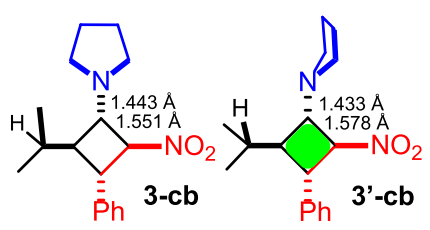

$\begin{array}{ll}\mathrm{MP}^{\mathrm{a}} & \mathbf{0 . 0}\end{array}$
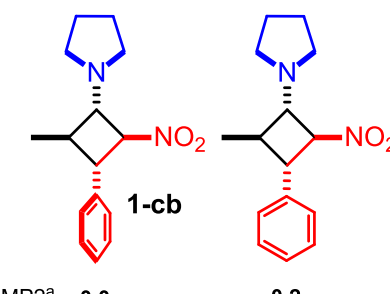

0.2
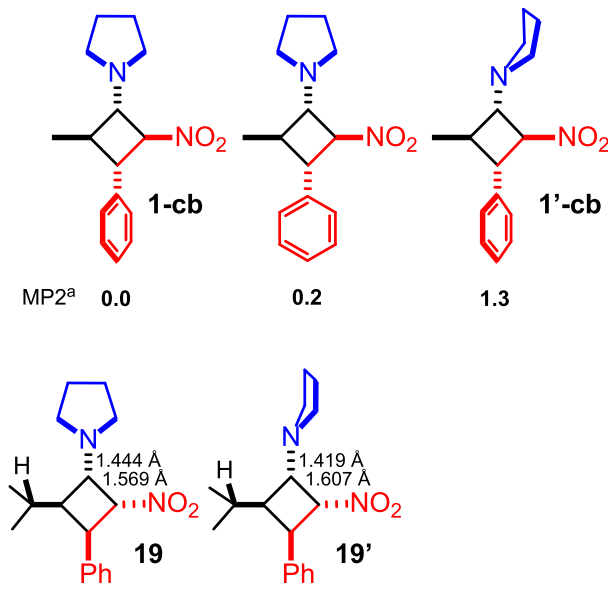

$$
\text { E } G^{\circ}
$$

E $G^{\circ}$

E $G^{\circ}$

E $G^{\circ}$

$\begin{array}{lll}\mathrm{MP}^{\mathrm{a}} & 0.9 & 0.8\end{array}$

MP2
M06

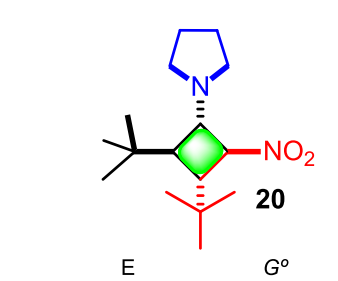

$\begin{array}{ll}0.0 & 0.0 \\ 0.0 & 0.0\end{array}$

$\begin{array}{ll}5.5 & 6.9 \\ 5.1 & 6.8\end{array}$

$\begin{array}{ll}4.5 & 5.7 \\ 3.6 & 5.7\end{array}$
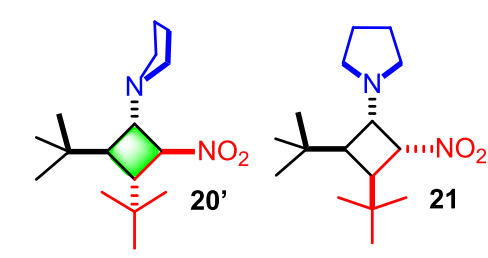

\begin{tabular}{cc}
$E$ & $G^{\circ}$ \\
\hline 10.6 & 13.5 \\
9.8 & 12.6
\end{tabular}

MP2 $-884.650590 .9-884.260041 .5-884.651990 .0-884.262400 .0$

${\mathrm{M} 06^{\mathrm{b}}}^{\mathrm{B}}-887.46117 \mathbf{0 . 0}-887.05915 \mathbf{0 . 0}-887.46073 \mathbf{0 . 3}-887.05858 \mathbf{0 . 4}$

${ }^{a} M P 2=M P 2 / 6-31 G(d) / / B 3 L Y P / 6-31 G(d)$

${ }^{b} M 06=M 06-2 X / 6-311+G(d, p)$
(B)

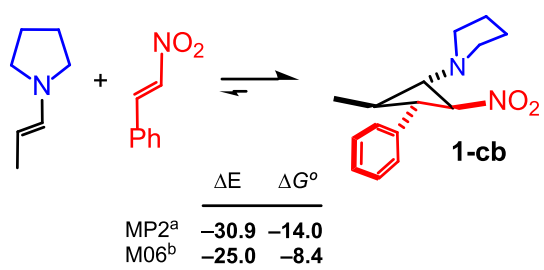

Figure 10. Lowest-energy conformers of $1-\mathbf{c b}, 3-\mathbf{c b}$, and 20. Relative energies of their isomers 18, 19, and 21 (A); predicted total electronic energies (au) in small letter. Relative energies in $\mathrm{kcal} / \mathrm{mol}$, in bold, on the right side, for the reactions leading to these cyclobutanes (B).

First, with a simple model, we compared the relative energies of all of the possible stereoisomeric nitrocyclobutanes, by means of molecular orbital (MO) calculations (Figure 9) with the Gaussian 16 program package. ${ }^{16}$ All-trans-nitrocyclobutane 16-cb, henceforward often called $\mathbf{1 6}$ for simplicity's sake, with the four substituents of the cyclobutane ring in an equatorial arrangement, or almost equatorial, was calculated to be thermodynamically more stable than the other seven isomers (Figure 9A), in which one or more groups must be axial, almost axial, or pseudoaxial. Some of these stereoisomers could be generated by epimerization of the $\mathrm{CHNO}_{2}$ stereocenter via its nitronate (i.e., in the presence of any base, relatively strong such as pyrrolidine or moderate such as the tertiary $\mathrm{N}$ atom of any nitrocyclobutylpyrrolidine or enamine group). Other stereoisomers might be generated: (1) if the cycloaddition reaction was produced without retention of configuration of the partners; (2) if either the starting $(E)$-enamine or $(E)$ nitroalkene was impure, containing some percentages of their $Z$ isomers (which is seldom the case), and no $Z$-to- $E$ isomerization occurred during or after the cycloaddition. Particularly interesting is isomer $\mathbf{1 7}$, since it is the product of the alternative approach between the enamine and nitroalkene, with configuration retention: substituents at $\mathrm{C} 1$ and $\mathrm{C} 2$ of the cyclobutane are in trans; substituents at $\mathrm{C} 3$ and $\mathrm{C} 4$ are also in trans. However, under equilibrium conditions, Figure 9A suggests that 17 would be converted into 16 (with calculated $\Delta G^{\circ}$ values between -3.0 and $-4.2 \mathrm{kcal} / \mathrm{mol}$ ).

Figure $9 \mathrm{~B}$ indicates that the cycloaddition reaction for this model is exothermic, with $\Delta E$ values between -33.8 and -24.8 $\mathrm{kcal} / \mathrm{mol}$. The mean value between the MP2/6-31G(d) and M06-2X/6-311+G(d,p) results is close to the higher-level $\operatorname{CCSD}(\mathrm{T})$ value, as it is the mean of the first six values. The reaction is also exergonic or exoergic: approximate $\Delta G^{\circ}$ values lie between -7 and $-14.5 \mathrm{kcal} / \mathrm{mol}$ (depending on the method, assuming that from $\Delta E$ to $\Delta G^{\circ} \mathrm{ca} .17 \mathrm{kcal} / \mathrm{mol} \mathrm{must}$ be added) in apolar solvents and between -5.5 and $-14 \mathrm{kcal} /$ mol in polar solvents (see footnotes in Figure 9). Also, there is free rotation around the $\mathrm{N}-\mathrm{C} 1$ bond, but the conformer with both rings almost coplanar has the lowest energy. Conformer 16' deserves comment, since a clear stereoelectronic effect appears, due to the arrangement of the $\mathrm{N}$ lone pair, the $\mathrm{C} 1-$ $\mathrm{C} 4$ bond, and the $\mathrm{NO}_{2}$ group: $\mathrm{N}-\mathrm{C} 1$ is shorter, $\mathrm{C} 1-\mathrm{C} 4$ is longer, and $\mathrm{C} 4-\mathrm{NO}_{2}$ is shorter. The relevant interatomic distances given in Figure 9C are those obtained at the B3LYP/ 6-31G(d) level, for the sake of simplicity, but the same effect was observed at all levels of theory, as expected.

Relevance of the Size of Groups R (Enamine) and $\mathbf{R}^{\prime}$ (Nitroalkene). Model $\mathbf{1 6}$ is too simple, so that we calculated other cyclobutanes closer to $\mathbf{1 - c b}-\mathbf{4}-\mathbf{c b}$. Figure 10 summarizes only the lowest-energy conformers relevant for each case, among a plethora ${ }^{5,6}$ of conformations that we examined. The gap between 1-cb and $\mathbf{1 8}$ (Figure 10A) is larger than that between 16 and 17. The gap between 3-cb and 19 is even larger (and all of the remaining forms, not shown to save space, are $5.0-14.0 \mathrm{kcal} / \mathrm{mol}$ above $3-\mathrm{cb}$ ). When the steric crowding between $\mathrm{C} 2-\mathrm{R}$ and $\mathrm{C} 3-\mathrm{R}^{\prime}$ increases more, the gap $(\Delta E)$ significantly increases (compare 20 and 21). In other words, the use of $\beta$-branched aldehydes and nitroethenes substituted 


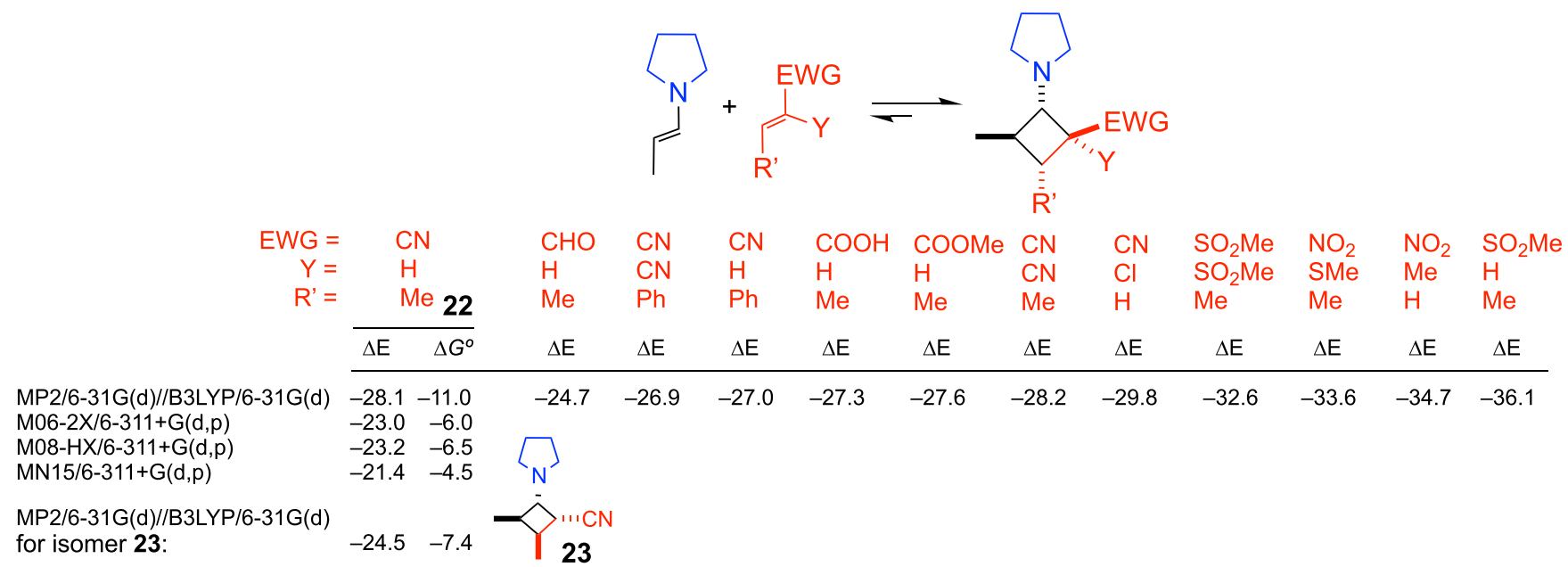

Figure 11. Predicted reaction energies (in $\mathrm{kcal} / \mathrm{mol}$ ) for a variety of EWG-activated alkenes that lead to cyclobutanes.

by aryl groups or branched chains increases the energy difference between the approach of the substrates or reactants to give one all-trans-nitrocyclobutane (we will call it antiperiplanar or ap approach) or the alternative one (the synclinal or sc approach). See below for further details, where it will be demonstrated that the $\mathrm{dr}$ will depend on these gaps. In other words, the sizes of groups $\mathrm{R}$ (enamine chain) and $\mathrm{R}^{\prime}$ (nitroalkene) are significant for the diastereoselectivity.

This explains "point or problem (d)" of the Introduction. The larger or more branched the $\mathrm{R}$ and $\mathrm{R}^{\prime}$ groups at $\mathrm{C} 2$ and C3, respectively, of the $N$-(4-nitrocyclobutyl)pyrrolidines, the higher the gap between each all-trans-cyclobutane and its isomers and, thus, the higher the diastereoselectivity ( $d r)$ of the final 4-nitrobutanal.

The $\mathrm{NO}_{2}$ and $\mathrm{Ph}$ groups were predicted to be perpendicular to the approximate plane of the cyclobutane and pyrrolidine rings in most of the minimum-energy conformers. The situation is more complex in the case of $\mathbf{3 - c b}$, where the rotation of the isopropyl group gives rise to unfavorable van der Waals (vdW) interactions with the pyrrolidine ring and/or with $\mathrm{Ph}$. Here, conformer $3^{\prime}$-cb turned out to be slightly favored over $3-\mathbf{c b}$. When the substituents at $\mathrm{C} 2$ and $\mathrm{C} 3$ are ${ }^{t} \mathrm{Bu}$, both rotamers $\left(\mathbf{2 0}\right.$ and $\left.\mathbf{2 0}^{\prime}\right)$ were predicted to have a similar energy (as far as possible, we always take the mean values between the MP2 and M06 results for the comparisons).

The reaction energies shown in Figures $9 \mathrm{~B}$ and $10 \mathrm{~B}$ also indicate that the formation of racemic compounds 16, 1-cb, 3$\mathbf{c b}$, and $\mathbf{2 0}$ is exothermic. In other words, the formation of nitrocyclobutylpyrrolidines from enamines and nitroalkenes can be general. The steric hindrance may slow the rate of formation of 20, but in principle, even this reaction is thermodynamically feasible. Nevertheless, the predicted $\Delta G^{\circ}$ value at the M06 level is only $-5.9 \mathrm{kcal} / \mathrm{mol}$, that is, $3 \mathrm{kcal} /$ mol less favorable than the other two cases shown in Figure 10. It is likely that starting from pyrrolidines with large substituents, branched aldehydes and branched nitroalkenes, the $\Delta G^{\circ}$ values are even less favorable.

The corollary here is that reactions between aldehyde enamines and nitroalkenes can go through formal $[2+2]$ cycloadditions. When reactions of aldehydes, secondary amines, and nitroalkenes are carried out in wet polar solvents at $>20{ }^{\circ} \mathrm{C}$, the cyclobutanes have less chance to be detected, as will be explained below.
Cyclobutanes Can Be Formed with All Double Bonds Conjugated with EWGs. The two preceding paragraphs may be general. The experimental examples shown in Figure 1 suggest that the reaction of any enamine with any EWGactivated double bond may afford a cyclobutane, as a more or less stable product or intermediate, depending on the reaction conditions. We calculated the series of reactions shown in Figure 11. All were predicted to be exothermic.

If the formation of all-trans-3,4-dimethyl-4- $N$-pyrrolidinocyclobutanenitrile, 22, is compared to those of E-substituted nitroalkenes in Figures 9 and 10, the parallelism is clear; e.g., $\Delta E$ values between -31.5 and -24.8 (Figure 9) can be compared to $\Delta E$ between -28.1 and -21.4 (Figure 11). The $\Delta G^{\circ}$ values for the formation of $\mathbf{2 2}$ are predicted to still be negative, at all of the levels of theory examined, even for the formation of the alternative isomer, $\mathbf{2 3}$ (which is formed with retention of configuration of the two reactants).

With groups such as $\mathrm{CHO}, \mathrm{COOH}$, and COOMe, it was noted that the values of $\Delta E$ were less negative, but we would still expect values of $\Delta G^{\circ}$ slightly negative. See the SI (Figure S1) for additional details. In contrast, cyclobutanes from conjugated sulfones, from a methylthio derivative of nitropropene, and from $\mathrm{H}_{2} \mathrm{C}=\mathrm{C}(\mathrm{Me}) \mathrm{NO}_{2}$ were calculated to be even more favored than our standard nitrocyclobutanes. In short, all types of double bonds conjugated with EWGs, not only $\beta$-nitrostyrene, have a tendency to yield cyclobutanes, in agreement with Figure 1. The stronger the EWG, the more exothermic the cyclobutane formation appears. Other details such as steric hindrance and the contribution of group Y seem to modulate this effect, as could be expected. The real chances of isolating these cyclobutanes again will probably depend on the thermodynamic or kinetic stability of each structure in the medium at a given temperature.

The preceding paragraphs answer "question (a)" posed in the Introduction: cyclobutanes are formed in all of the reactions reported here (Figure 6) and/or are predicted at different levels of theory to be thermodynamically more stable (Figure 11) than their precursors. The formation of cyclobutanes is more general than previously thought.

The isomer alternative to 22 (see 23 ) was found $3.6 \mathrm{kcal} /$ mol above the corresponding all-trans-cyclobutane. The gaps, for the cases that we examined in Figures 11 and S1, were 3.6, $3.3,3.6$, and $2.2 \mathrm{kcal} / \mathrm{mol}$. These isomers (also see $17-19$ and 21) are always predicted to lie a few $\mathrm{kcal} / \mathrm{mol}$ above. In short, 

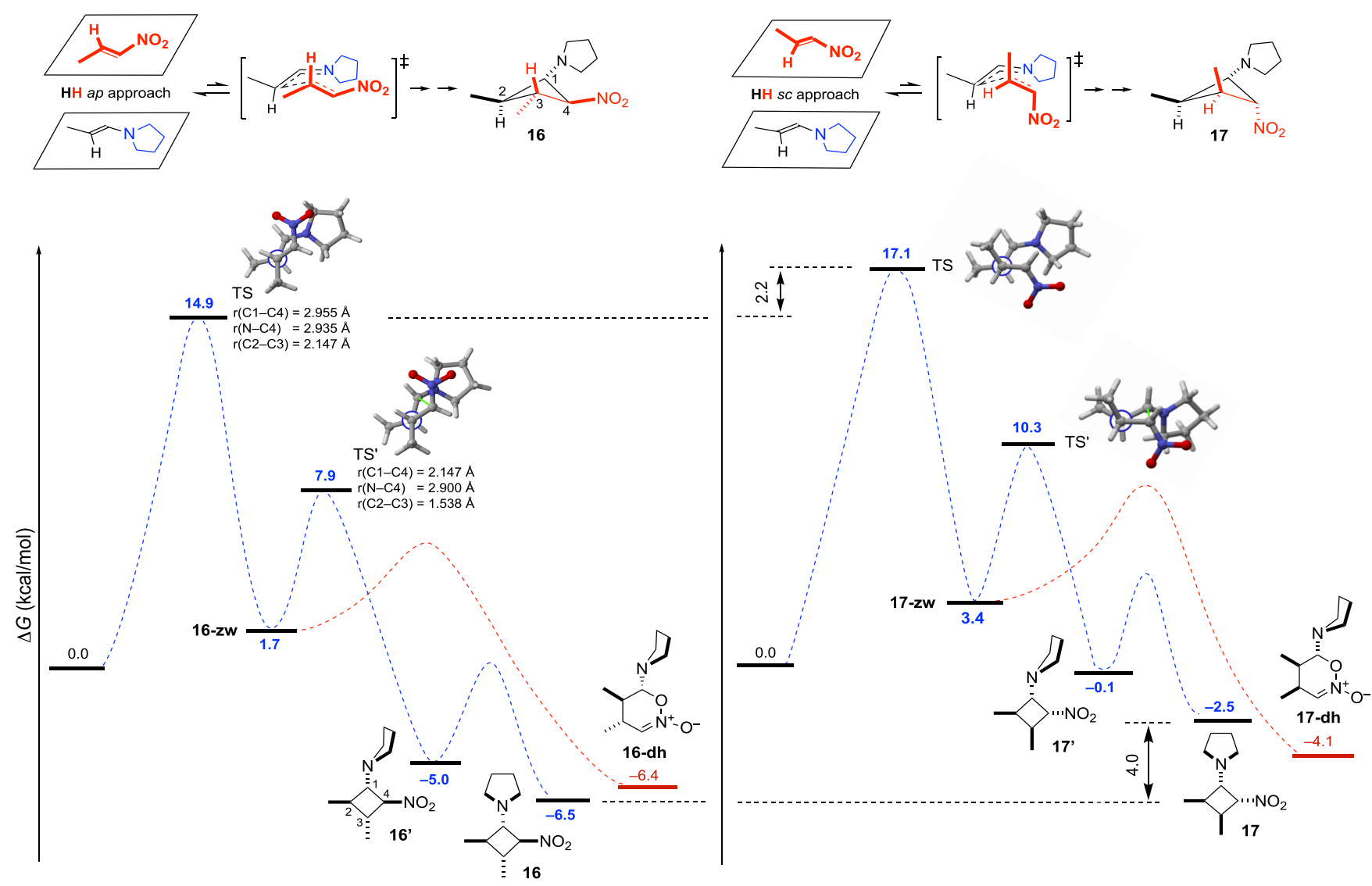

Figure 12. Two main possible approaches of a simple nitroalkene to a simple aldehyde enamine and the corresponding transition states (TSs). Gibbs free energy profiles (free enthalpies, $\Delta G$ in $\mathrm{kcal} / \mathrm{mol}$ ) optimized at the M06-2X/6-311+G(d,p) level including DMSO/solvent model density $(\mathrm{SMD})$.

the fact that the $\mathrm{R}$ and $\mathrm{R}^{\prime}$ substituents and, on the other hand, the pyrrolidino and EWG groups are cis implies a penalty of ca. $3 \mathrm{kcal} / \mathrm{mol}$ as a mean value, which increases if these substituents are larger.

Approaches between the Two Reactants. As the preceding paragraph suggests, the reaction of the two achiral reactants will mainly lead to the all-trans- $( \pm)-\mathbf{c b}$, over its alternative isomer. What matters is the trans/cis ratio between the $\mathrm{R}$ and $\mathrm{R}^{\prime}$ groups of nitrocyclobutanes, which by ring opening and hydrolysis can give rise, after rotation through the $\mathrm{C} 2-\mathrm{C} 3$ bond, to the final syn/anti ratio or $\mathrm{dr}$ of the nitroMichael adducts. It relies on the greater thermodynamic stability of the all-trans-cyclobutanes, as already established in the preceding sections, but the key question is whether the alltrans isomer is, also and always, kinetically favored or not. In this regard, we studied the mechanism of the possible cycloaddition between our simple models computationally, i.e., the reaction of pyrrolidine-propanal enamine (in its largely predominant form E,s-trans) with (E)-1-nitropropene to give nitrocyclobutylpyrrolidine $\mathbf{1 6}$ or its alternative isomer 17 (Figure 12).

Optimization of the equilibrium geometries of TSs and intermediates, for the approaches between the reactants that go to all-trans-cyclobutane $\mathbf{1 6}$ and to the alternative cyclobutane 17 , was attempted at different levels of theory. In the gas phase, we were unable to locate zwitterionic intermediates ( $\mathbf{z w}$, which are relatively much higher in energy, as expected). Even in polar solvents, it was hard to locate some $\mathbf{z w}$ species, but eventually we were able to obtain the representative reaction profiles shown in Figure 12, with M06-2X geometries optimized in DMSO/SMD. In the first transition state (TS), the $\mathrm{C} 2-\mathrm{C} 3$ distance is around $2.15 \AA$, while $\mathrm{C} 4$ is almost equidistant from $\mathrm{C} 1$ and $\mathrm{N}$, at ca. $2.95 \AA$. Later, the $\mathrm{C} 2-\mathrm{C} 3$ covalent bond was already formed, while $\mathrm{C} 4$ was still far from $\mathrm{C} 1$ and $\mathrm{N}$, that is, there is an ionic bond between an iminium cation and a nitronate anion (16-zw is formed). Afterward, a small shortening of the $\mathrm{C} 1-\mathrm{C} 4$ distance produced the collapse to cyclobutane 16 (while a small rotation of the $\mathrm{C}-\mathrm{NO}_{2}$ bond angle caused the collapse to the six-membered ring, 16-dh). It is likely that the relative energy values of $\mathbf{z w}$ species are higher in nonpolar solvents and lower in water. In fact, the calculated total energies for $\mathbf{1 6 - z w}$ and $16^{\prime}$ at M06-2X/6-311+G(d,p) in tetrahydrofuran (THF)/conductor-like polarizable continuum model (CPCM) were -651.63529 and $-651.64333 \mathrm{au}$, respectively, that is, $16-\mathrm{zw}$ was predicted to be $5.0 \mathrm{kcal} / \mathrm{mol}$ above $16^{\prime}$; at the same level, in water and in DMF, 16-zw was calculated to lie only $2.0 \pm 0.2 \mathrm{kcal} / \mathrm{mol}$ above $16^{\prime}$.

In all of the methods examined, in agreement with Figure 9, cyclobutane 16 was predicted to have a lower energy than its stereoisomer 17. The corresponding first TS was also predicted to have a lower energy than the first TS, leading to 17 . The gap was calculated to be $2.2 \mathrm{kcal} / \mathrm{mol}\left(\Delta \Delta G^{\ddagger}\right.$, Figure 12) at the indicated M06-2X level. Similarly, the gaps were 4.4, 2.1, 3.2, and $3.5 \mathrm{kcal} / \mathrm{mol}$ by single-point calculations from B3LYP geometries optimized in DMSO at MP2/6-31G(d), $\omega$ B97X$\mathrm{D} / 6-311+\mathrm{G}(\mathrm{d}, \mathrm{p}), \mathrm{M} 06-2 \mathrm{X} / 6-311+\mathrm{G}(\mathrm{d}, \mathrm{p})$, and M08-HX/6$311+\mathrm{G}(\mathrm{d}, \mathrm{p})$, respectively. In short, 16 is favored over 17 from both the thermodynamic and kinetic points of view. The 


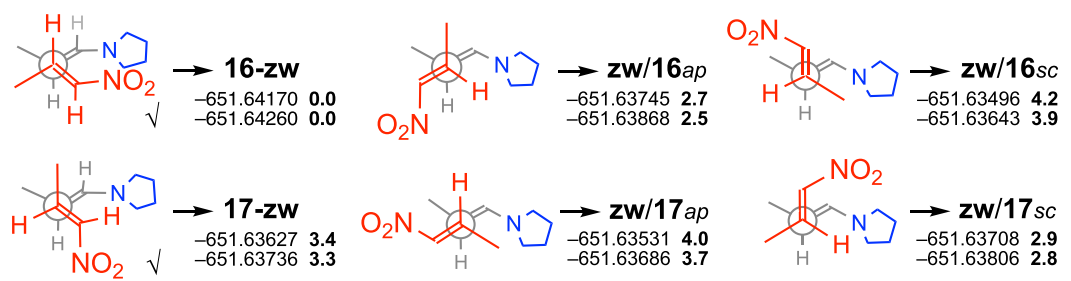

Figure 13. Possible approaches of $(E)-1$-nitropropene to the enamine model, $(E)-N-(1$-propenyl)pyrrolidine. $\mathrm{M} 06-2 \mathrm{X} / 6-311+\mathrm{G}(\mathrm{d}, \mathrm{p})$ results in $\mathrm{DMF} / \mathrm{CPCM}$ (first row) and in $\mathrm{H}_{2} \mathrm{O} / \mathrm{CPCM}$ (second row) for the zwitterionic species. Relative energy values (kcal/mol) are in bold.

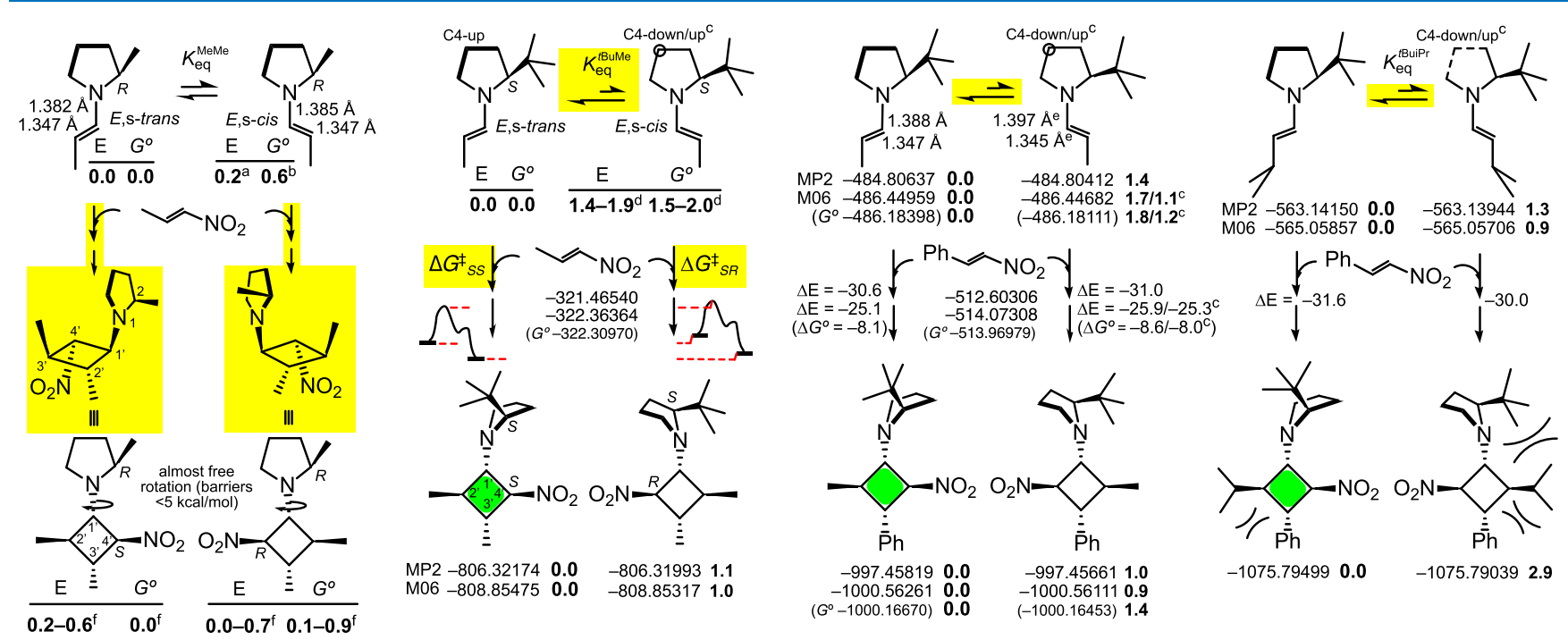

a $0.2-0.3 \mathrm{kcal} / \mathrm{mol}$ at the four levels examined: MP2/6-31G(d)//B3LYP/6-31G(d), M06-2X/6-311+G(d,p), M08-HX/6-311+G(d,p), and MN15/6311+G(d,p). When there is only a row of results, these are $\mathrm{MP} 2 / 6-31 \mathrm{G}(\mathrm{d}) / / \mathrm{B} 3 \mathrm{LYP} / 6-31 \mathrm{G}(\mathrm{d})$; when there are two rows, the second indicates the M06-2X/6-311+G(d,p) values. Relative energies in $\mathrm{kcal} / \mathrm{mol}$ are in bold. ${ }^{\mathrm{b}} 0.6 \pm 0.1 \mathrm{kcal} / \mathrm{mol}$ with the four methods examined. ${ }^{C}$ The C4-down conformation $\left(E_{4}\right)$ is $0.5 \mathrm{kcal} / \mathrm{mol}$ lower than $\mathrm{C} 4-\mathrm{up}\left({ }^{4} \mathrm{E}\right)$ with MP2; however, using M06-2X/6-311+G(d,p), C4-up is $0.6 \mathrm{kcal} / \mathrm{mol}$ more stable for propanal enamine, and there is no gap for 3-methylbutanal enamine. ${ }^{\mathrm{d}}$ Range of values at the 4 levels examined. ${ }^{\mathrm{e}} 1.395$ and $1.344 \AA$ for $\mathrm{C} 4$-up. ${ }^{\mathrm{f}}$ Four species were very close in energy; only the lowest-energy conformers of each stereoisomer are depicted.

Figure 14. Relative energies of the main conformers of chiral enamines and all-trans-nitrocyclobutanes. The s-trans-enamines yield ( $\left.4{ }^{\prime} S\right)$ nitrocyclobutylpyrrolidines and the s-cis-enamines their diastereomers $\left(4^{\prime} R\right)$, respectively. For $(S)$-2-tert-butylpyrrolidine derivatives, in each case, the more stable enamine conformer-the more abundant in the very rapid equilibrium between the enamine forms-affords the nitrocyclobutylpyrrolidine highlighted in green, the more stable form of each cyclobutane.

factors that make $\mathbf{1 6}$ more stable than $\mathbf{1 7}$ make the barrier to 16 of lower energy than that to 17 . This was intuitive, but not previously evaluated. With other $\mathrm{R}$ and $\mathrm{R}^{\prime}$, obviously larger than simple methyl groups, it is likely that these gaps will be much larger.

It is also worth noting that the $\Delta G^{\ddagger}$ value calculated for the first step (in DMSO, Figure 12) is quite small (only $14.9 \mathrm{kcal} /$ mol): the reaction between simple preformed enamines and nitroalkenes can be very rapid at $\mathrm{rt}$, as happens experimentally. In benzene at the M06-2X/6-311+G(d,p) level, the calculated value of $\Delta G^{\ddagger}$ was $17.6 \mathrm{kcal} / \mathrm{mol}$. At the other levels mentioned in the preceding paragraph, the $\Delta G^{\ddagger}$ values in DMSO oscillated between 16.0 and $12.8 \mathrm{kcal} / \mathrm{mol}$.

A final note of caution is required. We should take into account all of the possible approaches between the nitroalkene and enamine models (Figure 13), in which the bonds between $\mathrm{C} 2$ and $\mathrm{C} 3$ are being formed. The three drawings in the top row may lead to cyclobutane 16-cb; the three drawings in the bottom row may lead to $17-\mathrm{cb}$. In some cases, as in the two central approaches, the positive and negative charges of the resulting $\mathbf{~} \mathbf{w}$ intermediates are more separated. As expected, these chemical species were found much above those examined in Figure 12. However, the energy differences among all of the possible intermediates were reduced when very polar solvents were introduced in the implicit-solvent calculations (see Figure
13). Nevertheless, 16-zw (and then zw/16ap), which leads to the thermodynamically more stable cyclobutane, $16-\mathrm{cb}$, is favored in relation to those zwitterions that lead to $17-\mathbf{c b}$, as well.

Effect of the Size of the Substituent at the Pyrrolidine C2 Atom on the Relative Percentages of strans- and s-cis-Aldehyde Enamines. So far, achiral substrates and trans/cis ratios of substituents at $\mathrm{C} 2$ and $\mathrm{C} 3$ (and hence syn/anti final ratios or dr values) have only been discussed. With a substituent on the pyrrolidine ring, enantiopure intermediates and products may be obtained instead of racemic compounds. The enantiomeric ratio (er) or the ee\% of the nitrocyclobutane can depend on the approach of the nitroalkene through one face or another of the chiral aldehyde enamine. As is well known,, ${ }^{1,3}$ the larger the substituent at $\mathrm{C} 2$ of the pyrrolidine ring, the higher the probability that the reaction occurs through the opposite face of the pyrrolidine (Figure 14) and consequently the higher the enantioselectivity. We aimed to evaluate how the size of the C2-pyrrolidine substituent and its electronic features may affect enantioselectivity.

To simplify matters, we will consider that only all-transcyclobutanes are generated, without any trace of the other isomers. The two major cyclobutane stereoisomers can then be those depicted in Figure 14, where the lowest-energy 

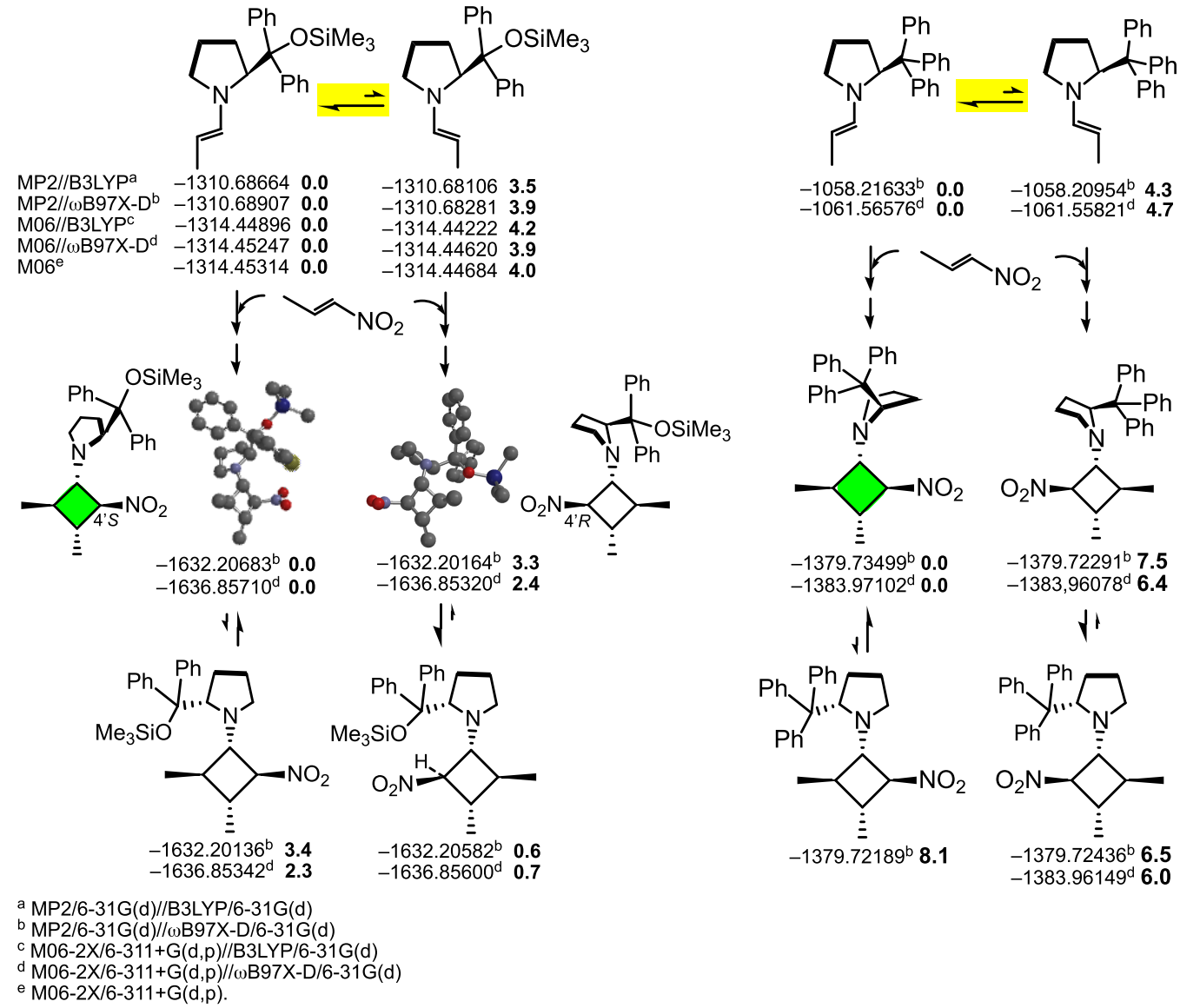

$-1061.56576^{\mathrm{d}} \mathbf{0 . 0}-1061.55821^{\mathrm{d}} \mathbf{4 . 3}$<smiles>CCCC=C[N+](=O)[O-]</smiles><smiles>C1=CC(c2ccccc2)(c2ccccc2)C(c2ccccc2)N1</smiles>
N

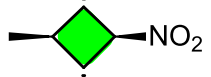

$\vdots$

$-1383.97102^{\mathrm{d}} \mathbf{0 . 0}$

$-1383.96078^{\mathrm{d}} 6.5$
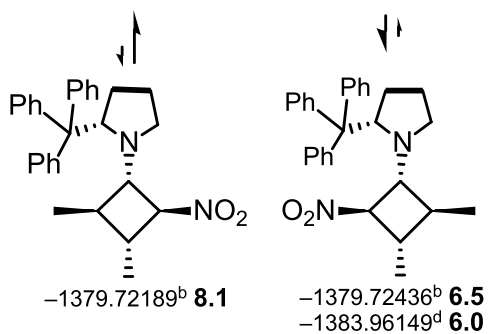

MP2/6-31G(d)//WB97X-D/6-31G(d)

M06-2X/6-311+G(d,p)//B3LYP/6-31G(d)

$M 06-2 X / 6-311+G(d, p)$.

Figure 15. Cases of the JH catalyst and 2-tritylpyrrolidine. Effect on the model reaction (propanal + 1-nitropropene).

conformer for each chemical entity is represented. It is noted that the s-trans conformers give rise to 4-nitrocyclobutanes of configuration $4 \mathrm{~S}$, whereas the s-cis conformers afford those of configuration $4 \mathrm{R}$, according to the mechanism shown in the preceding sections. Before any discussion, we should recall that the s-trans/s-cis-enamine equilibria are very rapidly established, since the barriers for aldehyde enamines are often around 5 $\mathrm{kcal} / \mathrm{mol}$ and always, even for sterically crowded enamines, below $10 \mathrm{kcal} / \mathrm{mol}^{\mathrm{S}}$

When the enamine chirality is due to a methyl group on the C2 of the pyrrolidine ring (as in Figure 14, left column), the gap between the main conformation of the s-trans-enamine and that of the s-cis-enamine is small $\left(\Delta E=0.2 \mathrm{kcal} / \mathrm{mol}, \Delta G^{\circ}=\right.$ $0.6 \mathrm{kcal} / \mathrm{mol})$. It is also predicted that the diastereomeric nitrocyclobutanes, in which they are respectively converted, may have very close energy. It is thus expected that, for this case, the stereoselectivity is poor or nil and that, after ring opening and hydrolysis, the enantiomeric ratio (er) of the final adducts will also be poor.

However, when there is a tert-butyl instead of a methyl group, the steric clashes may be more significant. It is predicted that the s-trans-enamine (the conformer of the $(E), \mathrm{s}$-transenamine shown in the second, third, and fourth columns in Figure 14) will largely predominate $\left(K_{\mathrm{eq}}>10\right)$. This more abundant enamine is transformed, according again to the mechanism discussed above, to a nitrocyclobutane with the $\mathrm{NO}_{2}$ group on the right side in the structures depicted. One conformer of this $(4 S)$-nitrocyclobutane is thermodynamically favored in relation to its other conformers and with respect to all of the conformers of its $4 \mathrm{R}$ isomer (see Figure S3 for additional details). In simple words, the most abundant s-transenamine, in reacting with a nitroalkene, selectively affords one nitrocyclobutane, which is furthermore the thermodynamically stable isomer. The preferred conformation of the pyrrolidine ring of these enamines-usually between ${ }^{4} \mathrm{E}$ and ${ }^{4} \mathrm{~T}_{3}$, which we call C4-up for the sake of simplicity, but sometimes ${ }^{3} \mathrm{~T}_{4}$, which we call C4-down-is not relevant, as the energy gap for each pair is generally very low $(\leq 0.6 \mathrm{kcal} / \mathrm{mol})$ and within the calculation error.

Seebach et al..$^{3 a, d}$ and Burés et al. ${ }^{3 b, c}$ have demonstrated, by means of exchange reactions, that the formation of nitrocyclobutanes containing the JH catalyst is reversible. In other words, the formation of $\mathrm{JH}$-derived cyclobutanes, even at $\mathrm{rt}$, is under thermodynamic control. In spite of this irrefutable argument, we have calculated the first of the TSs for the strans- and s-cis-enamines of our model (with ${ }^{t} \mathrm{Bu}$ ). We planned to evaluate whether, for the formation of these cyclobutane derivatives, the energy barriers were similar or not and whether they were as low as in Figure 12. At the M06-2X/6$311+\mathrm{G}(\mathrm{d}, \mathrm{p})$ level, the transition state from the s-trans-enamine (C4-up) was located at -808.81374 au and that for s-cisenamine (C4-up) at -808.81291 ( $0.5 \mathrm{kcal} / \mathrm{mol}$ above); including single-point calculations in $\mathrm{DMSO}$, the difference was larger $(1.6 \mathrm{kcal} / \mathrm{mol})$ and the two $\Delta G^{\ddagger}$ values were calculated to be 14.4 and $14.3 \mathrm{kcal} / \mathrm{mol}$ (close to the value given in Figure 12). At the $\omega \mathrm{B} 97 \mathrm{X}-\mathrm{D} / 6-31 \mathrm{G}(\mathrm{d})$ level, the four TSs (from s-trans/C4-up, s-trans/C4-down, s-cis/C4-up, and s-cis/C4-down conformers) could be located; the M06-2X/6$311+\mathrm{G}(\mathrm{d}, \mathrm{p}) / \mathrm{H}_{2} \mathrm{O} / / \omega \mathrm{B} 97 / 6-31 \mathrm{G}(\mathrm{d})$ total energies were -808.83691 (0.0), -808.83589 (0.6), -808.83464 (1.4), 
(A)

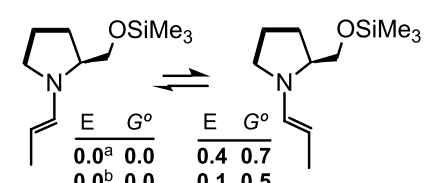

$\begin{array}{llll}0.0^{\mathrm{b}} & 0.0 & 0.1 & 0.5\end{array}$

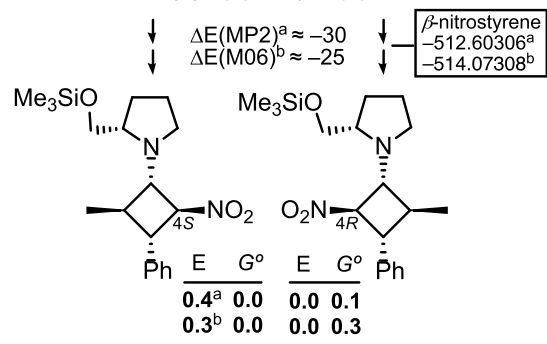

(B)
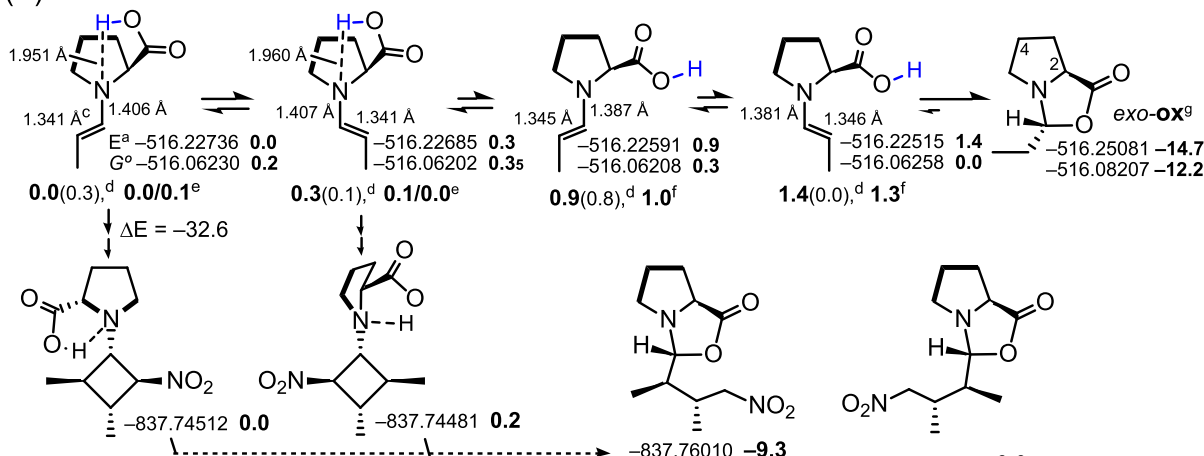

$1-837.744810 .2$

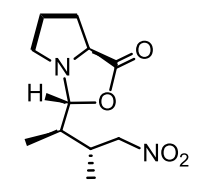

$-837.76010-9.3$
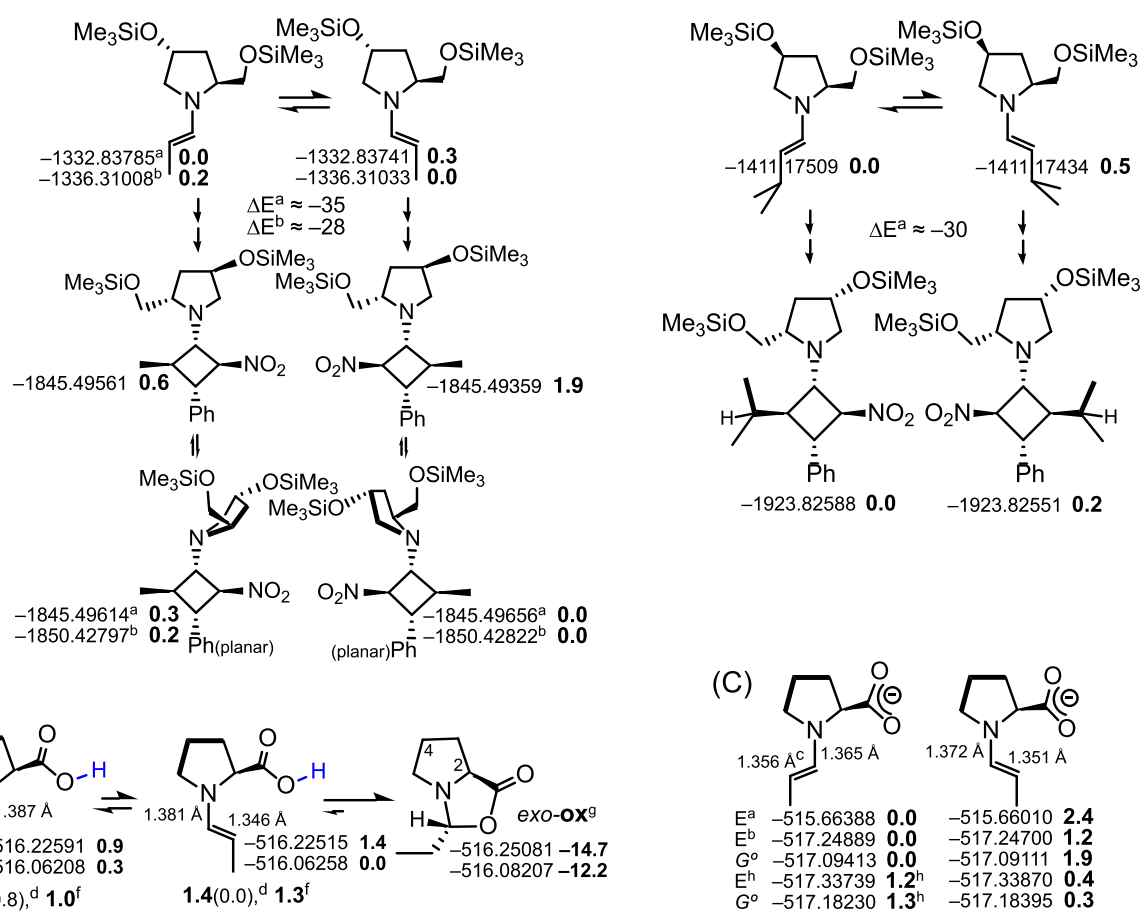

${ }^{a}$ MP2/6-31G(d)//B3LYP/6-31G(d). ${ }^{\text {b } M 06-2 X / 6-311+G(d, p) . ~}{ }^{c} B 3 L Y P / 6-31 G(d)$ bond lengths; practically identical at the B3LYP/6-311+G(d,p) level. ${ }^{d}$ Results within parentheses are single-point calculations in $\mathrm{H}_{2} \mathrm{O}$. ${ }^{e}$ Geometry optimization in DMSO and in $\mathrm{H}_{2} \mathrm{O}$ (SMD, both). ${ }^{f}$ Geometry optimization in DMSO. 9 For exo-ox, the gap between conformer C4-up ( ${ }^{4} \mathrm{E}$ ) and $\mathrm{C} 4-$ down ( $\mathrm{E}_{4}$ ) is only of $0.1 \mathrm{kcal} / \mathrm{mol}$. The lowest-energy conformer of its isomer endo-ox (arising from the cyclization of the s-trans enamine, instead from that of the s-cis enamine) was predicted to be $0.8 \mathrm{kcal} / \mathrm{mol}$ above in the gas phase (but $1.4 \mathrm{kcal} / \mathrm{mol}$ below in water). ${ }^{\mathrm{h}} \mathrm{M} 06-2 \mathrm{X} / 6-311+\mathrm{G}(\mathrm{d}, \mathrm{p})$ results in DMSO/SMD (single-point calculations).

Figure 16. Energies calculated for the lowest-energy conformers of representative s-trans- and s-cis-enamines of silylated prolinols and of the corresponding all-trans-cyclobutanes (A). The proline case (B). The case of prolinate enamines (C). Relative energies are in $\mathrm{kcal} / \mathrm{mol}$, as always, and in bold.

and -808.83429 au $(1.6 \mathrm{kcal} / \mathrm{mol})$, respectively. In summary, the barriers are very low and almost identical for the different conformers $\left(\Delta H^{\ddagger} \approx 1 \mathrm{kcal} / \mathrm{mol}, \Delta G^{\ddagger} \approx 16 \mathrm{kcal} / \mathrm{mol}\right.$, lower values in polar solvents). This could be expected as both reactions take place through the face opposite to the ${ }^{t} \mathrm{Bu}$ group. Therefore, the calculations again suggest that the most abundant enamine tautomer is converted into the most stable cyclobutane derivative via a low-energy TS or the lowestenergy TS (and likely the lowest-energy $\mathbf{z w}$ ). The reactions are reversible (thermodynamic control), and there is no need to resort to the Curtin-Hammett principle.

With three ${ }^{t} \mathrm{Bu}$ groups as substituents, one on $\mathrm{C} 2$ of the pyrrolidine and the other two on $\mathrm{C}^{\prime}$ and $\mathrm{C}^{\prime}$ ( $\mathrm{C} 2$ and $\mathrm{C} 3$ of the cyclobutane ring), the energy gaps between the two series of stereoisomers and among their conformers are still higher than those shown in Figure 14. See Figure S4 for an explanation based on the van der Waals (vdW) repulsions of the substituents. Again, one or two conformers with the $\mathrm{NO}_{2}$ group on the right (configuration $2 \mathrm{~S}, 4^{\prime} \mathrm{S}$ of the cycloadduct) are more stable than any other isomer and conformer.

A last question is whether, as indicated by one reviewer, the results obtained with the ${ }^{t} \mathrm{Bu}$ group, which is a too simple model of a large substituent, may be extrapolated to the special case of the popular JH catalyst. An exhaustive study of all of the conformational space at high levels of theory would require months of additional work, but there are earlier calculations of simple JH enamines $3 \mathrm{~d}, \mathrm{f}, \mathrm{g}, 5,6,15 \mathrm{~b}, 17$ upon which we can rely. For the sake of brevity, we will only compare the lowest-energy conformers of each species for the cases $\mathrm{CPh}_{2} \mathrm{OTMS}(\mathrm{JH})$ and $\mathrm{CPh}_{3}$ (trityl, Tr), as shown in Figure 15. Due to the crowded structure of these molecules, we also carried out geometry calculations with $\omega$ B97X-D (that is, with a functional that includes long-range dispersion corrections) ${ }^{16 c}$ the stability order of the plethora of conformations was more reliable than using B3LYP and the MP2 and M06 single-point total energies improved (Figure 15, top), but the relative energies did not change. In comparing Figure 15 to Figure 14, it appears that the gaps between the pairs of related stereoisomers are larger now than in the ${ }^{t} \mathrm{Bu}$ case, as could be expected due to the larger size of both groups and the special features of $\mathrm{CPh}_{2} \mathrm{OTMS}$, but the "rule" is maintained: the more stable the s-trans starting enamine, the more stable the cyclobutane with $\mathrm{NO}_{2}$ at the right. Starting from branched aldehydes and from $\beta$-nitrostyrene or branched nitroalkenes (that is, with larger substituents at $\mathrm{C} 2^{\prime}$ and $\mathrm{C}^{\prime}$ ), the gaps would be even higher, as predicted for other examples in preceding sections.

Calculations of Further Aldehyde Enamines. Calculations of aldehyde enamines that pose more difficulties (than $2-{ }^{t} \mathrm{Bu}$ and 2-Tr-pyrrolidine) from the viewpoint of the conformational analysis, due to the huge number of possible 


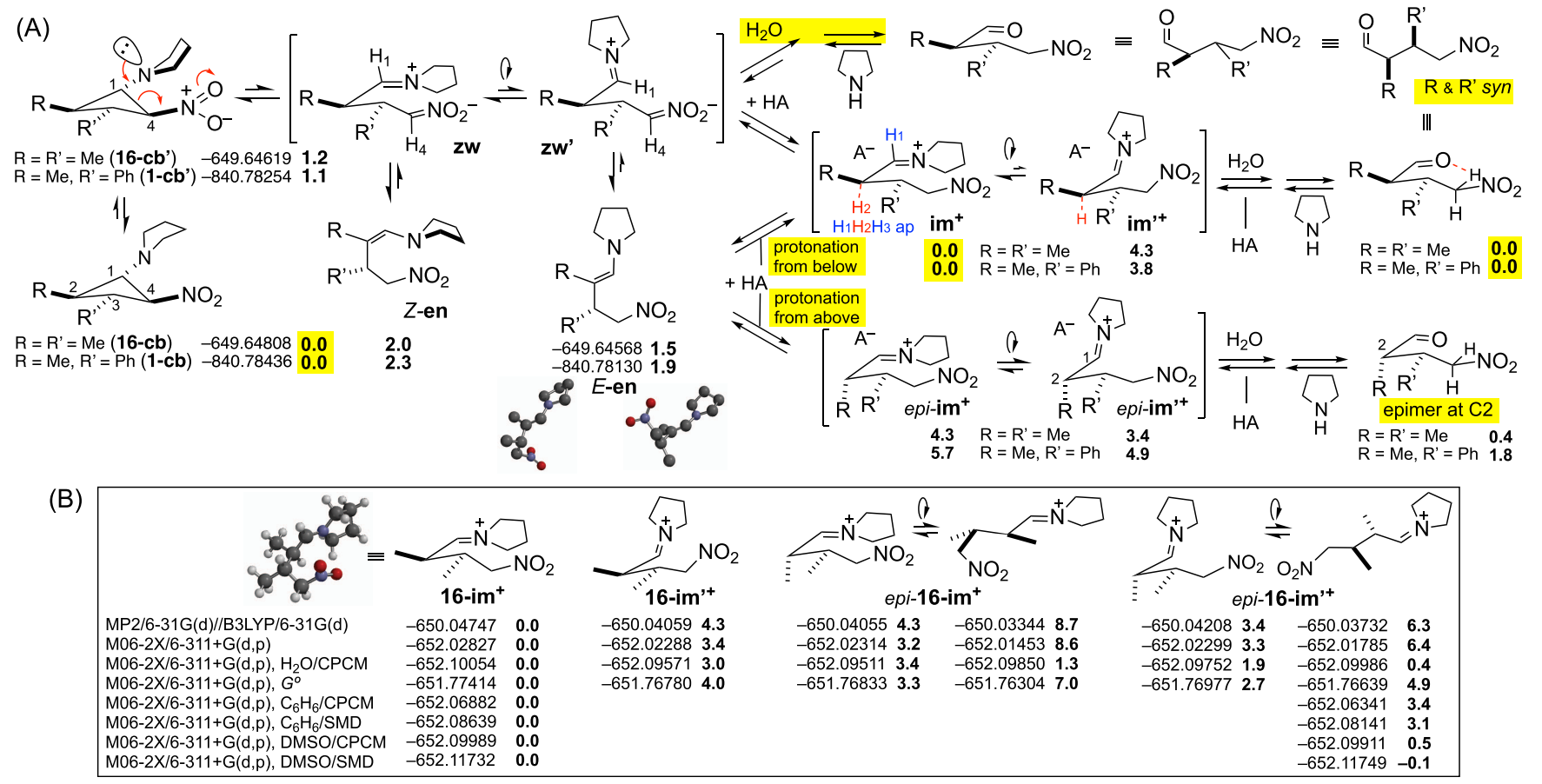

Figure 17. Plausible hydrolyses of nitrocyclobutanes through zwitterions and iminium salts (A). MP2/6-31G(d)//B3LYP/6-31G(d) energies are in au; relative energies are in $\mathrm{kcal} / \mathrm{mol}$, in bold. Protonation of species $\mathbf{z w}$ gives $\mathbf{i m}^{+}$and that of $\mathbf{z w}^{\prime}$ affords $\mathbf{i m}^{\prime+}$, but $^{\mathbf{i m}^{+}}$and $\mathbf{i m}^{\prime+}$ are in rapid equilibrium by a simple rotation. Protonation of $(Z)$-en may give $\mathbf{~ i m}^{+}$and epi-im ${ }^{+}$while that of $(E)$-en may give $\mathbf{i m}^{\prime+}$ and epi-im' ${ }^{\prime+}$. M06-2X/6$311+\mathrm{G}(\mathrm{d}, \mathrm{p})$ energies are also compared (B) for the iminium ions of $\mathrm{R}=\mathrm{R}^{\prime}=\mathrm{Me}(16)$ including single-point implicit-solvent calculations.

conformers, and their formal $[2+2]$ cycloadditions are summarized in Figure 16. Only the lowest-energy minima of each species are drawn in Figure 16.

The three examples in Figure 16A showed that the gaps between the lowest-energy conformers of s-trans- and s-cisenamines are minimal. The differences between the lowestenergy (4S)- and (4R)-nitrocyclobutanes were also minimal. We calculated other cases, from other silylated prolinediols and other nitroalkenes, with similar results. These prolinol derivatives are the models of catalysts $\mathbf{A}, \mathbf{C} / \mathbf{D} / \mathbf{E}$, and $\mathbf{G} / \mathbf{H}$ shown in Figure 4. We recognize that the models are simple, but the tendency is clear: these substituents are not sufficiently large to discriminate the two options. This happens experimentally, since in the trials with aldehydes and $\mathbf{A}-\mathbf{I}$, we had obtained poor er values.

This explains "point or issue (e)" mentioned in the Introduction. If the gaps between s-trans- and s-cis-enamine conformers are small (which means that the substituents on the chiral pyrrolidines do not favor sufficiently the s-trans conformers), a mixture of two all-trans-nitrocyclobutanes will be formed. The all-trans arrangement only ensures an excellent $\mathrm{dr}$ (that is, a good or excellent final syn/anti ratio, provided that no epimerization occurs during the following steps). The ring opening and hydrolysis of a mixture of two diastereomeric nitrocyclobutanes cannot afford a good er or ee\%. A chiral pyrrolidine with a large $\alpha$-branched substituent at C2 is required to obtain an excellent enantioselectivity. ${ }^{1}$

The fourth example (Figure 16B) poses the problem of proline, which in practice is one of the worst catalysts for enantioselective nitro-Michael reactions (e.g., a 55:45 mixture of 7-cb and 8-cb was obtained in the lab; see Figure 6). Moreover, the gap between the pair of enamines is so small that a change of solvent polarity may favor one or the other. Thus, despite the fact that the natural amino acid $(S)$-proline was the trigger of the organocatalysis field and itself or its surrogates are essential for aldol reactions, it is the most complex case to study in silico and to account for in vitro because of (1) its insolubility in most organic solvents that almost only permits the use of DMSO or DMF (and/or an excess of wet aldehydes); (2) the features of the $\mathrm{COOH}$ group (inappropriate for exerting a significant steric effect but good for hydrogen bonding or intramolecular proton transfer); (3) the possibility that the s-cis forms of the $\mathrm{COOH}$ groups of enamines, which are not far away in energy, form well-known dimers (either homo, hetero, or with unreacted proline) in the reaction medium by intermolecular hydrogen bonding; (4) the large predominance of bicyclic oxazolidinones in the equilibria, not only those from the starting aldehydes but also those from the intermediate zwitterions and nitrocyclobutanes (only the more stable exo forms are depicted in Figure 16B); and (5) the disparate reactivity of prolinate anions, always potentially present in the medium (in polar solvents with basic properties, due to the tertiary nitrogen atoms of oxazolidinones or to the exchange of protons with other carboxylate ions).

Regarding this last point, the $\mathrm{COO}^{-}$groups may behave differently from the $\mathrm{COOH}$ groups, as expected; for example, they can afford much better anchimeric assistance to electrophilic attacks ${ }^{18}$ to the enamine double bond than a carboxyl group, of course. Among the prolinate enamines, one s-trans conformation predominates (see Figure 16C), but calculations in DMSO with geometry optimization and singlepoint calculations in $\mathrm{H}_{2} \mathrm{O}$ (data not shown) revert the order in such a way that the abundance of both s-cis forms is predicted to increase. Thus, the reactivity and stereochemical outcome of proline enamines may dramatically depend on the presence of catalytic amounts of bases in the medium and on the solvent polarity. 
(A)
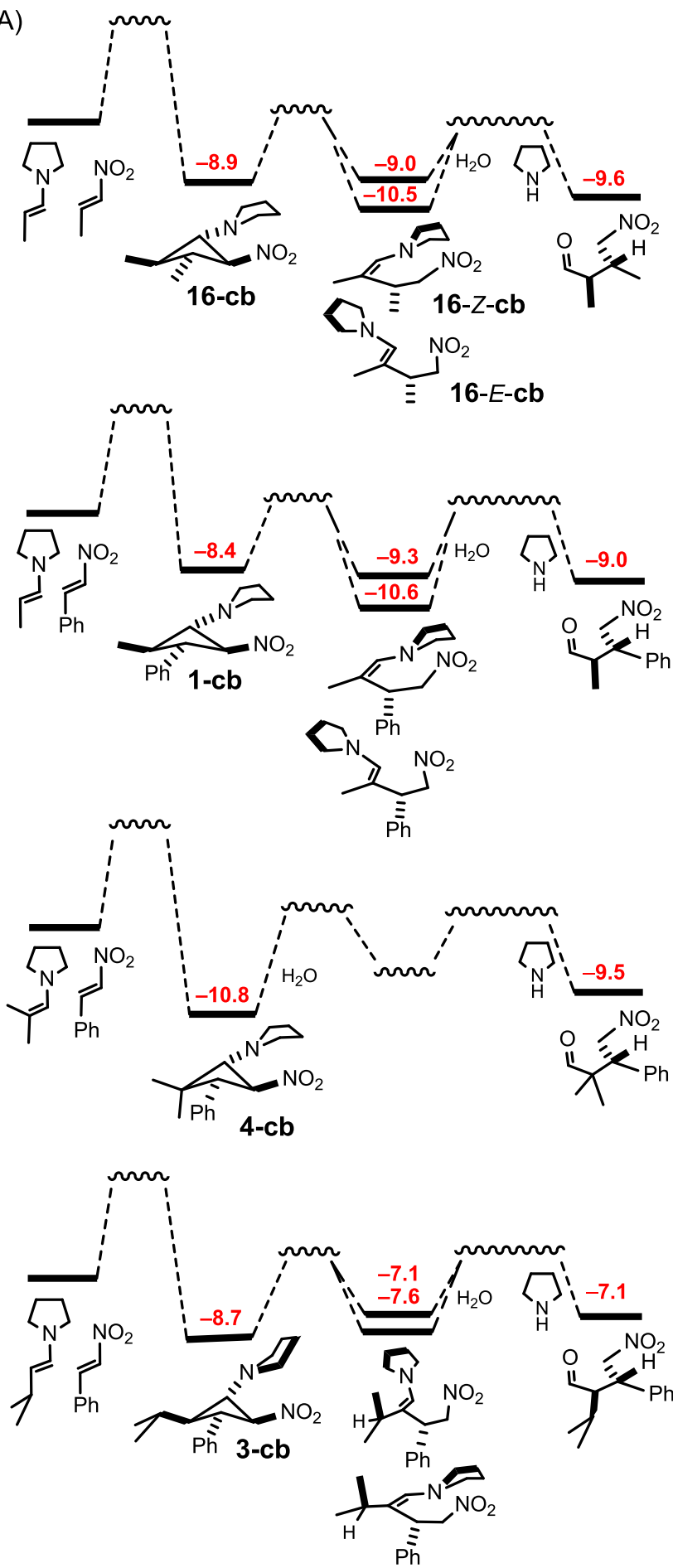

(B)
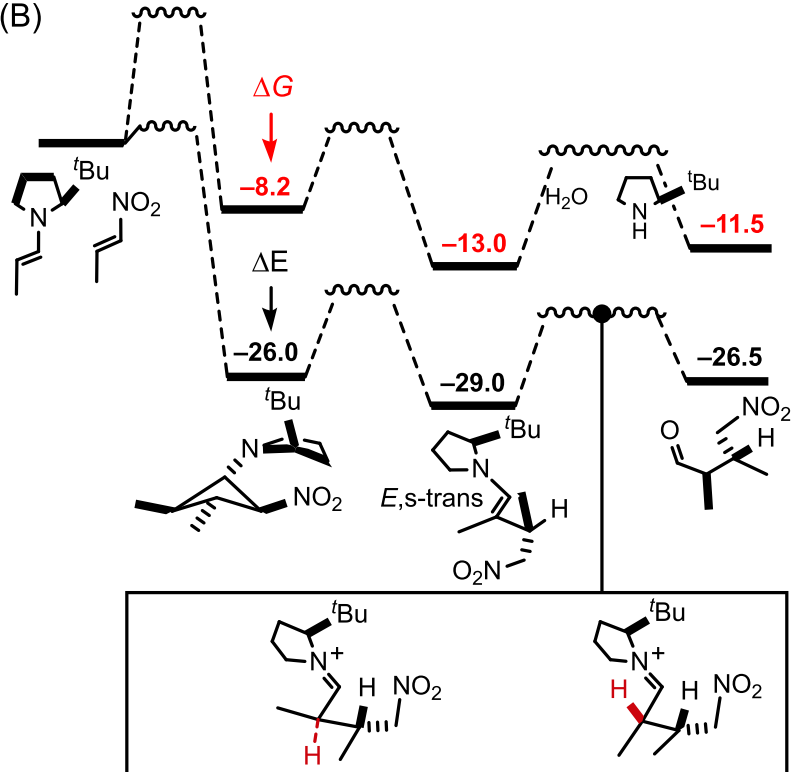

$\mathrm{E}(\mathrm{MP} 2)^{\mathrm{a}}-806.72306 \quad \mathbf{0 . 0}$ $E(M 06)-809.25381 \quad 0.0$

$-806.716872 .6$ $-809.248513 .3$ protonation of the $E, \mathrm{~s}$-trans enamine protonation from from below the double bond (im'+) above (epi-im'+

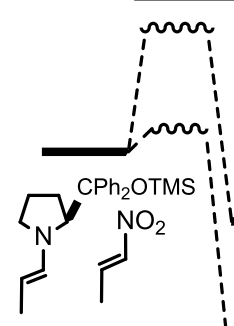
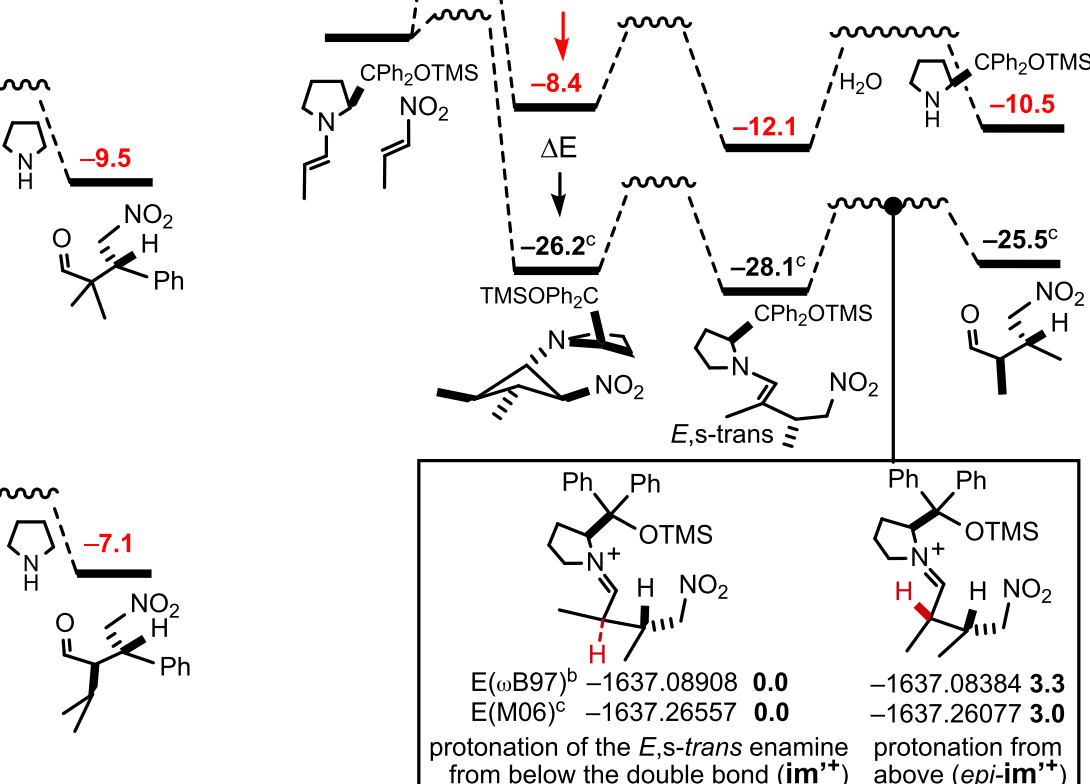

$\mathrm{H}) \mathrm{H} \mathrm{NO}_{2}$

a $M P 2 / 6-31 G(d) / / B 3 L Y P / 6-31 G(d)$

b $\omega B$ 97X-D/6-31G(d)

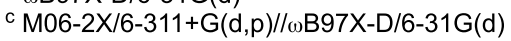

Figure 18. Relative M06-2X/6-311+G(d,p)-calculated Gibbs free energies, unless otherwise indicated, in $\mathrm{kcal} / \mathrm{mol}$, for representative sequences of reactions from pyrrolidine enamines (A) and for models from 2-tert-butylpyrrolidine and the JH catalyst (B). Column B also includes the relative total electronic energies $(\Delta E$, numbers in black) of the same intermediates and of the lowest-energy conformers of the two possible cations arising from the protonation of the predominant $(E)$,s-trans-enamines.

From $\mathrm{N}$-(4-Nitro-1-cyclobutyl)pyrrolidines to 4(Nitroethyl)enamines and 4-Nitrobutanals: Plausible Mechanisms. Mechanistically, the hydrolysis that leads to nitrobutanals may take place from the zwitterions and the iminium salts. From zwitterions, as soon as $\mathbf{z w}$ is formed as an intermediate (Figure 12), some hydrolysis may occur, before the formation of the nitrocyclobutane (see Figure 17A, first row). The nitronate group would capture a proton from water, and the resulting iminium hydroxide would be spontaneously cleaved.

Figure 17 also indicates that hydrolysis can occur when cyclobutanes are formed, after ring opening. This may take place from the conformer with the pyrrolidine ring perpendicular to the plane of cyclobutane (e.g., 16-cb'), in 
which the $\mathrm{N}$ lone pair is antiperiplanar to the $\mathrm{C} 1-\mathrm{C} 4$ bond (Figure 9C). In the light of Figure 12, 16-zw is found only 6.7 $\mathrm{kcal} / \mathrm{mol}$ above 16-cb" in DMSO and the barrier to "come back" is only of ca. $13 \mathrm{kcal} / \mathrm{mol}$. The ring opening may be triggered by an increase of the polarity of the mediumzwitterions will be favored as far as the medium becomes more polar-and by the temperature because of the term $T \cdot \Delta S$, as we observed and already commented on. In fact, cyclobutanes cb can be considered covalent forms of zwitterions $\mathbf{z w}$, the ionic forms, as mentioned above.

Hydrolysis can also occur from iminium salts $\mathrm{im}^{+}$and $\mathrm{im}^{\prime+}$ (Figure 17A, second row on the right), which is a standard step for the hydrolysis of any enamine, in the presence, from the very beginning, of catalytic amounts of any proton source (HA $=\mathrm{ArCOOH}$, phenols with EWGs, $\mathrm{H}_{3} \mathrm{O}^{+}$or solvated protons in general, appropriate pyrrolidinium ions, thioureas with EWGs, etc.), capable of partially or fully neutralizing the nitronate moiety of $\mathbf{z w}$ as soon as it is formed.

It is known ${ }^{3}$ that some nitrocyclobutanes spontaneously isomerize to the adduct enamines (final enamines); we have provided additional examples of this transformation (Figures 7 and 8) occurring at the NMR probe temperature, without any additive. Our calculations indicate that there is a set of conformations for $(E)$-en of very close energy, in which there is some favorable interaction between the polar groups (the enamine double bond and $\mathrm{NO}_{2}$, which is located either above or below the enamine plane). The aldehyde enamines with a 2nitroethyl substituent seem to be more stable and less sensitive to water than enamines of standard aliphatic aldehydes. Hydrolysis of enamines (E)-en and $(Z)$-en must occur according to standard mechanisms, via their iminium salts. The reasonable equilibria are shown in Figure 17, which includes a comparison of the relative energies of these iminium intermediates.

Figure 17 shows that adduct enamines $E[(E)$-en $]$ are predicted to be slightly more stable than the corresponding $Z$ enamines (in polar solvents, see below, even more). Figure 17 also indicates that one $\left(\mathrm{im}^{+}\right)$of the four iminium ions is more stable than the others, after a careful conformational analysis of these cations, without its counterion. Even though the structure is open, it seems as if a six-membered arrangement was favored (see 16-im ${ }^{+}$), with interactions between the polar groups [the $\left(\mathrm{RCH}_{2}\right)_{2} \mathrm{~N}^{+}=\mathrm{CH}$ moiety and $\mathrm{NO}_{2}$ ] and with $\mathrm{R}$ and $\mathrm{R}^{\prime}$ in pseudoequatorial positions (i.e., $\mathrm{H} 1$ and $\mathrm{H} 2$ as well as $\mathrm{H} 2$ and $\mathrm{H} 3$ antiperiplanar). Zigzag conformers of $\mathrm{im}^{+}$and im $^{\prime+}$ were not favored, even in polar solvents (results not included). Since all of the iminium ions are in equilibrium, by rotation around the $\mathrm{C} 1-\mathrm{C} 2$ single bond and through the enamines by deprotonation and protonation (general acid catalysis), it may appear that the protonation step is rather stereoselective. $^{3}$ At least in apolar solvents, all of the iminium species fall down to $\mathrm{im}^{+}$. In other words, the calculations suggest that the hydrolysis of the final enamines goes through this iminium ion.

This is a plausible explanation for the fact that many nitroMichael reactions, even though being multistep, occur with high stereoselectivity. For simple aldehydes, the opening of the four-membered ring and/or the C-protonation step of the adduct enamines can reasonably be the rate-limiting steps, at least in nonpolar solvents. ${ }^{3}$ As deduced from Figure 17, since enamines $E$ (with the pyrrolidine ring and the more branched substituent in trans, to be more precise) are the most abundant intermediates detected by NMR, it may also be assumed that their hydrolyses, when they are not sufficiently shifted to the right and/or when they are slow, will affect the overall reaction rate. Again, it suggests that the C-protonation step of such enamines may then become the rate-limiting step. ${ }^{3 g}$ It requires a very selective protonation of $(E)$-en from below the double bond (the lower or $\alpha$ face in Figure 17, to give im $^{\prime+}$ and hence the most stable $\left.\mathrm{im}^{+}\right)$, by any proton source. It must be the pathway, when $(E)$-en is predominant but no epimerization occurs.

In contrast, in very polar solvents, especially for epi-16-im ${ }^{+}$ (Figure 17, bottom), the conformers with $\mathrm{R}$ and $\mathrm{R}^{\prime}$ in antiperiplanar orientation, i.e., with $\mathrm{H} 2$ and $\mathrm{H} 3$ ap, turned out to be close to the lowest-energy minimum. It suggests that in very polar solvents epimerization is possible through epi-16im $^{\prime+}$.

Further comparisons of representative ring opening and hydrolysis reactions are shown in Figure 18. Nitrocyclobutanes (cb), the resulting enamines (en), and 4-nitrobutanals were predicted to have similar Gibbs free energy values. Only the M06-2X/6-311+G(d,p)-calculated relative $\Delta G^{\circ}$ values are shown in Figure 18A, but the complete figure is given as SI (Figure S5). It implies that in the absence of a sufficient concentration of water the equilibria will not be fully shifted to the right. For the first two compounds in Figure 18A, we can observe that the nitrobutanals are found $0.6-0.7 \mathrm{kcal} / \mathrm{mol}$ below the corresponding nitrocyclobutanes, whereas for the last two cases, with branched aldehydes and larger substituents, each nitrobutanal is predicted to lie $1.3-1.7 \mathrm{kcal} / \mathrm{mol}$ above each nitrocyclobutane. Thus, the cyclobutane intermediates are predicted to be $\geq 2 \mathrm{kcal} / \mathrm{mol}$ relatively more stable than the final adducts in the last two cases (that is, the overall equilibria may be less shifted to the right, so the release of pyrrolidine may be less favored, probably slower, and hence the entire aminocatalytic process may be slower as well, as it happens).

These last results explain "point (c)" of the Introduction, regarding nitro-Michael reactions that involve isobutyraldehyde and related $\alpha$-branched aldehydes, which seem to stop at the nitrocyclobutylpyrrolidine stage. They are probably hydrolyzed via their $\mathbf{z w}$ partners, but the hydrolysis equilibria are not shifted so far to the right in this case as in other cases. This would explain why the more highly substituted or branched the starting aldehyde, the relatively easier the detection of the corresponding cyclobutane. Branched starting aldehydes may eventually be converted into even more crowded final aldehydes, which are not particularly favored in relation to the cyclobutanes. Thus, another rule of thumb would be that the more crowded the final aldehydes, the higher the chances of the catalytic process to stop at the nitrocyclobutane stage. As indicated, the corresponding all-transcyclobutanes with large substituents, far to each other, are relatively more stable than expected.

When the energies shown in Figure 18A were systematically recalculated for the model compounds (16, first row) in benzene and in DMSO by single-point calculations with the SMD method, slight changes were noted. These results are as follows: forms $\mathbf{c b},(Z)$-en, $(E)$-en, and the indicated 4nitrobutanal moved up 1.4/1.4 (benzene/DMSO), 1.5/2.3, $0.8 / 0.0$, and $0.9 / 1.4 \mathrm{kcal} / \mathrm{mol}$, respectively. Thus, in relation to nitrocyclobutane and 4-nitrobutanal, (Z)-en is slightly destabilized, while $(E)$-en is stabilized, mainly in DMSO. This solvent effect may be quite general. It explains why $(E)$-en is the intermediate with a longer half-life in several experiments reported to date ${ }^{3}$ and others described above. It also agrees 


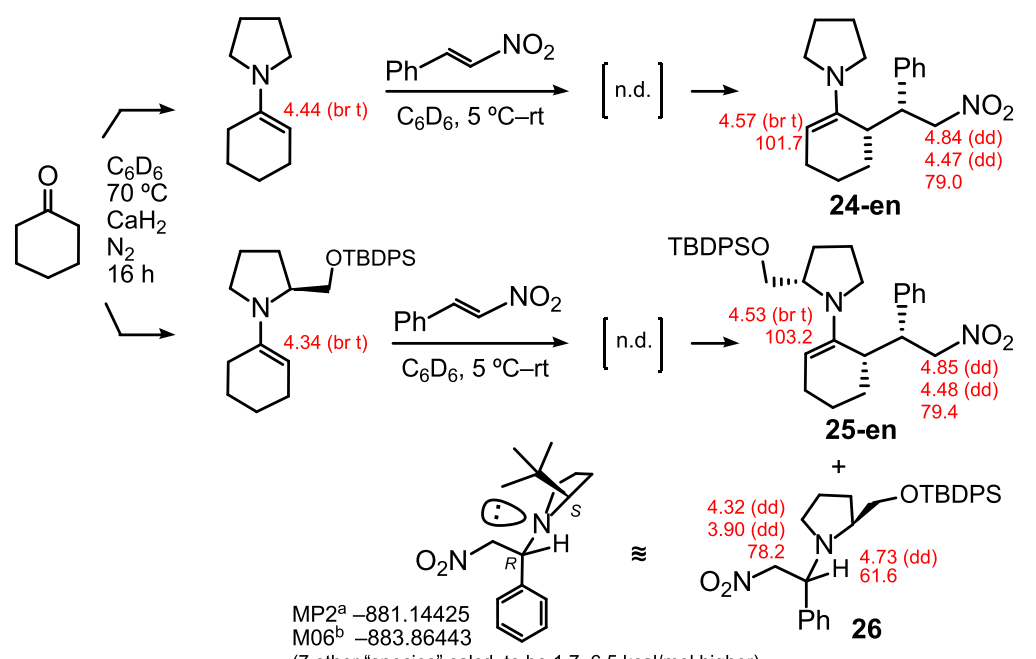

(eq 1)

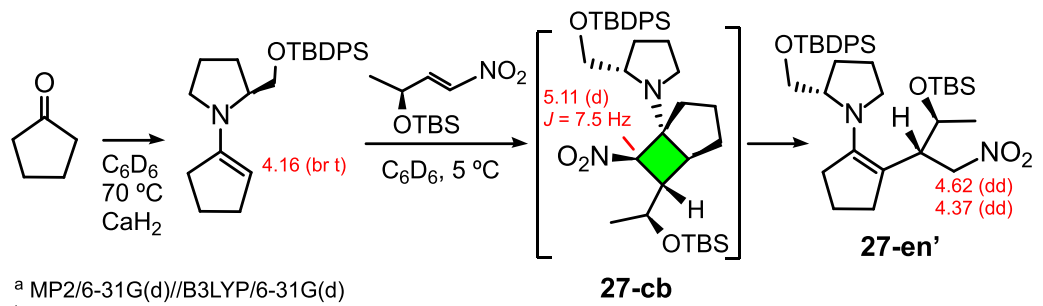

${ }^{b} \mathrm{M} 06-2 \mathrm{X} / 6-311+\mathrm{G}(\mathrm{d}, \mathrm{p})$

Figure 19. Examples of intermediates detected during the reactions of nitroalkenes with some enamines of cyclohexanone (eqs 1 and 2) and cyclopentanone (eq 3) (n.d. = plausible intermediates not detected). Spectra registered in $\mathrm{C}_{6} \mathrm{D}_{6}$.

with the experimental data, in the sense that the aminocatalyzed nitro-Michael reactions take place at $\mathrm{rt}$ in most organic solvents, although they often stop at intermediates $\mathbf{c b}$ or $(E)$-en, with ratios that are different from one solvent to another.

To go further, Figure 18B shows the effect of medium-large $\left({ }^{t} \mathrm{Bu}\right)$ and very large $\left(\mathrm{CPh}_{2} \mathrm{OTMS}\right)$ groups at $\mathrm{C} 2$ of the pyrrolidine ring on the reaction model. Only the lowest-energy minimum of each form is indicated. Relatively, both $(E)$,strans-enamines of the adducts were calculated to be even more stable than that of the model: their hydrolysis equilibria were less shifted to the right. Thus, these enamines may have a long half-life, so that the corresponding catalytic processes may be quite slow. It is also worthwhile that the protonation of these major enamines from the $\alpha$ face (from below the double bond) is preferred over the protonation that would produce the undesired epimer. Our computational capability did not allow us to calculate all of the cyclobutanes and adduct enamines that we detected by ${ }^{1} \mathrm{H}$ NMR, but the tendencies are clear. It is likely that, for those catalytic nitro-Michael reactions in which nitrocyclobutylpyrrolidines and adduct enamines are generated in significant amounts, one or another intermediate may be involved in the rate-limiting step (depending on the substituents; see examples in Figures 18 and S5).

In summary, Figures 17 and 18 show that nitrocyclobutylpyrrolidine derivatives may be hydrolyzed via their zwitterionic isomers and via their isomeric enamines to yield the corresponding nitrobutanals (final Michael adducts). The intermediates have similar free energies (free enthalpies) to the final aldehydes. Thus, the equilibria are not shifted very far to the right at $\mathrm{rt}$, in general, depending on the substituents. Protonation of pyrrolidines can help, but higher than equivalent amounts of water in the organic solution can be required for a complete hydrolysis. For further plausible mechanisms of the ring opening of nitrocyclobutylpyrrolidine derivatives, see the SI.

Reaction of Cyclic Ketones with Nitroalkenes. The enamines of ketones are different from those of aldehydes examined until now. As mentioned, the formation equilibria are, with few exceptions, less shifted to the right, ${ }^{5}$ since as known (1) they are less reactive against nucleophilic attacks, as it is well known, since there are two chains on the carbonyl group and (2) in the corresponding enamines there are more steric clashes between the $\alpha$-positions of the pyrrolidine ring and the alkenyl or cycloalkenyl substituents.

We were interested in identifying the possible intermediates of reactions of cycloalkanones with $\beta$-nitrostyrene and analogues. We prepared representative enamines of cyclohexanone, in the presence of $\mathrm{CaH}_{2}$ as a dehydrating agent, as shown in Figure 19; after filtering, the $\mathrm{C}_{6} \mathrm{D}_{6}$ solutions, which are relatively concentrated in the corresponding enamine but obviously contained starting materials, were treated with approximately equimolar amounts of $\beta$-nitrostyrene at 5-10 ${ }^{\circ} \mathrm{C}$. Consecutive NMR spectra were then registered under typical conditions, at the probe temperature. The olefinic proton of the initial enamine at $4.44 \mathrm{ppm}$ disappeared in few minutes, and several other peaks appeared between 4 and 5 $\mathrm{ppm}$. The main signals were attributed to the adduct enamine shown in Figure 19 (eq 1, see 24-en), with the less substituted double bond. However, no cyclobutane signalsbicyclo[4.2.0] octane derivatives-were detected.

In the reaction shown in eq 2 , we also observed the initial or starting enamine and rapidly the resulting adduct enamine (the final enamine) with a trisubstituted double bond (25-en). 
(A)

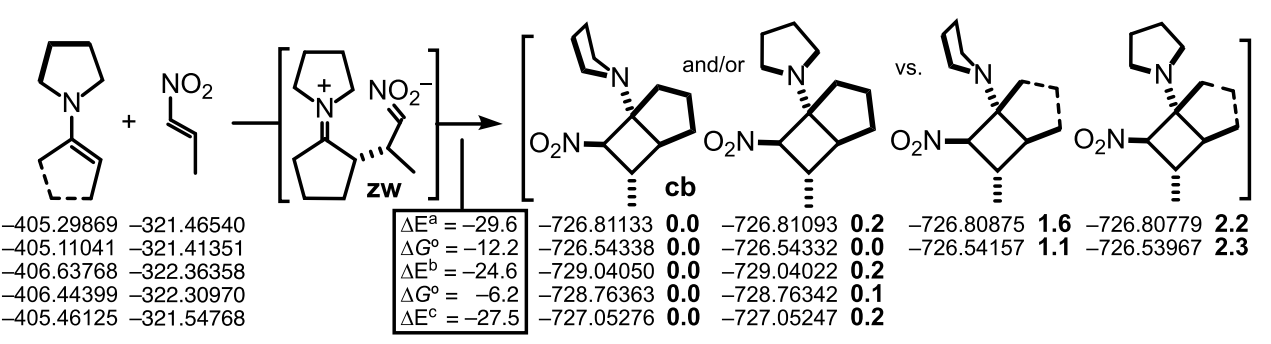

(B)
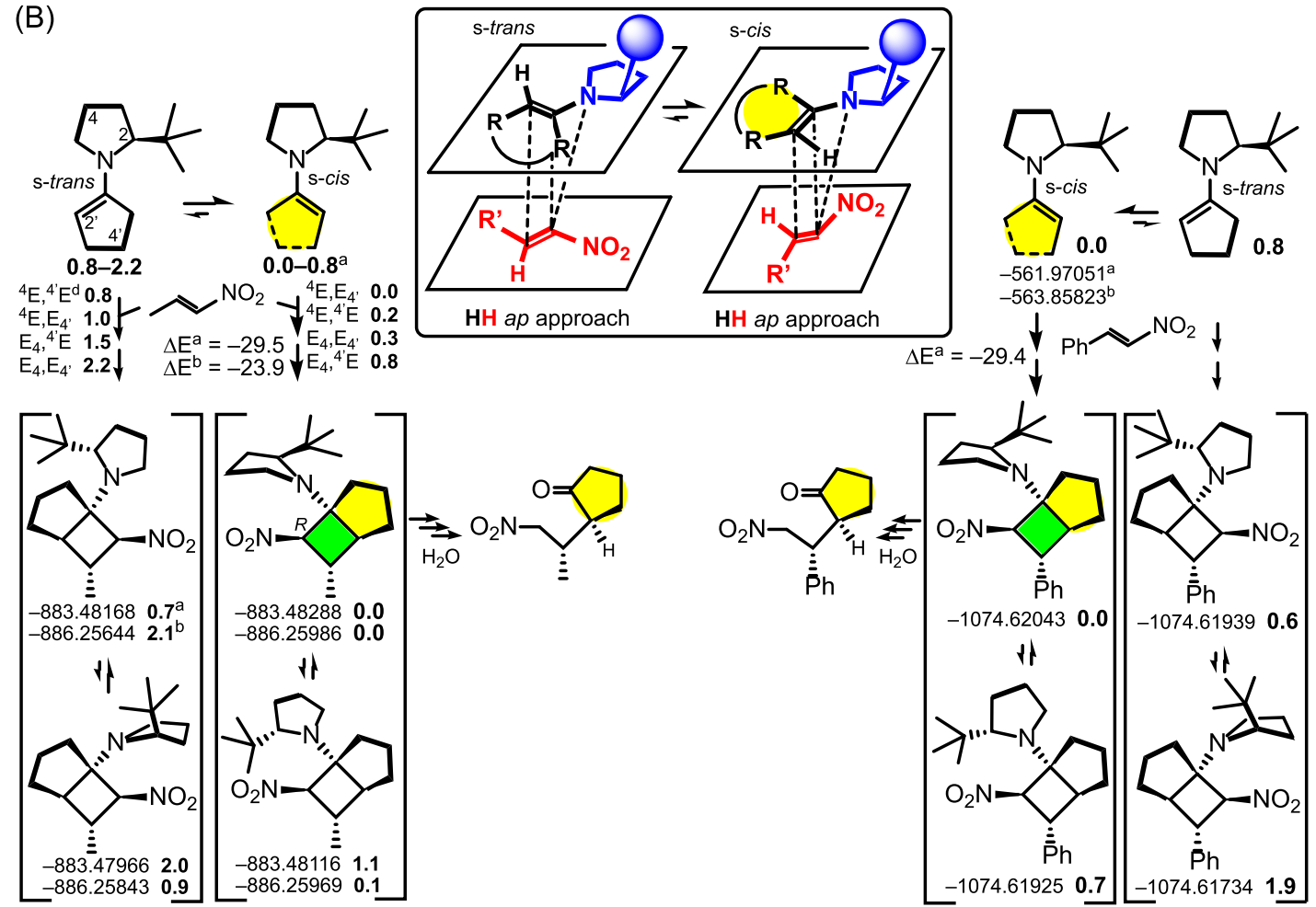

(C)

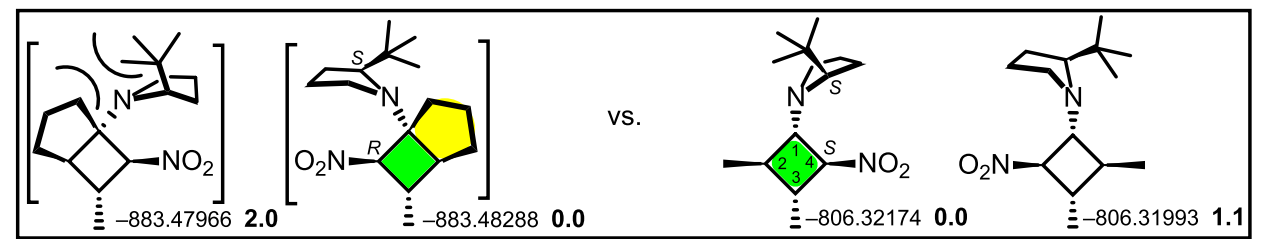

a MP2/6-31G(d)//B3LYP/6-31G(d)

b $M 06-2 X / 6-311+G(d, p)$

c $\operatorname{CCSD}(\mathrm{T}) / 6-31+\mathrm{G}(\mathrm{d}) / / \mathrm{M} 06-2 \mathrm{X} / 6-311+\mathrm{G}(\mathrm{d}, \mathrm{p})$

d ${ }^{4} \mathrm{E},{ }^{4} \mathrm{E}=\mathrm{C} 4$-up \& $\mathrm{C} 4^{\prime}-$ up

Figure 20. Calculated reaction energies for the model reaction between the pyrrolidine-cyclopentanone enamine and $(E)$-1-nitropropene (A). Fused cyclobutanes that may be formed from the 2-tert-butylpyrrolidine-cyclopentanone enamine and $(E)$-1-nitropropene (B, left) or $\beta$ nitrostyrene (B, right). Comparison of cyclobutanes from cyclopentanone with those from propanal (C). Relative energies of isomers (in bold) are in $\mathrm{kcal} / \mathrm{mol}$, as always.

Furthermore, a direct adduct of the secondary amine to the $\beta$ nitrostyrene was also present (26). We explain this last fact as follows: since the formation of the starting enamine was not shifted as far to the right as in eq 1 , there was an excess of the secondary amine in the medium, which underwent an obvious conjugated addition to $\beta$-nitrostyrene. This interpretation was independently confirmed by mixing Peng's catalyst ${ }^{14}$ and an excess of $\beta$-nitrostyrene in $\mathrm{C}_{6} \mathrm{D}_{6}$ in a NMR tube, and only one diastereomer was formed; calculations of model analogues suggested that the conformer of the S,R-stereoisomer indicated in Figure 19 may largely predominate. However, what matters is that in these and other trials we were unable to detect any trace of a cyclobutane derivative at the temperature of the NMR probe.

Starting from cyclopentanone enamines, which were formed in larger proportions than cyclohexanone enamines ${ }^{5}$ operating under identical conditions, we obtained similar results by treating the resulting solutions with $\beta$-nitrostyrene in $\mathrm{C}_{6} \mathrm{D}_{6}$ at 5 ${ }^{\circ} \mathrm{C}$. However, more complex mixtures of adduct enamines were obtained (the chemical equations are not depicted to save space). For example, from cyclopentanone-pyrrolidine enamine and $\beta$-nitrostyrene, three of the possible enamines were detected, two of them with the double bond at the less substituted position, with typical enamine signals at $\delta$ 4.17/ 
(A)
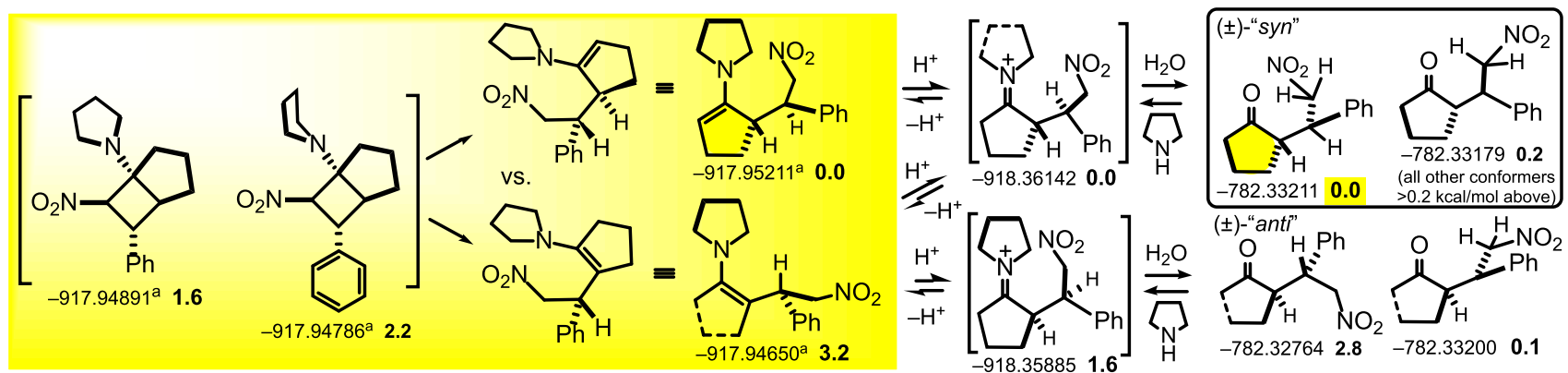

(B)
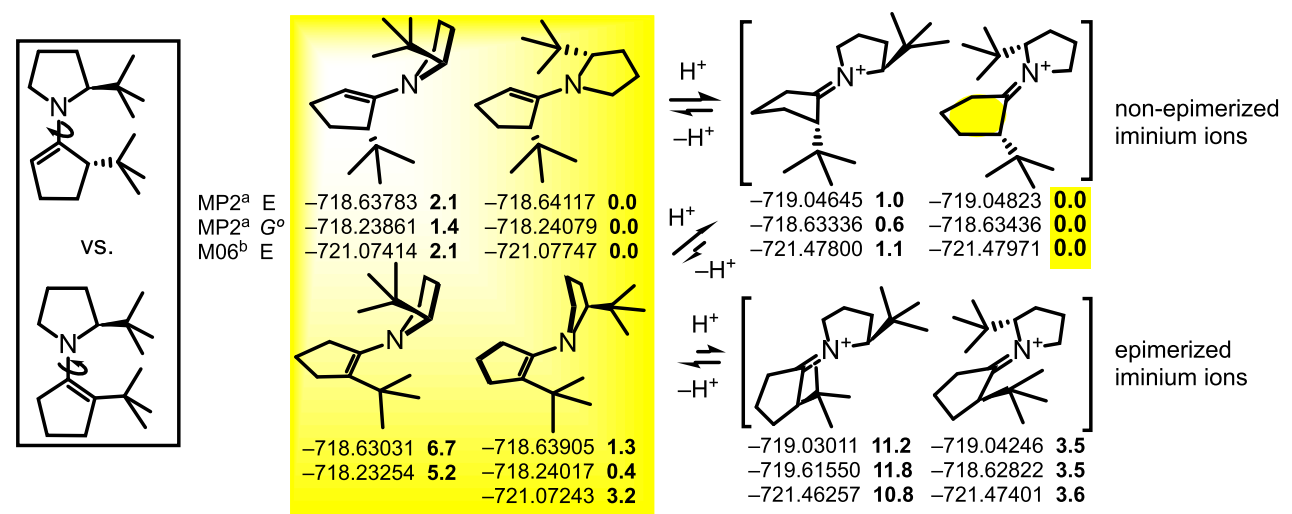

${ }^{\mathrm{a}} \mathrm{MP} 2 / 6-31 \mathrm{G}(\mathrm{d}) / / \mathrm{B} 3 \mathrm{LYP} / 6-$

Figure 21. Relative energies, within each set of isomers, of the lowest-energy conformers of plausible intermediates involved in the reaction of cyclopentanone-pyrrolidine enamine and $\beta$-nitrostyrene and of the final products (A). Relative stability of tri- vs tetrasubstituted enamine models (highlighted in yellow) and of the possible iminium ions, where the substituents on pyrrolidine and cyclopentene are represented by ${ }^{t} \mathrm{Bu}$ groups (B).

99.3 and $4.23 / 98.2$ (by HSQC). Reactions in $\mathrm{CD}_{3} \mathrm{CN}$ at -40 ${ }^{\circ} \mathrm{C}$ gave similar mixtures of adduct enamines when the spectra were registered at rt. Only in one experiment with a nonaromatic nitroalkene (Figure 19, eq 3) were we able to detect a cyclobutane-derived intermediate $(27-\mathbf{c b})$ at the probe temperature; it appeared $3 \mathrm{~min}$ after mixing but disappeared 15 min later at the same time as the typical signals of the adduct enamine 27-en' grew (see Figure S75).

Calculations of Cycloadducts from Cyclopentanone. Let us assume as a working hypothesis, by analogy with the aldehydes, that the initial Michael-type zwitterionic species (zw) are partially or fully converted into fused nitrocyclobutanes (fused $\mathbf{c b}$ ) in the reactions just mentioned. Anyway, the energies of these hypothetical intermediates can be calculated, to evaluate their possible participation in the reaction mechanism(s). Species hardly detected or not detected by ${ }^{1} \mathrm{H}$ NMR are depicted within brackets.

A summary of our calculations for representative achiral and chiral enamines of cyclopentanone is shown in Figure 20. The reaction energies, to give the corresponding fused cyclobutanes, are between -30 and $-25 \mathrm{kcal} / \mathrm{mol}$, with the mean value between MP2/6-31G(d) and M06-2X/6-311+G(d,p) = $-27 \mathrm{kcal} / \mathrm{mol}$ (very close to the CCSD value of $-27.5 \mathrm{kcal} /$ $\mathrm{mol}$ ) and $-\Delta G^{\circ}<-6 \mathrm{kcal} / \mathrm{mol}$. These values are quite similar to those of aldehydes. However, none of these fused cyclobutanes were detected by ${ }^{1} \mathrm{H}$ NMR spectroscopy at rt. We suspected that the cause was not the rapid hydrolysis of the corresponding $\mathbf{z w}$-the overall process would then be unusually rapid, which is absolutely not the case-but the easier conversion of $\mathbf{z w}$ (the "ionic partner") and $\mathbf{c b}$ (the "covalent partner") to the adduct enamines. In fact, attempts to locate in silico a minimum for $\mathbf{z w}$ (from suitable geometries) failed, as the structures collapsed to the fused $\mathbf{c b}$, except when optimization was carried out in polar solvents and a large basis set. The lowest-energy $\mathbf{z w}$-like and $\mathbf{c b}$ conformers (Figure 20A) were then found to have similar free energies.

The detection of fused cyclobutanes (from ketones) may be more difficult than that of simple cyclobutanes (from aldehydes), since the ring strain is higher in the former, which inevitably contain one methylene group in an axial position and other methylenes over the cyclobutane ring; also, the entropy term should benefit the open-chain isomers. In the fused cyclobutanes shown in Figure 20A, the C2 methylene of the bicyclo[3.2.0] system has a preference for the endo arrangement as it avoids steric clashes. Other examples, with larger or additional substituents, confirm this observation, although they are not depicted to save space. The $\mathrm{NO}_{2}$ group, which turned out to be perpendicular to the plane of the cyclobutane ring in the more stable conformers of the simple nitrocyclobutanes depicted in preceding sections, is skewed, due to the presence of the $\mathrm{CH}_{2}$ axially positioned at $\mathrm{C}$.

The analysis of the most plausible approaches between the ketone enamines and simple $(E)$-nitroalkenes clearly indicates that the case is more complicated than that for the aldehyde enamines examined so far. If we assume that bicyclo[3.2.0]heptanes may be formed, intermediates with the fused rings in trans were expected to be highly disfavored (and have not been calculated). The so-called alternative or $\mathrm{HH}$ sc approaches are also disfavored (see Figure S6).

Let us focus attention on the central part of Figure 20 (Figure 20B). The calculations suggested that the main s-cis conformer of the starting enamine, from cyclopentanone and 2-(S)-tert-butylpyrrolidine, highlighted in yellow, had lower energy (or energies) than the s-trans conformer (i.e., than the lowest-energy form of the s-trans conformer). This is in sharp contrast with aldehyde enamines (Figure 14), where the s-trans 
(A)

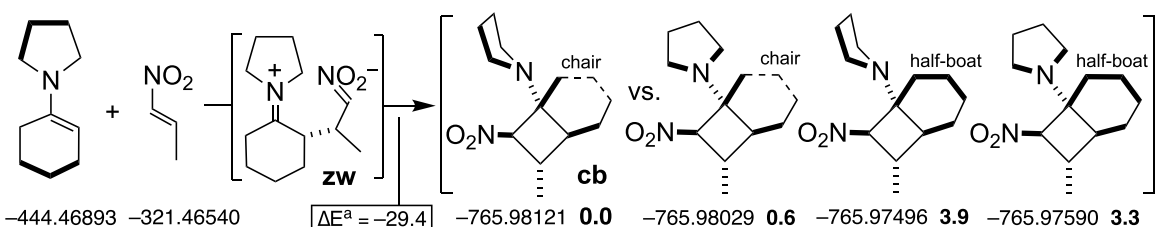

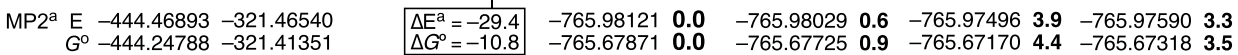
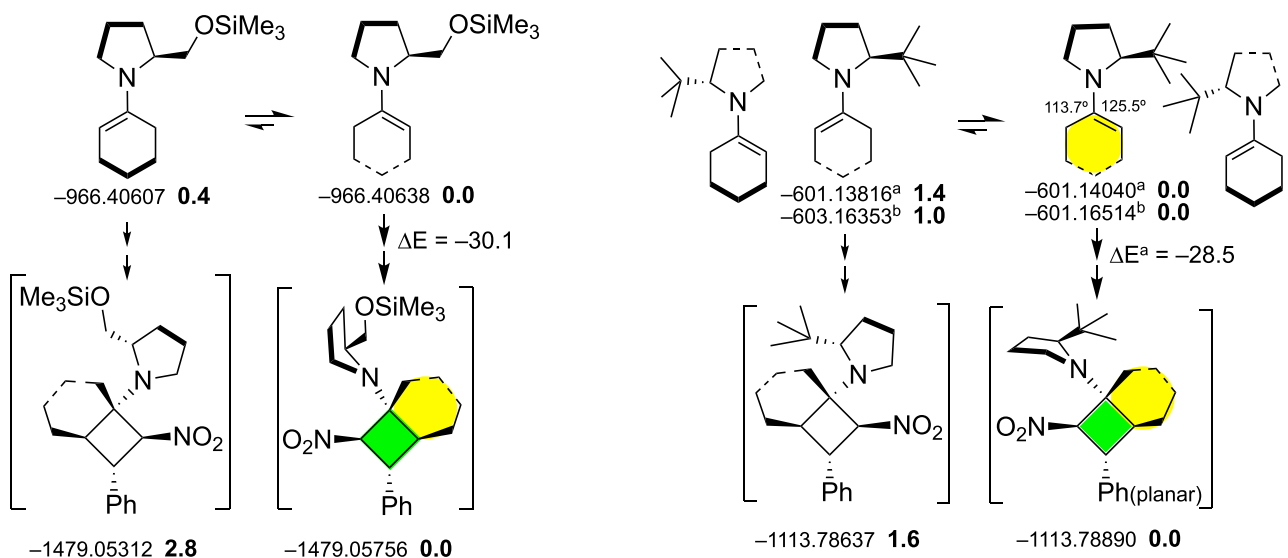

$-1113.786371 .6 \quad-1113.78890 \mathbf{0 . 0}$

(B)
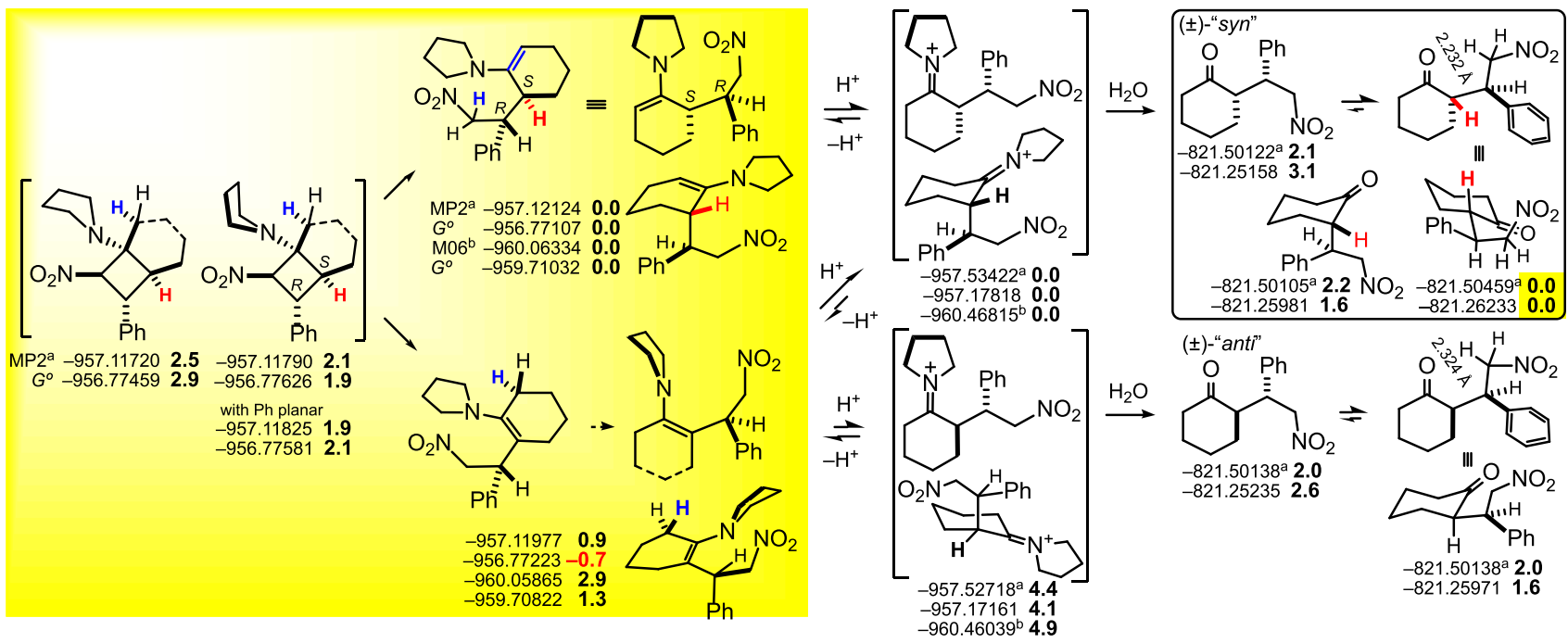

(C)

a MP2/6-31G(d)//B3LYP/6-31G(d)
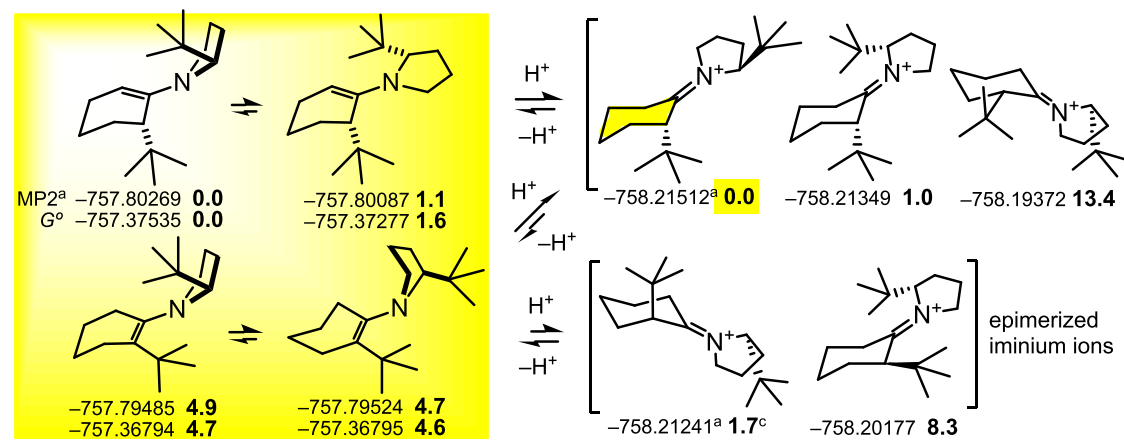

b $M 06-2 X / 6-311+G(d, p)$

4.7

Figure 22. Calculated reaction energies for the formation of cyclobutanes from cyclohexanone (A). Relative energies, within each set, of the plausible intermediates of the reaction of cyclohexanone, pyrrolidine, and $\beta$-nitrostyrene (B); only the lowest-energy conformers are represented. Relative energies of models of enamines (with ${ }^{t} \mathrm{Bu}$ groups) and of the corresponding iminium ions (C). Total energies are in au and, in bold numbers, relative energies are in $\mathrm{kcal} / \mathrm{mol}$.

conformers largely predominated in the conformational equilibrium. It is, however, reasonable since the steric effects to be compared, considering the cyclopentenyl group, are one methylene group $\left(\mathrm{CH}_{2}\right)$ vs the methine or methyne of a double bond ( $=\mathrm{CH}$ group). This methine implies fewer or 
lower vdW repulsions (only one $\mathrm{H}$ atom) with the $2-\mathrm{CH}^{t} \mathrm{Bu}$ group and slightly favorable $\pi-\mathrm{CH}_{3}$ interactions.

If the mechanism is similar to that elucidated for aldehydes, the s-cis-enamine will give rise to the bicyclo[3.2.0] derivative with the $\mathrm{NO}_{2}$ group on the left, as depicted in Figure 20B (i.e., with the $\mathrm{R}$ configuration), whereas the s-trans-enamine will afford the derivative with the $\mathrm{NO}_{2}$ group on the right. The rule of thumb advanced in Figures 14 and 15 is maintained: if the double bond of the starting enamine is mainly on the right, in the figures in this work, the $\mathrm{NO}_{2}$ group of the nitrocyclobutane (or of the folded conformer of its ionic precursor, $\mathbf{z w}$, in very polar solvents) appears predominantly on the left, when depicted as throughout this paper, and vice versa. Calculations indicate that the lowest-energy conformer of all of the bicyclic species for the reaction of the s-cis-enamine with 1-nitropropene (left) is that highlighted in green; also for the reaction with $\beta$-nitrostyrene (right), it is highlighted in green in Figure 20B. Again, the most abundant initial enamine is transformed to a cyclobutane (or to its ionic equivalent, $\mathbf{z w}$ ) that turns out to be the most stable. It may be assumed that the approach of reactants and the activation free energies are similar (although not identical).

The explanation for the calculated greater stability of the fused cyclobutanes with the $\mathrm{NO}_{2}$ group on the left is based on the new steric interactions generated by the presence of the additional ring, which introduces a chain at $\mathrm{C} 1$. Thus, the conformers in which the ${ }^{t} \mathrm{Bu}$ group and/or the pyrrolidine methylenes are close to the cyclopentane ring are clearly destabilized. The less-affected conformer is highlighted in yellow and green in Figure 20, where ${ }^{t} \mathrm{Bu}$ is as far as possible from the fused system. This changes the order: the $\mathrm{R}$ configuration of the $\mathrm{NO}_{2}$ group is preferred, whereas the $S$ configuration was favored in the case of cyclobutanes from aldehydes shown in Figures 14 and 15. Moreover, the N lone pair is properly oriented for the interaction with the $\mathrm{CH}-$ $\mathrm{CH}-\mathrm{NO}_{2}$ moiety. In other words, the issue, if cyclobutanes are wanted, is that such a conformer is prone to ring opening (the $\mathrm{C}-\mathrm{C}$ bond between $\mathrm{N}$ and $\mathrm{NO}_{2}$ is longer).

We also studied computationally the adduct enamines, adduct iminium salts, and final nitroketones from the abovementioned reaction of cyclopentanone, pyrrolidine, and $\beta$ nitrostyrene, as examples. The results are shown in Figure 21A. The adduct enamines were more stable than their fused cyclobutane precursors (and consequently than their associated $\mathbf{z w}$ ). The calculations predicted the ring opening affording the less substituted enamines to be quite favorable. The diastereoselectivity was envisaged to be higher than with simple aliphatic nitroalkenes (results not included for the sake of brevity), again as was observed experimentally. However, once the hydrolysis was accomplished, the lowest-energy syn and anti adducts were predicted to have practically identical energies. Epimerization may be feasible at such a stage. This could explain why the diastereoselectivity of nitro-Michael reactions with cyclopentanone is lower than that of parallel reactions with cyclohexanone (see below).

Our next worry was to evaluate whether epimerization can occur during the intermediate steps or not. Figure $21 \mathrm{~B}$ includes the protonation equilibria of an enamine model, from a chiral pyrrolidine with a ${ }^{t} \mathrm{Bu}$ group and a substituted cyclopentanone, with another ${ }^{t} \mathrm{Bu}$ group instead of the $\mathrm{CH}(\mathrm{Ph}) \mathrm{CH}_{2} \mathrm{NO}_{2}$ group. This decreased by a factor of $3^{n}$ the number of conformations to be calculated. The lowest-energy enamine shown in Figure $21 \mathrm{~B}$ is a non-epimerized trisubstituted enamine, with both the
${ }^{t} \mathrm{Bu}$ groups in the lower face. Our calculations also indicate that two iminium-like non-epimerized intermediates, especially those highlighted in yellow, would largely predominate. Fortunately, after hydrolysis, they would afford the same product. Epimerizations, if they actually occur, should take place toward the end of the processes, from the substituted cyclopentanones.

Calculations of Cycloadducts from Cyclohexanones. In parallel, we studied the reactions of cyclohexanone, pyrrolidine(s) and (E)-1-nitropropene or $\beta$-nitrostyrene, ${ }^{19}$ as examples (Figure 22). They may pass through the corresponding $\mathbf{z w}$ (in very polar media) and through fused cyclobutanecyclohexane rings (fused cb, Figure 22A), although, as we mentioned in a preceding section, we were unable to detect these plausible intermediates under standard conditions. If this hypothesis becomes inconsistent in the light of the MO calculations, it will be rejected. We were able to locate such a zw only when polar solvents were included in the calculations; otherwise, $\mathbf{z w}$ collapsed to the fused $\mathbf{c b}$. For example, optimizations with the M06-2X/6-311+G(d,p)/CPCM method located the lowest-energy $\mathbf{z w} 3.6 \mathrm{kcal} / \mathrm{mol}$ above the corresponding $\mathbf{c b}$ in THF and only $0.7 \mathrm{kcal} / \mathrm{mol}$ in DMF; in water, the free energies of $\mathbf{z w}$ and $\mathbf{c b}$ were estimated to be similar.

These formal cycloadditions are again predicted to be very exothermic and exergonic or exoergic. However, there is a feature that did not appear in the fused cyclobutanecyclopentane systems: the strong tendency of the cyclohexane ring to adopt chair conformations forces the pyrrolidine ring to acquire conformations that avoid the additional vdW repulsions. There is only one further exo-methylene, but it introduces significant steric hindrance. The fact is that the conformer with the pyrrolidine ring perpendicular to the bicyclic system-the one that is highly prone to ring opening-predominates more than in Figure 21.

With chiral pyrrolidines, s-trans-enamine conformers should go to bicyclic systems with the $\mathrm{CHNO}_{2}$ carbon atom of configuration $\mathrm{S}$, while s-cis-enamine conformers should go to (R)- $-\mathrm{HNO}_{2}$. Now, once again as in the cyclopentanone case, the $(R)-\mathrm{CHNO}_{2}$ isomer is the most stable bicyclic system. In other words, the bicyclic structures with the $\mathrm{NO}_{2}$ group on the left, in the drawings of this work, are always preferred (highlighted in Figure 22A).

Therefore, there is a simple consistent explanation for "point (b)" mentioned in the Introduction. Cyclopentanone and cyclohexanone, in the presence of chiral pyrrolidines, react with nitroalkenes to afford different "syn" adducts to those afforded by aldehydes due to the fact that the most stable of the two assumed all-trans fused bicyclic nitrocyclobutanes (or presumably of its open, ionic form, $\mathbf{z w}$ ) has not the same configuration at $\mathrm{C}-\mathrm{NO}_{2}$ than the most stable of the two simple nitrocyclobutanes. We have explained this in preceding paragraphs. That the fused cyclobutanes are less stable at rt, with respect to their zwitterions and enamines, than the simple nitrocyclobutanes is another story, although it is understandable on the basis of the additional steric repulsions that appear in the fused systems (see below).

For cyclohexanone, the relative stabilities of the intermediates arising from the ring opening and hydrolysis of the hypothetical but computationally plausible fused systems are included in Figure 22B. We note that (1) both enamines, particularly that with the trisubstituted double bond, are more stable than the lowest-energy fused system (the steric strain of 


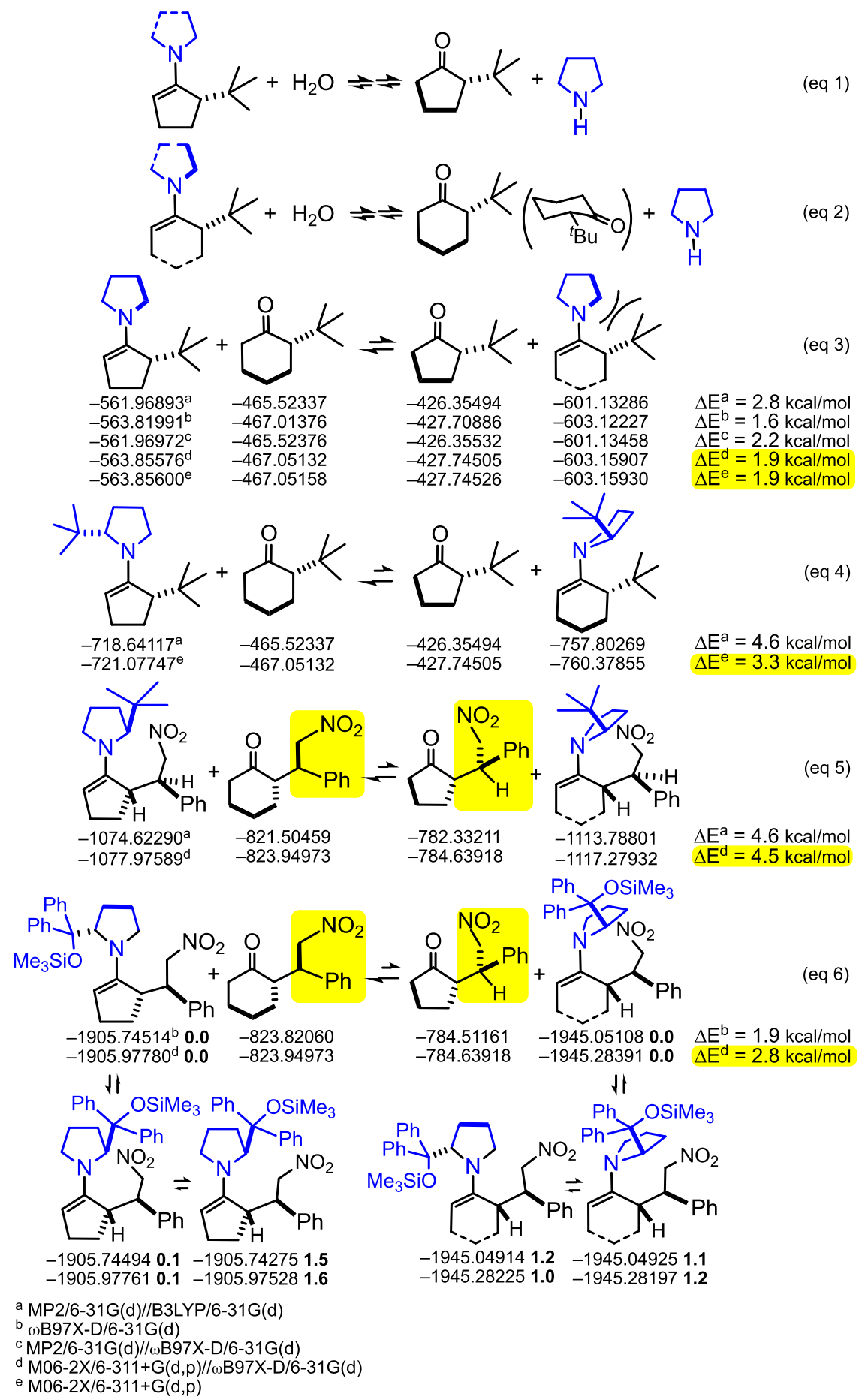

Figure 23. Hydrolysis of enamines from pyrrolidine and 2-tert-butylcyclopentanone (eq 1) and from pyrrolidine and 2-tert-butylcyclohexanone (eq 2). Equilibrium 3 (eq 3 = eq $1-$ eq 2). Exchange of 2-tert-butylpyrrolidine between $2{ }^{-}$Bu-substituted cycloalkanones (eq 4). Exchange of 2-tertbutylpyrrolidine involving cycloalkanone- $\beta$-nitrostyrene adducts (eq 5). Exchange of the $\mathrm{JH}$ catalyst between cycloalkanone- $\beta$-nitrostyrene adducts (eq 6); the lowest-energy conformers are compared, with their relative energies $(\mathrm{kcal} / \mathrm{mol})$ indicated in bold.

the fused systems is released during ring opening); (2) the pyrrolidine ring in the equilibrium geometry of the enamine with the tetrasubstituted double bond (a half-chair conformer with a short double bond between the two "substituents") is not coplanar with the cyclohexenyl moiety, in contrast to the cyclopentenyl case, a fact that can be related to the well-known concept of the inhibition of resonance (that is, any cyclohexenyl derivative exerts higher steric hindrance on the neighboring pyrrolidine group than its related cyclopentenyl derivative would); (3) the expected iminium ion (with its lowest-energy conformer showing the $\mathrm{NO}_{2}$ group closest to the iminium substructure) is more stable than its epimer; and (4) the syn adduct, particularly its conformer with an ap arrangement and an $\mathrm{O}-\mathrm{H}$ distance at the $\mathrm{C}=\mathrm{O} \cdots \mathrm{HCHNO}_{2}$ moiety that resembles that of a hydrogen bond, is more stable than any conformer of its epimerized adduct (anti). The respective gaps between the two rows (expected vs epimerizable/epimerized intermediates) are larger than in the 
cyclopentanone case. The features of the six-membered rings-equilibrium between two preferred chair conformations, ${ }^{1} \mathrm{C}_{4}$ and ${ }^{4} \mathrm{C}_{1}$, with substituents clearly axial or equatorial, as well as bond angles close to $120^{\circ}$ in half-chair conformations of cyclohexenyl derivatives in comparison with bond angles close to $108^{\circ}$ for cyclopentenyl analogues-are responsible of these gaps. Thus, epimerization during the intermediate steps of the process is predicted to be less probable than in the case of cyclopentanone, as happens in practice.

For a chiral pyrrolidine model with a second ${ }^{t} \mathrm{Bu}$ group on the cyclohexenyl ring, shown in Figure 22C, non-epimerized iminium ions were predicted, as in Figure 21B, to be more stable than those epimerized.

Adduct Enamines from Cyclopentanone Are More Resistant to Hydrolysis Than Those from Cyclohexanone. The fact that completion of the nitro-Michael reactions of cyclopentanone requires larger amounts of catalyst than those of cyclohexanone (Figure 5) cannot be explained on the basis of a great stability of the nitrobicyclo[3.2.0] systems with regard to the nitrobicyclo[4.2.0] systems. Calculations indicate that the additional $\mathrm{CH}_{2}$ in the cyclohexane ring, which has a strong tendency to adopt the wellknown chair conformation, causes further destabilizing vdW interactions with the pyrrolidine ring or with the substituents of the pyrrolidine ring. Thus, the [4.2.0] systems may be relatively less stable than the [3.2.0] systems. Nevertheless, we had experimentally observed that, at least above $5{ }^{\circ} \mathrm{C}$, both bicyclic systems, if formed, open spontaneously to afford enamines, even in apolar solvents and in the absence of moisture. Therefore, the ring opening cannot be the ratelimiting step of the process, in either case.

As the 2-tert-butylcyclohexanone-pyrrolidine enamine was calculated to be relatively less stable than the 2-tertbutylcyclopentanone-pyrrolidine enamine, the respective hydrolyses might not be equally shifted to the right, independently of the intermediates involved. Figure 23 shows the calculations. Both hydrolyses (eqs 1 and 2) are exothermic, as expected, but what matters is the difference between them; in other words, if the concentration of water in the organic layer is very low, which hydrolysis will be less affected. It is observed that eq 3 , which is obtained by the subtraction of eq 2 from eq 1 , is shifted to the left, that is, the hydrolysis of the enamine of the cyclohexenyl derivative is predicted to be around $2 \mathrm{kcal} / \mathrm{mol}$, as a mean value, more favored than that of enamine of the cyclopentenyl derivative.

The steric repulsion between the ${ }^{t} \mathrm{Bu}$ group and pyrrolidine ring was higher when they were neighbors on the cyclohexene ring than on the cyclopentene. Actually, the $\mathrm{C} 2 \mathrm{~N} 1 \mathrm{Cl}^{\prime} \mathrm{C}^{\prime}$ dihedral angle of the cyclohexene derivative was predicted to be larger than the $\mathrm{C} 2 \mathrm{~N} 2 \mathrm{C}^{\prime} \mathrm{C}^{\prime}$ dihedral of the cyclopentene derivative. Thus, some steric inhibition of resonance occurs again, mainly in the cyclohexene case.

When the steric hindrance increased (eqs 4-6), the values of $\Delta E$ also increased. Conformers were located for each $N$ cyclopentenylpyrrolidine in which resonance between the $\mathrm{N}$ atom and the double bond is still possible. For the analogous $\mathrm{N}$-cyclohexenylpirrolidines, the steric inhibition of resonance was comparatively higher. As known ${ }^{1,3,5}$ and mentioned in preceding sections, with large substituents on $\mathrm{C} 2$ of the pyrrolidine ring, aminocatalytic reactions do not work in practice-starting enamines are hardly formed, but these imaginary cases can also be computationally investigated, as we have done in Figure 23 (eq 6), to find a general explanation of the differences between cyclopentanone and cyclohexanone enamines.

For the isomer of the example shown in eq 4 with the tetrasubstituted double bond, the $\Delta E$ values were $\approx 1.5 \mathrm{kcal} /$ mol higher; for the enamine from 2-tritylpyrrolidine with the tetrasubstituted double bond, the predicted $\Delta E$ values were $\approx 5$ $\mathrm{kcal} / \mathrm{mol}$ higher than those given in eq 4 . These data are not included in Figure 23 but indicate again that the larger and closer the substituents, the lower the stability of cyclohexanone enamines in relation to cyclopentanone enamines.

To summarize, in the same way as the equilibrium constants for the formation of the initial enamines are very disparate, ${ }^{5}$ the hydrolysis of the final enamines to afford the final adducts with release of the secondary amine may have quite different equilibrium constants. If the water concentration in the organic solution is low, some of these hydrolyses may not be completely shifted to the right.

The last paragraphs and figures explain the anomalous fact indicated as "point (f)" (Figure 5) in the Introduction. Since the hydrolysis of the final cyclopentanone enamines is not shifted so far to the right as that of the final cyclohexanone enamines, the overall nitro-Michael reaction will hardly proceed with really catalytic amounts of chiral pyrrolidines in the first case since these (the catalysts) are less easily released.

The corollary is that, before ruling out disappointing aminocatalytic trials as unfeasible, they should be attempted with substoichiometric amounts of the chiral secondary amine and a little water or, if economically possible, with stoichiometric amounts of the chiral amines, in solvents, mixtures of solvents, or media that do not exclude water from the organic phase.

\section{CONCLUSIONS}

When enamines from simple aldehydes and pyrrolidine or chiral pyrrolidines were treated with nitroalkenes and the reactions were followed by ${ }^{1} \mathrm{H}$ NMR spectroscopy, all-transcyclobutanes $\mathbf{c b}$ were the major compounds in many organic solvents. Different computational methods predicted that these cb are the most stable isomers. The initial Michael-type zwitterionic intermediates with the ionic groups close together (zw, Figures 12 and 13) were not detected by NMR and were even difficult to locate in silico, except in polar solvents, due to their tendency to collapse to $\mathbf{c b}$. Each $\mathbf{z w}$ may be viewed as the ionic form of a tautomer with a $\mathrm{C} 1-\mathrm{C} 4$ covalent bond (cb).

Calculations indicated how the s-trans conformers of the starting chiral enamines predominated in the equilibria and that their corresponding $\mathbf{c b}$ (Figures 14-16) were also thermodynamically favored. The first barriers, calculated for model compounds, were very small and similar for the different enamine conformers.

We have confirmed that cyclobutanes cb (if not 2,2disubstituted) are slowly converted into adduct enamines, with a reaction rate depending on the temperature, substituents, and solvent polarity. The relative energies of these species have been calculated (Figures 7, 8, 17, and 18).

All of the species mentioned [zw, cb, and $(E)-\mathbf{e n}]$ can be hydrolyzed to the final adducts. As shown in Figure 17, part of the zw-like intermediates can directly react with $\mathrm{H}_{2} \mathrm{O}$ or with $\mathrm{H}_{2} \mathrm{O} / \mathrm{HA}$; however, if this route was predominant, as the chiral pyrrolidine would be immediately released, almost all of the aminocatalytic reactions of aldehydes would be very quick, which is absolutely not the case. Cyclobutanes (cb), which are in equilibrium with $\mathbf{z w}$, can be hydrolyzed via such a route or 


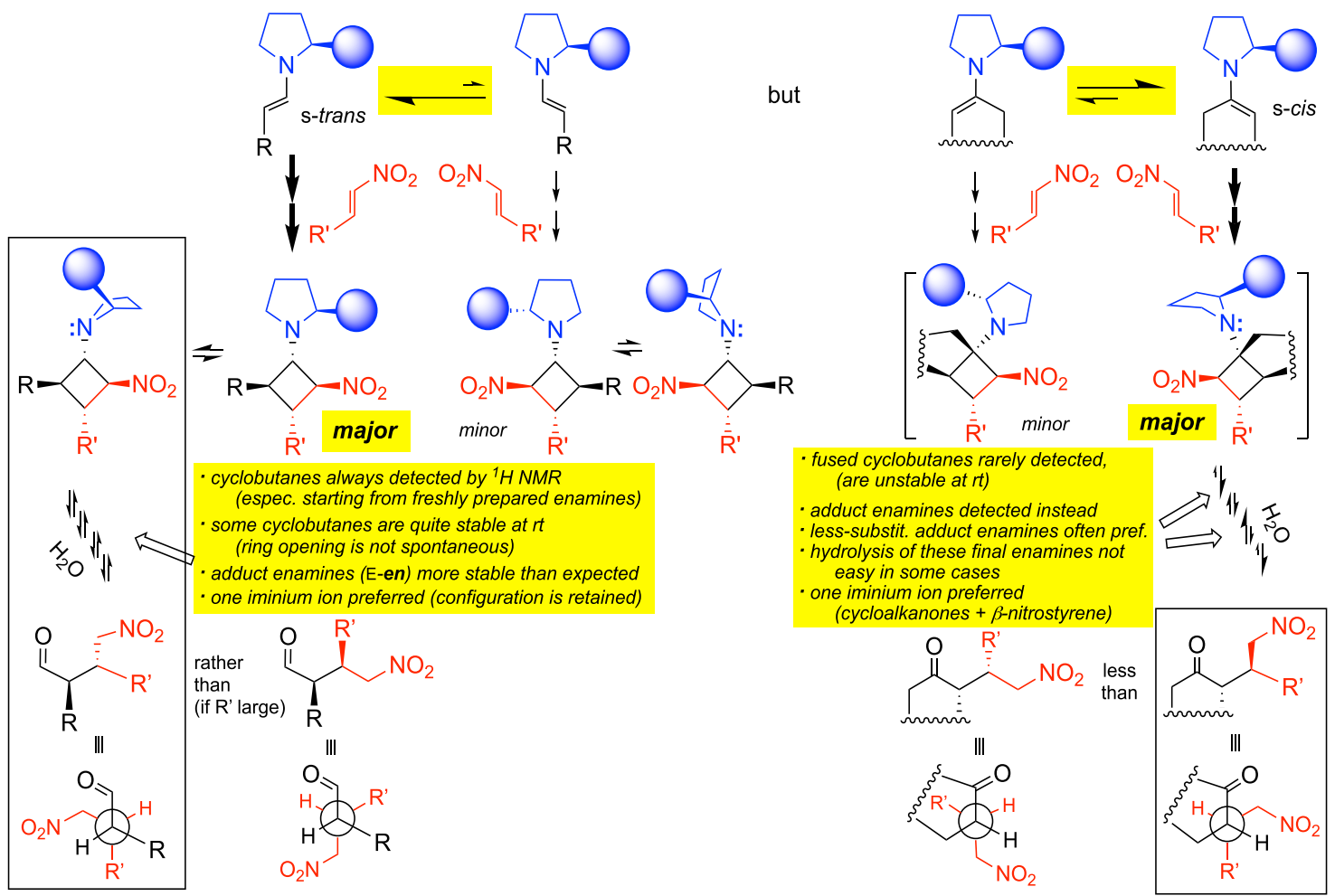

Figure 24. Graphical summary from the starting enamines. Preferred stereoisomers of nitrocyclobutanes and relative stability of the main conformers of 4-nitrobutanals (left column) and 2-(2-nitroethyl)cycloalkanones (right).

through the adduct enamines $[(E)$-en $]$. These adduct enamines should be hydrolyzed via the corresponding iminium ions, by general acid catalysis. This is the point where the stereoselectivity may be lost. However, the calculations predicted that, for pyrrolidine-derived enamines, iminium ions folded as the cyclic structures of the precursors, here called $\mathrm{im}^{+}$, with favorable electrostatic interactions between the polar groups and with $\mathrm{H} 1, \mathrm{H} 2$, and $\mathrm{H} 3$ in ap arrangements, were the lowest-energy cations. For the chiral enamines of the adducts, the protonation turned out also to be stereoselective (Figure 18B). Thus, the acid-catalyzed hydrolysis of any adduct enamine can go through non-epimerized cations. In other words, it does not matter if a percentage of $\mathbf{z w}$ (possible) and of $\mathbf{c b}$ (demonstrated) is converted into $(E)$-en, as the enamine-iminium protonation/deprotonation equilibrium is very stereoselective.

Cyclopentanone and cyclohexanone pose different problems. As a working hypothesis, we assumed that the fused cyclobutanes derived from the starting enamines were also formed as intermediates, although at rt we had only detected one transient species. Again, the corresponding zwitterions (zw, the initial adducts, undetectable) may cyclize to fused $\mathbf{c b}$ (their covalent tautomers). The hypothesis is supported by calculations. Zw may also afford the corresponding adduct enamines $(E)$-en by prototropy. The predominant intermediates detected by NMR were the adduct enamines with a trisubstituted double bond, in agreement with the calculations. Again, all of these intermediates-zw, fused $\mathbf{c b}$, and $(E)$-enare eventually converted into the final ketones. Actually, our calculations predict that fused cyclobutanes can be formed but the ring opening is more favored than in cyclobutanes from aldehyde enamines, due to the mutual steric hindrance of the fused rings. From the point of view of stereoselectivity, this is an advantage if the very major adduct enamine is the least substituted isomer, but also if some of the more substituted adduct enamine is also formed but its protonation and hydrolysis occur stereoselectively. This may be the case of cyclohexanone, since we have calculated that there is always one preferred iminium ion. It seems that, for this reason as well, cyclohexanone has turned out to be the substrate of choice for the comparison of the performance of a series of catalysts.

The main problematic points are graphically summarized in Figure 24. A moderate reactivity of aldehydes, which with catalysts other than proline is due to a lack of turnover, is explained by the well-known stability of some cb (which we have calculated for the first time) and by the resistance to hydrolysis of the resulting enamines. For many ketones, the lack of reactivity is explained by the low concentration of starting enamines, as well as by the relative resistance to hydrolysis of some final enamines (as calculated here).

Therefore, for those nitro-Michael reactions that go mainly through cyclobutanes, the rate-limiting step may be the ring opening of these nitrocyclobutylpyrrolidines and/or the hydrolysis of the resulting enamines (depending on the substituents; see Figures 18 and S5 for the relative energies of these intermediates). That the preference of cyclobutane substituents for the trans arrangement controls the stereoselectivity is not incompatible with the existence of subsequent equilibrium steps, more or less shifted to the right, more or less slow. The different points of view are thus reconciled.

Figure 25 summarizes our calculations (see $\Delta G^{\circ}$ for the different steps). All of the steps are equilibrium reactions, but the cycloaddition is the most shifted to the right. For cases with large substituents and the $\mathrm{JH}$ catalyst, the relative stability of nitrocyclobutanes with respect to the precursors may not be so high, but such a step is still exoergic or exergonic. 

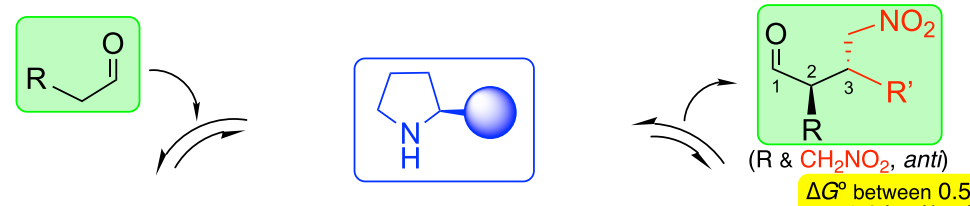

and $1.6 \mathrm{kcal} / \mathrm{mol}$

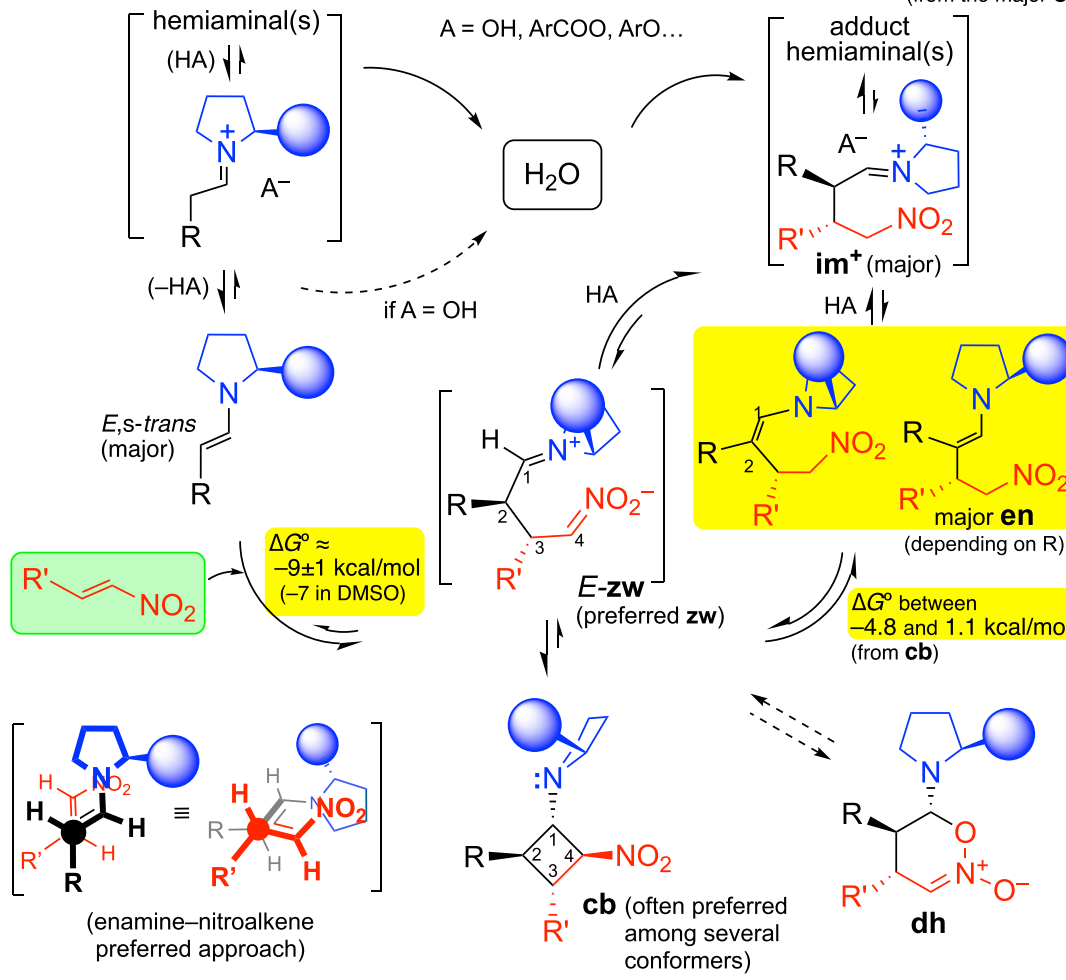

$\mathrm{A}=\mathrm{OH}, \mathrm{ArCOO}, \mathrm{ArO}$.

$$
\text { (from the major en) }
$$

Figure 25. Updated version of Figure 2 in the light of the new experiments and calculations, for the reaction of aldehydes with nitroalkenes. The $\Delta G^{\circ}$ values, from $\mathbf{c b}$ to en and from en to nitrobutanal, are those predicted for the case of pyrrolidine, simple aliphatic aldehydes, and $\beta$ nitrostyrene by the M06-2X/6-311+G(d,p) method.

A similar but not identical catalytic cycle could be depicted for cyclic ketones (not included). The changes or modifications should be that (1) the s-cis conformers of the starting ketone enamines are not only the productive species, but also, as the calculations predict, the most abundant in the equilibria and give rise to the most stable intermediates and final adducts; (2) the calculations explain why the configurations of the two newly created stereocenters of the consecutive intermediates and final nitro-Michael adducts are the opposite to those from aldehydes and/or how much is the gap between the two series of intermediates; (3) the suspected or hypothetical fused cyclobutanes or their ionic forms (zw), which are more crowded than the cyclobutanes arising from aldehydes, are not resting states, as we have demonstrated in one case and calculated in many others that they easily isomerize to the adduct enamines; (4) consequently, the difficult formation of the starting enamines of crowded catalysts (with release of water), or the hydrolysis by general acid catalysis of the final enamines of less crowded catalysts (which requires the released water), can be the rate-limiting step of the process.

In short, the computational results reported here are in accordance with the experimental data and self-consistent. They can help to explain further possible bizarre results other than cases (a)-(f) and to choose appropriate catalysts and conditions when novel aminocatalyzed reactions of carbonyl compounds with activated alkenes are envisaged.

\section{EXPERIMENTAL SECTION AND METHODS}

Detection of Reaction Intermediates by NMR Spectroscopy. The starting enamines $(0.06-0.10 \mathrm{mmol})$ were prepared in a vial under Ar from approximately equivalent amounts (unless otherwise indicated) of the carbonyl compound and pyrrolidine or pyrrolidine derivative in the deuterated solvent $(0.7 \mathrm{~mL})$, in the presence of powdered $3 \AA$ MS and, except for the experiments with proline, of $\mathrm{CaH}_{2}$ powder (ca. $75 \mathrm{mg}$ ). When no more bubbles were observed (when $\mathrm{CaH}_{2}$ was used), the content was filtered and transferred to an NMR tube. The spectra indicated an almost complete formation of the desired initial enamine (with aldehydes) and residual amounts of reactants. After cooling the tube to $5{ }^{\circ} \mathrm{C}$, the nitroalkene (1.0 equiv) was slowly added and the reaction was monitored by ${ }^{1} \mathrm{H}$ NMR spectroscopy at the probe temperature (ca. $25^{\circ} \mathrm{C}$ ). Some attempts of purification or isolation in a pure condition of the following nitrocyclobutane intermediates were unsuccessful as they were progressively converted into enamines at $\mathrm{rt}$ and these enamines were gradually hydrolyzed on silica gel. The main NMR parameters are given below $[\delta$ values in parts per million (ppm), coupling constants in hertz, and multiplicities as usual]. 
For the full ${ }^{1} \mathrm{H}$ and ${ }^{13} \mathrm{C}\left\{{ }^{1} \mathrm{H}\right\}$ NMR spectra, as well as for COSY, NOESY, and HSQC experiments, see the SI.

1-cb: ${ }^{1} \mathrm{H}$ NMR (400 MHz, $\left.\mathrm{C}_{6} \mathrm{D}_{6}\right) \delta 7.1-6.9(\mathrm{~m}, 5 \mathrm{H}), 4.74$ $(\mathrm{dd}, J=9.0,7.6,1 \mathrm{H}), 3.20(\mathrm{t}, J=9.0,1 \mathrm{H}), 3.01(\mathrm{t}, J=7.6$, $1 \mathrm{H}), 2.36(\mathrm{~m}, 2 \mathrm{H}), 2.26(\mathrm{~m}, 2 \mathrm{H}), 1.90(\mathrm{~m}, 1 \mathrm{H}), 1.48$ (br s, $4 \mathrm{H}), 0.93(\mathrm{~d}, J=6.6,3 \mathrm{H})$.

2-cb: ${ }^{1} \mathrm{H}$ NMR (400 MHz, $\left.\mathrm{C}_{6} \mathrm{D}_{6}\right) \delta 7.1-6.9(\mathrm{~m}, 5 \mathrm{H}), 4.74$ $(\mathrm{dd}, J=9.0,7.1,1 \mathrm{H}), 3.30(\mathrm{t}, J=9.1,1 \mathrm{H}), 3.20(\mathrm{~m}, 1 \mathrm{H}), 2.40$ (m, 2H), $2.30(\mathrm{~m}, 2 \mathrm{H}), 1.95(\mathrm{~m}, 1 \mathrm{H}), 1.48($ br s, $4 \mathrm{H}), 1.30$ $(\mathrm{m}, 2 \mathrm{H}), 0.67(\mathrm{t}, J=7.5,3 \mathrm{H}) ;{ }^{13} \mathrm{C} \mathrm{NMR}\left(100.6 \mathrm{MHz}, \mathrm{C}_{6} \mathrm{D}_{6}\right)$ $\delta 129.0,127.5,127.3,84.4,66.9,50.5,46.4,42.9,27.5,23.8$, 11.4.

3-cb: ${ }^{1} \mathrm{H}$ NMR $\left(400 \mathrm{MHz}, \mathrm{C}_{6} \mathrm{D}_{6}\right) \delta 7.1-6.9(\mathrm{~m}, 5 \mathrm{H}), 4.79$ (triplet-like dd, $J \approx 8,1 \mathrm{H}$ ), 3.53 (triplet-like $\mathrm{dd}, J \approx 8,1 \mathrm{H}$ ), $3.37(\mathrm{t}, J=9.0,1 \mathrm{H}), 2.47(\mathrm{~m}, 2 \mathrm{H}), 2.36(\mathrm{~m}, 2 \mathrm{H}), 1.93(\mathrm{~m}$, $1 \mathrm{H}), 1.55(\mathrm{~m}, 1 \mathrm{H}), 1.48(\mathrm{~m}, 4 \mathrm{H}), 0.81(\mathrm{~d}, J=6.7,3 \mathrm{H}), 0.67$ $(\mathrm{d}, J=6.7,3 \mathrm{H}) ;{ }^{1} \mathrm{H}$ NMR $\left(400 \mathrm{MHz}, \mathrm{DMSO}-d_{6}\right) \delta 5.15(\mathrm{dd}, J$ $=8.4,7.0,1 \mathrm{H}), 3.63(\mathrm{dd}, J=8.9,7.0,1 \mathrm{H}), 3.33(\mathrm{~d}, J=8.4,7.3$, $1 \mathrm{H}), 2.11(\mathrm{~m}, 1 \mathrm{H}) ;{ }^{13} \mathrm{C}$ NMR $\left(100.6 \mathrm{MHz}, \mathrm{C}_{6} \mathrm{D}_{6}\right) \delta 83.1$, 65.2, 49.5, 44.8, 33.2, 23.9, 20.4, 20.0; HRMS (ESI+) calcd for $\mathrm{C}_{17} \mathrm{H}_{25} \mathrm{~N}_{2} \mathrm{O}_{2}^{+}[\mathrm{M}+\mathrm{H}]^{+}$289.1911, found 289.1914.

4-cb: ${ }^{1} \mathrm{H}$ NMR (400 MHz, $\left.\mathrm{C}_{6} \mathrm{D}_{6}\right) \delta 7.1-6.9$ (m, 5H), 5.04 (dd, $J=9.7,7.6,1 \mathrm{H}), 3.45(\mathrm{~d}, J=9.7,1 \mathrm{H}), 2.95(\mathrm{~d}, J=7.6$, $1 \mathrm{H}), 2.25(\mathrm{~m}, 4 \mathrm{H}), 1.46(\mathrm{~m}, 4 \mathrm{H}), 1.02(\mathrm{~s}, 3 \mathrm{H}), 0.59(\mathrm{~s}, 3 \mathrm{H})$; ${ }^{1} \mathrm{H}$ NMR (400 MHz, DMSO- $\left.d_{6}\right) \delta 5.52(\mathrm{dd}, J=9.8,7.6,1 \mathrm{H})$, $3.52(\mathrm{~d}, J=9.8,1 \mathrm{H}), 3.02(\mathrm{~d}, J=7.6,1 \mathrm{H}) ;{ }^{13} \mathrm{C}$ NMR $(100.6$ $\left.\mathrm{MHz}, \mathrm{C}_{6} \mathrm{D}_{6}\right) \delta 135.9,128.8,127.3,82.1,71.5,52.3,51.2,38.9$, 23.5, 18.2.

5-cb: ${ }^{1} \mathrm{H}$ NMR (400 MHz, DMSO-d $\left.)_{6}\right) \quad \delta .90$ (dd, $J=7.6$, 6.6, $1 \mathrm{H}), 3.44(\mathrm{dd} J=8.2,6.6,1 \mathrm{H}), 2.13(\mathrm{~m}, 1 \mathrm{H}), 1.75(\mathrm{~m}$, $1 \mathrm{H})$.

6-cb: ${ }^{1} \mathrm{H}$ NMR (400 MHz, DMSO- $\left.d_{6}\right) \delta 4.71(\mathrm{t}, J=8.0$, $1 \mathrm{H}), 2.68(\mathrm{~d}, J=8.0,1 \mathrm{H}), 1.84$ (br t $J \approx 8.0,1 \mathrm{H})$.

Proline-derived cyclobutanes 7-cb + 8-cb (a 55:45 mixture). Characteristic ${ }^{1} \mathrm{H}$ NMR signals of $7-\mathbf{c b}\left(400 \mathrm{MHz}, \mathrm{DMSO}-d_{6}\right)$ $\delta 5.27$ (dd, $J=8.8,7.5,1 \mathrm{H}), 3.81(\mathrm{dd}, J=9.0,7.5,1 \mathrm{H}), 3.67$ (dd, $J=8.6,5.7,1 \mathrm{H}), 3.25$ (br t, $J \approx 9.0,1 \mathrm{H}), 2.07(\mathrm{~m}, 1 \mathrm{H})$. Characteristic ${ }^{1} \mathrm{H}$ NMR signals of 8-cb $\left(400 \mathrm{MHz}, \mathrm{DMSO}-d_{6}\right)$ $\delta 5.13(\mathrm{dd}, J=8.4,7.5,1 \mathrm{H}), 3.76(\mathrm{dd}, J=9.0,7.5,1 \mathrm{H}), 3.51$ $(\mathrm{dd}, J=9.1,3.2,1 \mathrm{H}), 3.20($ br t $J \approx 9.0,1 \mathrm{H}), 2.14(\mathrm{~m}, 1 \mathrm{H})$. Methyl prolinate-derived cyclobutanes 9-cb + 10-cb. Major isomer: ${ }^{1} \mathrm{H}$ NMR $\left(400 \mathrm{MHz}, \mathrm{C}_{6} \mathrm{D}_{6}\right) \delta 4.76(\mathrm{dd}, J=8.3,7.4$, $1 \mathrm{H}), 3.96(\mathrm{dd}, J=9.0,7.4,1 \mathrm{H}), 3.66(\mathrm{dd}, J=8.5,5.2,1 \mathrm{H})$, $3.28(\mathrm{dd}, J=9.0,8.3,1 \mathrm{H}), 1.93(\mathrm{~m}, 1 \mathrm{H})$. Minor isomer: $\delta 5.00$ (dd, $J=8.4,7.4,1 \mathrm{H}), 3.77(\mathrm{dd}, J=9.0,7.4,1 \mathrm{H}), 3.50(\mathrm{dd}, J=$ 8.1, 3.0, $1 \mathrm{H}), 3.19$ (dd, $J=9.0,8.4,1 \mathrm{H}), 2.07(\mathrm{~m}, 1 \mathrm{H})$.

11-cb: ${ }^{1} \mathrm{H}$ NMR (400 MHz, DMSO- $\left.d_{6}\right) \delta 5.30(\mathrm{t}, J=8.0$, $1 \mathrm{H}), 3.94(\mathrm{t}, J=8.0,1 \mathrm{H}), 3.21(\mathrm{~m}, 3 \mathrm{H}), 2.05(\mathrm{~m}, 2 \mathrm{H})$. Some signals of a minor stereoisomer were detected (see the SI).

12-cb: ${ }^{1} \mathrm{H}$ NMR (400 MHz, DMSO- $\left.d_{6}\right) \delta 5.71$ (dd, $J=9.0$, 8.0, $1 \mathrm{H}$ ), 3.48 (overlapped, $1 \mathrm{H}$ ), 3.30 (overlapped, $1 \mathrm{H}$ ). Some signals of a minor stereoisomer were detected (see the SI).

13-cb: ${ }^{1} \mathrm{H}$ NMR $\left(400 \mathrm{MHz}, \mathrm{C}_{6} \mathrm{D}_{6}\right) \delta 4.88$ (dd, $J=8.2,7.3$, $1 \mathrm{H}), 4.23(\mathrm{dd}, J=9.2,7.3,1 \mathrm{H}), 4.13(\mathrm{~m}, 1 \mathrm{H}), 3.81(\mathrm{dd}, J=$ $9.8,6.9,1 \mathrm{H}), 3.62(\mathrm{dd}, J=9.8,5.4,1 \mathrm{H}), 3.42(\mathrm{t}, J=9.2,1 \mathrm{H})$, $3.28(\mathrm{~m}, 1 \mathrm{H}), 2.93(\mathrm{~m}, 1 \mathrm{H}), 2.70(\mathrm{dd}, J=9.4,5.1,1 \mathrm{H}), 1.92$ $(\mathrm{m}, 1 \mathrm{H}), 1.88(\mathrm{~m}, 1 \mathrm{H}), 1.69(\mathrm{~m}, 1 \mathrm{H}), 1.56(\mathrm{~m}, 1 \mathrm{H}), 1.03(\mathrm{~d}, J$ $=6.7,3 \mathrm{H}), 0.69(\mathrm{~d}, J=6.7,1 \mathrm{H}) ;{ }^{13} \mathrm{C} \mathrm{NMR}(100.6 \mathrm{MHz}$, $\left.\mathrm{C}_{6} \mathrm{D}_{6}\right) \delta 82.2,71.3,68.1,65.9,61.6,56.8,47.8,44.7,38.3,34.3$, 20.6, 18.6. Signals of the minor stereoisomer are observed, e.g., at $\delta 4.79$ (dd, $J=8.4,7.3 \mathrm{~Hz}, 1 \mathrm{H})$. See the SI.

The smooth hydrolysis of these nitrocyclobutanes allowed us to correlate the configuration of each major stereoisomer with the known major product of the reactions carried out under catalytic conditions (the corresponding nitro-Michael reactions).

NMR spectra of 14-cb and 15-cb were coincident with those reported. ${ }^{3 \mathrm{~d}}$ Only one stereoisomer was detected in these cases (i.e., with the $\mathrm{JH}$ catalyst).

Enamine (E)-1-en: ${ }^{1} \mathrm{H}$ NMR $\left(400 \mathrm{MHz}, \mathrm{C}_{6} \mathrm{D}_{6}\right) \delta 7.10-6.90$ $(\mathrm{m}, 5 \mathrm{H}), 5.82(\mathrm{~s}, 1 \mathrm{H}), 4.31(\mathrm{dd}, J=11.5,9.8,1 \mathrm{H}), 4.17(\mathrm{dd}, J$ $=11.5,6.4,1 \mathrm{H}), 3.99(\mathrm{dd}, J=9.8,6.4,1 \mathrm{H}), 2.80(\mathrm{~m}, 4 \mathrm{H}), 1.49$ $(\mathrm{s}, 3 \mathrm{H}), 1.38(\mathrm{~m}, 4 \mathrm{H}) ;{ }^{13} \mathrm{C} \mathrm{NMR}\left(100.6 \mathrm{MHz}, \mathrm{C}_{6} \mathrm{D}_{6}\right) \delta 137.7$, 128.7, 127.6, 127.1, 109.3, 78.0, 53.0, 51.0, 25.5, 13.3. NOESY indicated that the $\mathrm{Me}$ group and the olefinic proton are trans.

Enamine (E)-2-en: ${ }^{1} \mathrm{H}$ NMR $\left(400 \mathrm{MHz}, \mathrm{C}_{6} \mathrm{D}_{6}\right) \delta 7.10-6.90$ (m, 5H), $5.73(\mathrm{~s}, 1 \mathrm{H}), 4.16(\mathrm{dd}, J=11.8,7.2,1 \mathrm{H}), 4.08(\mathrm{~m}$, $1 \mathrm{H}), 2.81(\mathrm{~m}, 4 \mathrm{H}), 2.06(\mathrm{dt}, J=14.9,7.4,4 \mathrm{H}), 1.82(\mathrm{td}, J=$ $14.9,7.5,1 \mathrm{H}), 1.40(\mathrm{~m}, J=7.5,2 \mathrm{H}), 0.87(\mathrm{t}, J=7.5,3 \mathrm{H}) ;{ }^{13} \mathrm{C}$ NMR $\left(100.6 \mathrm{MHz}, \mathrm{C}_{6} \mathrm{D}_{6}\right) \delta 136.2,115.7,78.8,52.9,51.1$, $49.2,25.5,23.4,14.1$. NOESY indicated that the methylene of the Et group and the olefinic proton are trans.

Representative NMR spectra of reaction intermediates from cyclic ketones are included and commented in the SI.

Computational Methods. The Gaussian 16 package was used everywhere. ${ }^{16}$ All of the stationary points were characterized as usual. ${ }^{16}$ In previous works, ${ }^{5,17 a}$ we had noted that the order of stabilities between enamines was not always properly described by B3LYP calculations and that the minimum level of theory at which isomers were reliably compared was MP2/6-31G(d)//B3LYP/6-31G(d). Thus, we have used this relatively "low-cost" approach for the calculation of hundreds of chemical entities. We then recalculated the corresponding molecules at other levels of theory, mainly through full geometry optimizations with M06-2X/6-311+G$(\mathrm{d}, \mathrm{p})$, but also with single-point calculations from B3LYP geometries with $\mathrm{MP} 2 / 6-311+\mathrm{G}(\mathrm{d}, \mathrm{p})$ (although it tends to overestimate the dispersion forces), $\omega$ B97X-D/6-311+G(d,p) (a functional including long-range dispersion corrections), ${ }^{16 c}$ M08-HX/6-311+G(d,p), MN15/6-311+G(d,p), CCSD(T)/6$31+\mathrm{G}(\mathrm{d})$, and/or $\operatorname{CCSD}(\mathrm{T}) / 6-311+\mathrm{G}(\mathrm{d}, \mathrm{p})$. For large molecules, to save computing time, we compared the M06-2X/6$311+\mathrm{G}(\mathrm{d}, \mathrm{p}) / / \omega \mathrm{B} 97 \mathrm{X}-\mathrm{D} / 6-31 \mathrm{G}(\mathrm{d})$ energies, which appeared to be very close to the M06-2X/6-311+G(d,p) values. The calculations of $G^{\circ}$ values were carried out with the scaling factor of 0.9804 for B3LYP/6-31G; ${ }^{20}$ the correction (from $E$ to $G^{\circ}$ ) was added to the MP2/6-31G(d) energy to obtain an approximate $G^{\circ}$ value at this level. With the M06-2X/6$311+\mathrm{G}(\mathrm{d}, \mathrm{p})$ method, no correction was used (for the sake of simplicity). ${ }^{20 b}$ For the cases in which a huge number of conformations was possible, to ensure that no reasonable conformers were discarded, OPLS2005 (MacroModel) (1a $^{21 a}$ and $\mathrm{MMFF}^{21 \mathrm{~b}}$ were used in the initial searches; all of the relative minima up to $20 \mathrm{kcal} / \mathrm{mol}$ above the lowest minimum were afterward submitted to MP2/6-31G(d)//B3LYP/6-31G(d) calculations, as always. The calculations of the solvent effects, with the CPCM and/or SMD models, ${ }^{16 \mathrm{~b}}$ were also carried out with the Gaussian 16 suite of programs. When these disparate approaches led to similar results regarding the relative stability of isomers and conformers, the conclusions were deemed reliable. 


\section{ASSOCIATED CONTENT}

\section{S Supporting Information}

The Supporting Information is available free of charge on the ACS Publications website at DOI: 10.1021/acsomega.9b02074.

Reaction energies predicted for a variety of EWGactivated alkenes that lead to cyclobutanes, approaches between the two reactants (with simple models), relative energies of the conformers of chiral enamines and alltrans-nitrocyclobutanes, effect of ${ }^{t} \mathrm{Bu}$ groups on pyrrolidine/aldehyde/nitroalkene, alternative approaches of the reactants (cyclopentanone case), other plausible pathways for the ring opening of nitrocyclobutanes, conformational analysis of the nitroMichael adducts (4-nitrobutanals), comparison of fused cyclobutanes from cyclopentanone with cyclobutanes from propanal, relative stability of iminium ions from cyclopentanone and cyclohexanone, acyclic ketones, general experimental methods, preparation of prolinol derivatives $\mathbf{B}-\mathbf{I}$, reactions of cyclohexanone with $\beta$-nitrostyrene, selection of NMR spectra (PDF)

\section{AUTHOR INFORMATION}

\section{Corresponding Authors}

*E-mail: amcosta@ub.edu (A.M.C.).

*E-mail: jvilarrasa@ub.edu (J.V.).

ORCID $\odot$

Alejandro Castro-Alvarez: 0000-0001-8360-8027

Anna M. Costa: 0000-0003-4345-4750

Jaume Vilarrasa: 0000-0002-2522-8218

Notes

The authors declare no competing financial interest.

\section{ACKNOWLEDGMENTS}

We thank the Spanish government for financial support (CTQ2015-71506R, FEDER). A.C.-A. is grateful to the Fundació Privada Cellex de Barcelona for a fellowship during 2016 and 2017. H.C. received a studentship from the Spanish government for the 2013-2017 period (CTQ2012-39230, FEDER). Al-lot J.C. was an undergraduate and master's student in our lab (2017-2018). Erasmus student Vanessa Wandelt (Leibniz Universität Hannover, autumn 2014) carried out preliminary experiments, while Albert Pla, as an undergraduate, and afterward as a post-master, ran preliminary calculations during 2017. The senior author (J.V.) dedicates this work (a) to the chemist and entrepreneur Dr. Pere Mir (in memoriam, 1919-2017), who after his retirement from Derivados Forestales S. A. created the Fundació Privada Cellex of Barcelona to provide funds to hospitals, research institutes, and the Col-legi de Químics de Catalunya, as well as special studentships and fellowships; (b) to the ETH emeritus Prof. Dieter Seebach, a reference in the field of organic chemistry for decades; and (c) to one of his best undergraduate and doctorate students, the Manchester University lecturer Jordi Burés, who also was a fellow student of the Fundació Cellex for 1 year.

\section{REFERENCES}

(1) (a) Reyes-Rodríguez, G. J.; Rezayee, N. M.; Vidal-Albalat, A.; Jørgensen, K. A. The Prevalence of Diarylprolinol Silyl Ethers in Total Synthesis and Patents. Chem. Rev. 2019, 119, 4221-4260. (b) Liu, J.;
Wang, L. Recent Advances in Asymmetric Reactions Catalyzed by Proline and Its Derivatives. Synthesis 2017, 49, 960-972. (c) Renzi, P.; Hioe, J.; Gschwind, R. M. Enamine/Dienamine and Brønsted Acid Catalysis: Elusive Intermediates, Reaction Mechanisms, and Stereoinduction Modes Based on in Situ NMR Spectroscopy and Computational Studies. Acc. Chem. Res. 2017, 50, 2936-2948. (d) Heravi, M. M.; Zadsirjan, V.; Dehghani, M.; Hosseintash, N. Current Applications of Organocatalysts in Asymmetric Aldol Reactions: An Update. Tetrahedron: Asymmetry 2017, 28, 587-707. (e) Chauhan, P.; Mahajan, S.; Enders, D. Achieving Molecular Complexity via Stereoselective Multiple Domino Reactions Promoted by a Secondary Amine Organocatalyst. Acc. Chem. Res. 2017, 50, 2809-2821. (f) Halskov, K. S.; Donslund, B. S.; Paz, B. M.; Jørgensen, K. A. Computational Approach to Diarylprolinol-Silyl Ethers in Aminocatalysis. Acc. Chem. Res. 2016, 49, 974-986. (g) Lam, Y.; Grayson, M. N.; Holland, M. C.; Simon, A.; Houk, K. N. Theory and Modeling of Asymmetric Catalytic Reactions. Acc. Chem. Res. 2016, 49, 750-762. (h) Hayashi, Y. Pot Economy and One-Pot Synthesis. Chem. Sci. 2016, 7, 866-880. (i) Šebesta, R.; Sorádová, Z. Prolinol Silyl Ethers as Asymmetric Organocatalysts. In Sustainable Catalysis: Without Metals or Other Endangered Elements, Part 1; North, M., Ed.; Green Chemistry Series; Royal Society of Chemistry, 2016; Vol. 40, pp 166-199. (j) Reyes, E.; Uria, U.; Vicario, J. L.; Carrillo, L. The Catalytic, Enantioselective Michael Reaction. Org. React. 2016, 90, 1-898.

(2) (a) Brannock, K. C.; Bell, A.; Burpitt, R. D.; Kelly, C. A. Reactions of Isobutenylamines. I. Cyclobutane Formation. J. Org. Chem. 1961, 26, 625-626. (b) Brannock, K. C.; Bell, A.; Burpitt, R. D.; Kelly, C. A. Enamine chemistry. IV. Cycloaddition Reactions of Enamines Derived from Aldehydes and Acyclic Ketones. J. Org. Chem. 1964, 29, 801-812. (c) Brannock, K. C.; Burpitt, R. D.; Goodlett, W. V.; Thweatt, J. G. Enamine Chemistry. V. Cycloaddition Reactions of Enamines Derived from Alicyclic Ketones. J. Org. Chem. 1964, 29, 813-817. (d) Kuehne, M. E.; Foley, L. Reaction of Enamines with Nitro Olefins. J. Org. Chem. 1965, 30, 4280-4284. (e) Colonna, F. P.; Valentin, E.; Pitacco, G.; Risaliti, A. Vinylamines. XIV. Nitroalkylation of Enaminic Equilibrium Mixtures. Tetrahedron 1973, 29, 3011-3017. (f) Seebach, D.; Beck, A. K.; Golinski, J.; Hay, J. H.; Laube, T. Steric Course of the Conversion of Enamines from Open-Chain Aldehydes and Ketones with Nitro Olefins to 2,3-Disubstituted 4-Nitro Ketones. Helv. Chim. Acta 1985, 68, 162-172. (g) Felluga, F.; Nitti, P.; Pitacco, G.; Valentin, E. Carbo- and Heterocyclization Reactions of 2-(4Morpholinyl)-1-phenylpropene and Nitro Olefins. Tetrahedron 1989, 45, 5667-5678. (h) Felluga, F.; Nitti, P.; Pitacco, G.; Valentin, E. N(2-Phenylprop-1-enyl)proline Methyl Ester: Equilibrium between the Enamine and the Aza Methine Ylide Form. J. Chem. Soc., Perkin Trans. 1 1992, 2331-2335. (i) Sheldrake, H. M.; Wallace, T. W.; Wilson, C. P. Functionalized Cyclobutenes via Multicomponent Thermal [2+2] Cycloaddition Reactions. Org. Lett. 2005, 7, 4233-4236. (j) Korotaev, V. Y.; Barkov, A. Y.; Slepukhin, P. A.; Kodess, M. I.; Sosnovskikh, V. Y. Uncatalyzed Reactions of $\alpha$-(Trihaloethylidene)nitroalkanes with Push-Pull Enamines: a New Type of Ring-Ring Tautomerism in Cyclobutane Derivatives and the Dramatic Effect of the Trihalomethyl Group on the Reaction Pathway. Tetrahedron Lett. 2011, 52, 5764-5768. (k) Dobi, Z.; Holczbauer, T.; Soos, T. Schreiner's Thiourea Promoted [2+2] Cycloaddition of Captodative Azetidinones and Nitroolefins. Eur. J. Org. Chem. 2017, 1391-1395.

(3) (a) Patora-Komisarska, K.; Benohoud, M.; Ishikawa, H.; Seebach, D.; Hayashi, Y. Organocatalyzed Michael Addition of Aldehydes to Nitro Alkenes - Generally Accepted Mechanism Revisited and Revised. Helv. Chim. Acta 2011, 94, 719-745. (b) Burés, J.; Armstrong, A.; Blackmond, D. G. Mechanistic Rationalization of Organocatalyzed Conjugate Addition of Linear Aldehydes to Nitro-olefins. J. Am. Chem. Soc. 2011, 133, 8822-8825. (c) Burés, J.; Armstrong, A.; Blackmond, D. G. Curtin-Hammett Paradigm for Stereocontrol in Organocatalysis by Diarylprolinol Ether Catalysts. J. Am. Chem. Soc. 2012, 134, 6741-6750. (d) Seebach, D.; Sun, X.; Ebert, M.-O.; Schweizer, W. B.; Purkayastha, N.; Beck, A. K.; Duschmalé, J.; Wennemers, H.; Mukaiyama, T.; Benohoud, M.; 
Hayashi, Y.; Reiher, M. Stoichiometric Reactions of Enamines Derived from Diphenylprolinol Silyl Ethers with Nitro Olefins and Lessons for the Corresponding Organocatalytic Conversions - a Survey. Helv. Chim. Acta 2013, 96, 799-852. (e) Mukaiyama, T.; Ishikawa, H.; Koshino, H.; Hayashi, Y. One-Pot Synthesis of (-)-Oseltamivir and Mechanistic Insights into the Organocatalyzed Michael Reaction. Chem. - Eur. J. 2013, 19, 17789-17800. (f) Burés, J.; Armstrong, A.; Blackmond, D. G. Explaining Anomalies in Enamine Catalysis: "Downstream Species" as a New Paradigm for Stereocontrol. Acc. Chem. Res. 2016, 49, 214-222. (g) Földes, T.; Madarász, A.; Révész, A.; Dobi, Z.; Varga, S.; Hamza, A.; Nagy, P. R.; Pihko, P. M.; Pápai, I. Stereocontrol in Diphenylprolinol Silyl Ether Catalyzed Michael Additions: Steric Shielding or Curtin-Hammett Scenario? J. Am. Chem. Soc. 2017, 139, 17052-17063. (also see refs cited therein for other relevant calculations) (h) Arpa, E. M.; AguilarGalindo, F.; Díaz-Tendero, S. Unravelling the Mechanism of NonPhotoactivated [2+2] Cycloaddition Reactions: Relevance of Orbital Interactions and Zwitterionic Intermediates. ChemistrySelect 2017, 2, 1089-1093.

(4) (a) Chinchilla, R.; Bäckwall, J. E. Cycloadditions of 2-Nitro 1,3Dienes to Enamines. Asymmetric Induction and Synthesis of Unsaturated Nitroketones and Diels-Alder Adducts via [4+2] Heterocyloadditions. Tetrahedron Lett. 1992, 33, 5641-5644. (b) Seebach, D.; Sun, X.; Sparr, C.; Ebert, M.-O.; Schweizer, W. B.; Beck, A. K. 1,2-Oxazine N-Oxides as Catalyst Resting States in Michael Additions of Aldehydes to Nitro Olefins Organocatalyzed by $\alpha, \alpha$-Diphenylprolinol Trimethylsilyl Ether. Helv. Chim. Acta 2012, 95, 1064-1078. (c) Sahoo, G.; Rahaman, H.; Madarasz, A.; Papai, I.; Melarto, M.; Valkonen, A.; Pihko, P. M. Dihydrooxazine oxides as key intermediates in organocatalytic Michael additions of aldehydes to nitroalkenes. Angew. Chem., Int. Ed. 2012, 51, 13144-13148. (d) Gurubrahamam, R.; Chen, Y. M.; Huang, W.-Y.; Chang, Y.-T.; Chan, H.-K.; Tsai, M.-K.; Chen, K. Dihydrooxazine N-Oxide Intermediates as Resting States in Organocatalytic Kinetic Resolution of Functionalized Nitroallylic Amines with Aldehydes. Org. Lett. 2016, 18, 3046-3049. (e) Maillard, L. T.; Park, H. S.; Kang, Y. K. Organocatalytic Asymmetric Addition of Aldehyde to Nitroolefin by H-D-Pro-Pro-Glu-NH $\mathrm{N}_{2}$ : A Mechanistic Study. ACS Omega 2019, 4, $8862-8873$.

(5) Castro-Alvarez, A.; Carneros, H.; Costa, A. M.; Vilarrasa, J. Computer-Aided Insight into the Relative Stability of Enamines. Synthesis 2017, 49, 5285-5306. (an account requested by the Editor)

(6) Husch, T.; Seebach, D.; Beck, A. K.; Reiher, M. Rigorous Conformational Analysis of Pyrrolidine Enamines with Relevance to Organocatalysis. Helv. Chim. Acta 2017, 100, No. e1700182.

(7) (a) Gorde, A. B.; Ramapanicker, R. D-Prolyl-2-(trifluoromethylsulfonamidopropyl)pyrrolidine: An Organocatalyst for Asymmetric Michael Addition of Aldehydes to $\beta$-Nitroalkenes at Ambient Conditions. J. Org. Chem. 2019, 84, 1523-1533. (b) Mahato, C. K.; Mukherjee, S.; Kundu, M.; Pramanik, A. Pyrrolidine-Oxadiazolone Conjugates as Organocatalysts in Asymmetric Michael Reaction. J. Org. Chem. 2019, 84, 1053-1063. (c) Llopis, S.; García, T.; Cantin, A.; Velty, A.; Díaz, U.; Corma, A. Chiral Hybrid Materials Based on Pyrrolidine Building Units to Perform Asymmetric Michael Additions with High Stereocontrol. Catal. Sci. Technol. 2018, 8, 5835-5847.

(8) (a) Seebach, D.; Golinski, J. Synthesis of Open-Chain 2,3Disubstituted 4-Nitroketones by Diastereoselective Michael-Addition of (E)-Enamines to (E)-Nitroolefins. A Topological Rule for C,CBond Forming Processes between Prochiral Centers. Helv. Chim. Acta 1981, 64, 1413-1423. (b) Ref 2f. (c) List, B.; Pojarliev, P.; Martin, H. J. Efficient Proline-Catalyzed Michael Additions of Unmodified Ketones to Nitro Olefins. Org. Lett. 2001, 3, 2423-2425. (d) Betancort, J. M.; Barbas, C. F. Catalytic Direct Asymmetric Michael Reactions: Taming Naked Aldehyde Donors. Org. Lett. 2001, 3, 3737-3740. (e) Enders, D.; Seki, A. Proline-Catalyzed Enantioselective Michael Additions of Ketones to Nitrostyrene. Synlett 2002, 26-28. (f) Alexakis, A.; Andrey, O. Diamine-Catalyzed Asymmetric Michael Additions of Aldehydes and Ketones to Nitrostyrene. Org. Lett. 2002, 4, 3611-3614.
(9) (a) Ref 3d, footnote 28. (b) Yang, H.; Wong, M. W. (S) Proline-Catalyzed Nitro-Michael Reactions: Towards a Better Understanding of the Catalytic Mechanism and Enantioselectivity. Org. Biomol. Chem. 2012, 10, 3229-3235.

(10) Xiao, J.; Xu, F.-X.; Lu, Y.-P.; Loh, T.-P. Chemzimes: A New Class of Structurally Rigid Tricyclic Amphibian Organocatalyst Inspired by Natural Product. Org. Lett. 2010, 12, 1220-1223.

(11) (a) Donadío, L. G.; Galetti, M. A.; Giorgi, G.; Rasparini, M.; Comin, M. J. Anti-Selective Organocatalytic Michael Addition between Phenylacetaldehyde and Nitrostyrene. J. Org. Chem. 2016, 81, 7952-7957. (b) Roytman, V. A.; Karugu, R. W.; Hong, Y.; Hirschi, J. S.; Vetticatt, M. J. ${ }^{13} \mathrm{C}$ Kinetic Isotope Effects as a Quantitative Probe To Distinguish between Enol and Enamine Mechanisms in Aminocatalysis. Chem. - Eur. J. 2018, 24, 8098-8102.

(12) (a) Refs 7a and 7c. (b) Wujkowska, Z.; Zawisza, A.; Lesniak, S.; Rachwalski, M. Phosphinoyl-Aziridines as a New Class of Chiral Catalysts for Enantioselective Michael Addition. Tetrahedron 2019, 75, 230-235. (c) Szőllősi, G.; Gombkötô, D.; Mogyorós, A. Z.; Fülöp, F. Surface-Improved Asymmetric Michael Addition Catalyzed by Amino Acids Adsorbed on Laponite. Adv. Synth. Catal. 2018, 360, 1992-2004. (d) Avila-Ortiz, C. G.; Díaz-Corona, L.; JiménezGonzález, E.; Juaristi, E. Asymmetric Michael Addition Organocatalyzed by $\alpha, \beta$-Dipeptides under Solvent-Free Reaction Conditions. Molecules 2017, 22, No. 1328. (e) Szcześniak, P.; StaszewskaKrajewska, O.; Furman, B.; Młynarski, J. Asymmetric Synthesis of Cyclic Nitrones via Organocatalytic Michael Addition of Aldehydes to Nitroolefins and Subsequent Reductive Cyclization. ChemistrySelect 2017, 2, 2670-2676. (f) Kumar, T. P.; Sattar, M. A.; Prasad, S. S.; Haribabu, K.; Reddy, C. S. Enantioselective Michael Addition of Aldehydes to Nitroolefins Catalyzed by Pyrrolidine-HOBt. Tetrahedron: Asymmetry 2017, 28, 401-409. (g) Ma, Z.-W.; Liu, X.-F.; Sun, B.; Huang, X.-H.; Tao, J.-C. Chiral Primary Amine-Squaramide Catalyzed Highly Enantioselective Michael Addition of Isobutyraldehyde to Nitroolefins. Synthesis 2017, 49, 1307-1314. (h) Wang, W.-H.; Abe, T.; Wang, X.-B.; Kodama, K.; Hirose, T.; Zhang, G.-Y. Self-Assembled Proline-Amino Thioureas as Efficient Organocatalysts for the Asymmetric Michael Addition of Aldehydes to Nitroolefins. Tetrahedron: Asymmetry 2010, 21, 2925-2933. (i) Bai, J.-F.; Xu, X.-Y.; Huang, Q.-C.; Peng, L.; Wang, L.-X. Highly Asymmetric Michael Additions of $\alpha, \alpha$-Disubstituted Aldehydes to $\beta$ Nitroalkenes Promoted by Chiral Pyrrolidine-Thiourea Bifunctional Catalysts. Tetrahedron Lett. 2010, 51, 2803-2805. (j) Chen, J.-R.; Cao, Y.-J.; Zou, Y.-Q.; Tan, F.; Fu, L.; Zhu, X.-Y.; Xiao, W.-J. Novel Thiourea-Amine Bifunctional Catalysts for Asymmetric Conjugate Addition of Ketones/Aldehydes to Nitroalkenes: Rational Structural Combination for High Catalytic Efficiency. Org. Biomol. Chem. 2010, 8, 1275-1279. (k) Cao, C.-L.; Ye, M.-C.; Sun, X.-L.; Tang, Y. Pyrrolidine-Thiourea as a Bifunctional Organocatalyst: Highly Enantioselective Michael Addition of Cyclohexanone to Nitroolefins. Org. Lett. 2006, 8, 2901-2904.

(13) (a) Carneros, H. Organocatàlisi: addicions de Michael i formació d'enamines. Master Thesis, Universitat de Barcelona, 2012. (b) Carneros, H. Organocatálisis asimétrica. Desarrollo de catalizadores y estudio de los mecanismos implicados. Ph.D. Thesis, Universitat de Barcelona, 2018.

(14) Liu, F. Y.; Wang, S. W.; Wang, N.; Peng, Y. G. Prolinol tertButyldiphenylsilyl Ether as Organocatalyst for the Asymmetric Michael Addition of Cyclohexanone to Nitroolefins. Synlett 2007, 2415-2419.

(15) (a) Lokesh, N.; Seegerer, A.; Hioe, J.; Gschwind, R. M. Chemical Exchange Saturation Transfer in Chemical Reactions: A Mechanistic Tool for NMR Detection and Characterization of Transient Intermediates. J. Am. Chem. Soc. 2018, 140, 1855-1862. (b) Renzi, P.; Hioe, J.; Gschwind, R. M. Enamine/Dienamine and Brønsted Acid Catalysis: Elusive Intermediates, Reaction Mechanisms, and Stereoinduction Modes Based on in Situ NMR Spectroscopy and Computational Studies. Acc. Chem. Res. 2017, 50, 2936-2948. (and references cited therein) (c) Łągiewka, B.; Albrecht, L. Studies on the Formation of Dienamine and Trienamine 
Intermediates by ${ }^{1} \mathrm{H}$ NMR Spectroscopy. Asian J. Org. Chem. 2017, 6, $516-519$.

(16) (a) Frisch, M. J. et al. Gaussian 16; Gaussian, Inc.: Wallingford, CT, 2016; www.gaussian.com/gaussian16 see the SI for the full reference. (b) Marenich, A. V.; Cramer, C. J.; Truhlar, D. G. Universal Solvation Model Based on Solute Electron Density and on a Continuum Model of the Solvent Defined by the Bulk Dielectric Constant and Atomic Surface Tensions. J. Phys. Chem. B 2009, 113, 6378-6396. (c) Grimme, S. Density Functional Theory with London Dispersion Corrections. Wiley Interdiscip. Rev.: Comput. Mol. Sci. 2011, 1, 211-228.

(17) (a) Castro-Alvarez, A.; Carneros, H.; Sánchez, D.; Vilarrasa, J. Importance of the Electron Correlation and Dispersion Corrections in Calculations Involving Enamines, Hemiaminals, and Aminals. Comparison of B3LYP, M06-2X, MP2, and CCSD Results with Experimental Data. J. Org. Chem. 2015, 80, 11977-11985. (b) Zhao, J.-Q.; Gan, L.-H. Transition States of the Asymmetric Michael Reactions of Aldehydes Catalyzed by Trimethylsilyl-Protected Diphenylprolinol. Eur. J. Org. Chem. 2009, 2661-2665. (c) Shinisha, C. B.; Sunoj, R. B. Unraveling High Precision Stereocontrol in a Triple Cascade Organocatalytic Reaction. Org. Biomol. Chem. 2008, 6, 3921-3929.

(18) (a) Seebach, D.; Beck, A. K.; Badine, D. M.; Limbach, M.; Eschenmoser, A.; Treasurywala, A. M.; Hobi, R.; Prikoszovich, W.; Lindner, B. Are Oxazolidinones Really Unproductive, Parasitic Species in Proline Catalysis? - Thoughts and Experiments Pointing to an Alternative View. Helv. Chim. Acta 2007, 90, 425-471. (b) Blackmond, D. G.; Moran, A.; Hughes, M.; Armstrong, A. Unusual Reversal of Enantioselectivity in the Proline-Mediated $\alpha$ Amination of Aldehydes Induced by Tertiary Amine Additives. J. Am. Chem. Soc. 2010, 132, 7598-7599. (c) Mayr, H.; Lakhdar, S.; Maji, B.; Ofial, A. R. A Quantitative Approach to Nucleophilic Organocatalysis. Beilstein J. Org. Chem. 2012, 8, 1458-1478.

(19) (a) Refs 1f, 1g, 4e, 5, and 8c (and papers cited therein). (b) Bhaskararao, B.; Sunoj, R. B. Two Chiral Catalysts in Action: Insights into Cooperativity and Stereoselectivity in Proline and Cinchona-Thiourea Dual Organocatalysis. Chem. Sci. 2018, 9, 87388747. (c) Tafida, U. I.; Uzairu, A.; Abechi, S. E. Mechanism and Rate Constant of Proline-Catalysed Asymmetric Aldol Reaction of Acetone and $p$-Nitrobenzaldehyde in Solution Medium: Density-Functional Theory Computation. J. Adv. Res. 2018, 12, 11-19. (d) Ruiz-Olalla, A.; Retamosa, M. G.; Cossío, F. P. Densely Substituted L-Proline Esters as Catalysts for Asymmetric Michael Additions of Ketones to Nitroalkenes. J. Org. Chem. 2015, 80, 5588-5599. (e) Hubin, P. O.; Jacquemin, D.; Leherte, L.; Vercauteren, D. P. Quantum Mechanical Investigations on the Role of Neutral and Negatively Charged Enamine Intermediates in Organocatalyzed Reactions. Chem. Phys. 2014, 434, 30-36. (f) Fu, A.; Zhao, C.; Li, H.; Tian, F.; Yuan, S.; Duan, Y.; Wang, Z. Density Functional Study of Organocatalytic Cross-Aldol Reactions between Two Aliphatic Aldehydes: Insight into Their Functional Differentiation and Origins of Chemo- and Stereoselectivities. J. Phys. Chem. A 2013, 117, 2862-2872. (g) Hut'ka, M.; Poláčková, V.; Marák, J.; Kaniansky, D.; Šebesta, R.; Toma, S. Enantioselective Organocatalytic Michael Additions of Oxyacetaldehydes to Nitroolefins. Eur. J. Org. Chem. 2010, 64306435. (h) Groselj, U.; Seebach, D.; Badine, D. M.; Schweizer, W. B.; Beck, A. K.; Krossing, I.; Klose, P.; Hayashi, Y.; Uchimaru, T. Structures of the Reactive Intermediates in Organocatalysis with Diarylprolinol Ethers. Helv. Chim. Acta 2009, 92, 1225-1259.

(20) (a) Curtiss, L. A.; Raghavachari, K.; Redfern, P. C.; Pople, J. A. Investigation of the Use of B3LYP Zero-Point Energies and Geometries in the Calculation of Enthalpies of Formation. Chem. Phys. Lett. 1997, 270, 419-426. (b) Alecu, I. M.; Zheng, J.; Zhao, Y.; Truhlar, D. G. Computational Thermochemistry: Scale Factor Databases and Scale Factors for Vibrational Frequencies Obtained from Electronic Model Chemistries. J. Chem. Theory Comput. 2010, 6, 2872-2887. (cf. https://comp.chem.umn.edu/freqscale/190107_ Database_of_Freq_Scale_Factors_v4.pdf, last update 2018)
(21) (a) MacroModel, OPLS_2005 force field. https://www. schrodinger.com/macromodel). (b) MMFF (Merck Molecular Force Field), as implemented in Spartan and in MacroModel, see: Halgren, T. A. Merck Molecular Force Field. I. Basis, Form, Scope, Parameterization, and Performance of MMFF94. J. Comput. Chem. 1996, 17, 490-519. 